\title{
SALTCRETE FORMULATION
}

September 28, 1994

Prepared by:

J. M. Connell

S. C. Jorgensen

\section{Edited by:}

G. B. Semones

E. C. Garcia, Project Manager

\section{DISCLAIMER}

This report was prepared as an account of work sponsored by an agency of the United States Government. Neither the United States Government nor any agency thereof, nor any of their employees, makes any warranty, express or implied, or assumes any legal liability or responsibility for the accuracy, completeness, or usefulness of any information, apparatus, product, or process disclosed, or represents that its use would not infringe privately owned rights. Reference herein to any specific commercial product, process, or service by trade name, trademark, manufacturer, or otherwise does not necessarily constitute or imply its endorsement, recommendation, or favoring by the United States Government or any agency thereof. The views and opinions of authors expressed herein do not necessarily state or reflect those of the United States Government or any agency thereof. 


\section{DISCLAIMER}

Portions of this document may be illegible in electronic image products. Images are produced from the best available original document. 


\section{Executive Summary}

This is an addendum to the report entitled "Saltcrete Evaluation", dated August 16, 1993.

The information gathered since the first report shows that the currently generated waste and most of the waste in inventory has low concentrations of hazardous chemicals and is certifiable for disposable. This is based on preliminary analyses. Sampling and analysis for the purpose of gathering the legally defensible data required for certification and permanent disposal is in progress.

The main technical issue is the expansion of the waste form. Some of the cemented waste expands and damages the containers. According to a petrology study, the expansion is caused by the formation of darapskite, a nitrate-sulfate salt. Darapskite occurs when there is high porosity causing microfractures and waste form expansion. The study showed that the concentration of darapskite was as high as 22 percent by weight (wt\%) and that the concentration varied significantly within a single waste form. The variation may be the reason that most container damage occurred on one end only (damage occurred to all sides of some containers). It is also an indication that the saltcrete is not always well-mixed. It was found that after the initial expansion of one to two inches expansion, expansion is insignificant.

Expansion and its problems can be minimized but not eliminated completely. Reducing the waste loading to $30 \mathrm{wt} \%$ from $35 \mathrm{wt} \%$, placing 2-inch spacers in each end of the crates, mixing the paste well, accurately weighing the components (brine, salt, and cement) will reduce the expansion or in the case of the spacers, reduce the damage to the container.

Since the earlier report, the load cells that are used to weigh the components have been calibrated to improve and control the accuracy of the additions. The appropriate amount of each component is calculated by measuring the specific gravity of the brine and then calculating the solids content of the brine.

A formulation of $30 w t \%$ (maximum) water, $30 w t \%$ (maximum) salt, and $48 w t \%$ (maximum) cement/flyash blend is recommended. A blend of either three parts type I/II Portland cement one part Class $F$ flyash or pure type I/II Portland cement is suitable. Section 6 describes the formulation and how to mix it in more detail. A key concept in the mixing recommendation is to add the maximum allowable amount of salt and water to the mixture, then to add cement powder until the limits of the mixing equipment are reached. If this method were adopted, the waste loading would never exceed $30 \mathrm{wt} \%$ and the amount of unreacted water would be minimized.

Since the constituents in the waste will change over time, methods to test other possible formulations are provided in a separate report issued concurrently. A maintenance work package was initiated to use two brine feed tanks, each of which can be isolated. In this way, a few tests can performed to determine whether the formulation recommended in this report is compatible with a given tank of brine.

There are also recommendations to improve documentation of the process and the measurement of the process parameters. 


\section{TABLE OF CONTENTS}

Executive summary.

1.0 Introduction

2.0 Process Characterization.

2.1 Chemical Analysis

2.2 Petrology 2-16

Time-of-Set.

2.5 Instrumentation

3.0 Formulation

3.1 Operating Envelope, Lab-Scale.

3.2 Operating Envelope, Full-Scale

4.0 Conclusions and Recommendations.

\section{LIST OF TABLES AND FIGURES}

Table $\quad 2.1-1 \quad$ Cation Concentrations in Spray Dried Salt. . . . . . . . . . . . . . . . . $2-2$

Table $\quad 2.1-2 \quad$ Anion Concentrations in Spray Dried Salt. . . . . . . . . . . . . . . . . 2-8

Figure $\quad 2.1-1 \quad$ Major Cation Concentrations in Spray Dried Salt. . . . . . . . . . . . . . . . . . 2-12

Figure $\quad 2.1-2 \quad$ Chloride and Carbonate Concentrations in Spray Dried Salt. . . . . . . . . . . . 2-13

Figure $\quad 2.1-3 \quad$ Nitrate and Sulfate Concentrations in Spray Dried Salt. . . . . . . . . . . . 2-14

Figure $\quad 2.1-4 \quad$ LDR Metals Spray Dried Salt. . . . . . . . . . . . . . . . . . . . . . 2 2-15

Table $\quad 2.3-1 \quad$ Time-of-Set. . . . . . . . . . . . . . . . . . . . . . . . . . . . . .

Figure $\quad 2.3 .1-1$ Temperature vs Elapsed Time, Type I/II Cement. . . . . . . . . . . . . . . 2 2-19

Figure 2.3.1-2 Temperature vs Elapsed Time, Type I/II Cement Compared to Type V Cement . . 2-20

Figure $\quad 2.3 .1-3 \quad$ Temperature vs Elapsed Time, Type $V$ Cement. . . . . . . . . . . . . . 2-21

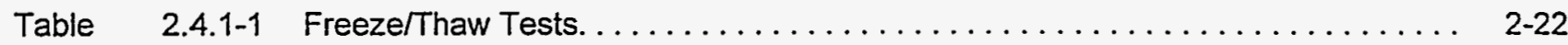

Table $\quad 3.1 .1-1 \quad$ Lab-scale Operating Envelope. . . . . . . . . . . . . . . . . . . . $3-1$

Figure $\quad 3.1 .1-1 \quad$ Lab-scale Operating Envelope. . . . . . . . . . . . . . . .

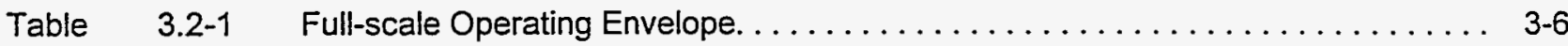

Figure $\quad 3.2-1 \quad$ Full-scale Test. . . . . . . . .

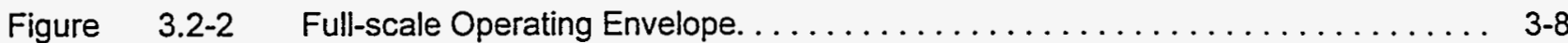

Figure $\quad 3.2-3 \quad$ Full-scale Operating Envelope and Contingency. . . . . . . . . . . . . $3-9$

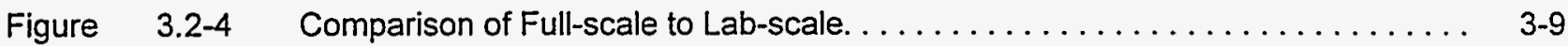

Table . $3.2-2$ Full-scale Operating Envelope and Contingency.................. 3-11 


\subsection{INTRODUCTION}

\subsection{Addendum to an Earlier Report}

This report is an addendum to "Saltcrete Evaluation, August 16, 1993". The first report contains information about process evaluation, waste characterization, process simulation with actual waste and surrogate waste and preliminary formulation studies. This current report contains additional waste characterization and finalizes the formulation studies.

\subsection{Saltcrete Description}

Saltcrete is a low level mixed waste produced in Building 374 from concentrated liquid waste brine, spray dried salt from that brine, and cement. The waste is stored temporarily at Rocky Flats Environmental Technology Site until a waste repository is able to accept it for final disposal. in order for a disposal site to accept the waste, proof that the waste meets regulatory standards is necessary.

\subsection{Purpose}

The purpose of this report is to provide the technical information necessary to produce certifiable waste. The information will be incorporated into other documents, identify important process parameters, provide an operating envelope, and provide methods for testing waste treatment in the future. This report, in conjunction with the August 1993 report, will provide a technical basis for operating the saltcrete process using the current production equipment. It is important to note that major changes to the equipment are beyond the scope of this project.

\subsection{Main Technical Issue}

The main technical issue is expansion of the waste forms which periodically causes damage to a portion of the waste containers which can make the container unsuitable for offsite shipment. The waste acceptance criteria (WAC) for the Nevada Test Site (NTS) and Envirocare of Utah such as free water and the land disposal restricted (LDR) waste treatment standards are not difficult for the saltcrete process to satisfy. The waste form expansion issue was raised by the inspection of the saltcrete in inventory at which time it was discovered that some of the containers were damaged. The August 1993 report addressed the secondary technical issues.

\subsection{Other Issues}

The lesser issues concern the physical properties of the waste form, ease of operation, and the chemical properties of the waste form. The chemical properties of the waste form were determined in two ways: by characterizing the untreated waste and by analyzing the treated waste form. The previous analysis of the untreated waste (spray-dried salt) indicated that it met the EPA treatment standards with the exception of nickel. Chemical analysis of the treated waste (HNUS, 1992 ) indicated that two of three subpopulations (Triwalls $\otimes$, collapsed Triwalls $₫$, and half-crates) of the waste forms in inventory met treatment standards. These analyses were performed according to EPA methods but are not legally defensible because the required documentation was not generated and because the maximum sample holding times were exceeded. The inventory of waste forms will be resampled with the objective of obtaining legally defensible data to demonstrate regulatory compliance for off-site shipment. 
Physical properties of the waste forms that pertain to WAC are free water and particulates. Visual observation of the waste forms in inventory indicate that there were no measurable amounts of particulate matter in the containers. Should particulates be above the limits in the WAC, the method to make the waste form compliant is to use double containment. Since the containers in use employ double containment, particulate matter is a problem assured of being solved with production practices in place at this time (and have been in place since April 1989). No free water was detected during the previous sampling efforts. The detection method was visual observation.

\subsection{Sampling the Treated Waste}

The saltcrete in inventory was sampled and analyzed twice and the expansion of the waste forms was measured twice. First, the inventory was sampled and analyzed by HNUS for chemical constituents (some of that data is summarized in the August saltcrete evaluation report). Since then, Statistical Applications has performed a statistical analysis of that data and found that two of the three subpopulations do indeed meet LDR. Saltcrete was sampled again in January 1994 for microstructure analysis by Halliburton Energy Services. The extent of bulging was measured in April 1993 and in January 1994.

\subsection{Petrology}

The microstructure of the saltcrete was analyzed to identify the mechanism that causes the waste form to expand. Containers of waste were cored, inspected, and photomicrographs were made. The photomicrographs of the waste that had expanded were compared to photomicrographs of waste that did not. Laboratory samples that were subjected to freeze/thaw cycling were also analyzed; photomicrographs of samples that had expanded were compared to ones that did not. The laboratory samples were made with various types of cement and flyash. The photomicrographs helped determine how minerals in the cement react with the chemicals in the waste.

\subsection{Chemical Analysis}

The waste exhibits the approximately the same physical and chemical properties as in the August 1993 report. Chemical analysis was performed on 15 additional samples of untreated waste since the August 1993 report. No additional chemical analysis of the of the saltcrete (the final waste form) was performed since the HNUS report. A Department of Transportation (DOT) test to determine if a material is an oxidizer indicated that the spray-dried salt is not an oxidizer. The untreated waste nearly meets the EPA treatment standards, which means that the treated waste is virtually certain to pass the TCLP. (Two samples of pure waste were slightly over the LDR standard for nickel when they were subjected to TCLP.) Therefore, emphasis was placed on the physical properties of the waste form for the development of the operating envelope. 


\subsection{Operating Envelope}

The operating envelope of the saltcrete process was developed in the laboratory then checked with the full-scale production equipment. The purpose of developing an operating envelope is to establish the limiting conditions for producing certifiable waste. The limits of the envelope were determined by the viscosity that the saltcrete mixer will tolerate and by determining when free water will appear in the final waste form. The envelope is based on the weights of the saltcrete components: water, salt, and cement. In other words, it is based on the amount of each component, not the type of cement or flyash. It was reported in the August 1993 that the type of cement or flyash did not affect the viscosity, but the tendency to expand during freeze/thaw cycling was affected.

\subsection{Freeze/thaw Cycling}

The type of cement and flyash that expanded least in laboratory testing were identified in the August 1993 report. The amount of cement and flyash are identified in the current report. The conclusions are based on two freeze/thaw cycles of one inch diameter by two inch long samples of saltcrete mixed in the laboratory with actual (not surrogate) waste. Since the full scale waste containers are mixed and stored under different conditions for years rather than days, the freeze/thaw testing and conclusions are potentially misleading. The petrology study indicated that the freeze/thaw test is misleading because the expansion mechanisms for the lab-scale samples was different from the full-scale blocks.

\subsection{Time-of-Set}

The length of time it takes the saltcrete to harden affects the production rate. The time-of-set for saltcrete crates varies from one week to one month. There is enough room in Building 374 to stage 15 crates (one production run), which is sufficient to process all the liquid waste that goes to Building 374. The time-of-set of various cement and flyash combinations was studied on a laboratory-scale and full-scale. There were two purposes: one was to use the information to predict the time-of-set for full-scale crates, the other was to compare the set times of two cement types.

\subsection{Instrumentation}

Instrumentation and data acquisition equipment requirements were investigated. This equipment would provide information to the waste processing operators as well as provide documentation for certification. Two data loggers are recommended to record process parameters such as the weights of the components, the density of the brine, and the temperature of the saltcrete as it cures. A nuclear densitometer for continuous measurement of brine density is recommended.

\subsection{Crate Measurements}

Bulged crates were remeasured to determine whether expansion continued over the past year. The crates were measured in April 1993 and again in January 1994. The amount of expansion over that period was insignificant. 


\subsection{Recommendations}

Detailed recommendations to produce certifiable waste forms are given in Section 4. A brief summary follows:

1. The optimum formulation will change from time to time due to inevitable changes in the untreated waste. The best formula now consists of approximately $30 \mathrm{wt} \%$ water, $30 \mathrm{wt} \%$ salt, $30 \mathrm{wt} \%$ type $1 / 1 / \mathrm{l}$ cement, and $10 \mathrm{wt} \%$ Class $\mathrm{F}$ flyash.

2. Tests to check for free water, viscosity, and time-of-set should be performed for a tank of brine (approximately eight production runs) If necessary, adjust the formula to treat the waste.

3. Occasionally during a production run, a batch will become very viscous with no warning. The fluid properties indicate that this is due to an increase in the surface area of the particles in suspension. Since there is no way to control this with existing equipment, the situation will have to be dealt with by adding brine. The SOP will include this step and the additional weight will be documented. This will not render the waste uncertifiable.

4. Periodic representative sampling and analysis will be needed to characterize the waste and demonstrate that the final waste form meets WAC.

5. Instruments and data acquisition equipment should be used to document the composition of the final waste form.

6. Tank $826-\mathrm{C}$ in Building 374 should be isolated so that the tests mentioned above and the sampling and analysis can be performed once for eight production runs rather than once per production run. 


\subsection{PROCESS CHARACTERIZATION}

2.1 Chemical Analysis

Chemical analysis on the spray-dried salt and the brine were performed to provide characterization data. These analyses were not intended to be legally defensible. They were performed to gain engineering information about the waste and to learn which test methods give the most reliable results. The data is presented in Tables 2.1-1, 2.1-2, and in Figures 2.1-1, 2.1-2, and 2.1-3. The data indicates that the salt nearly meets the LDR treatment standards even before it is mixed with cement at $30 \mathrm{wt} \%$ waste loading. Previous analysis of the backlog saltcrete with waste loading varying from $30 \mathrm{wt} \%$ to $55 \mathrm{wt} \%$ indicates that the treated waste meets LDR treatment standards. A sampling campaign to certify saltcrete with legally defensible data is in progress. 
Table 2.1-1

Analysis of Salt and Brine Samples, Cations

\begin{tabular}{|c|c|c|c|c|c|c|c|}
\hline & DATE: & $10 / 1 / 91$ & $11 / 9 / 91$ & $11 / 9 / 91$ & $11 / 9 / 91$ & $11 / 9 / 91$ & 11/9/91 \\
\hline & SAMPLE ID: & D884-10191 & $1-0118$ & $1-0120$ & $1-0124$ & $1-0127$ & $1-0130$ \\
\hline 1 & Sodium & 152,000 & 157,000 & 140,000 & 175,000 & 149,000 & 152,000 \\
\hline 3 & Calcium & 20,500 & 16,800 & 26,600 & 13,200 & 12,900 & 16,000 \\
\hline 4 & Magnesium & 3,660 & 6,170 & 5,200 & 3,590 & 2,970 & 3,990 \\
\hline 5 & Iron & 1,130 & 718 & 1,650 & 817 & 811 & 896 \\
\hline 8 & Boron & 230.00 & 177 & 159 & 186 & 161 & 162 \\
\hline 9 & Nickel & 35 & 19 & 33 & 36 & 30 & 32 \\
\hline 10 & Chromium & 60 & 18 & 91 & 52 & 55 & 39 \\
\hline 11 & Copper & 34 & 29 & 39 & 41 & 31 & 38 \\
\hline 12 & Silver & 58 & 35 & 74 & 52 & 46 & 56 \\
\hline 13 & Barium & 26 & 22 & 35 & 19 & 19 & 22 \\
\hline$\overline{18}$ & Cobalt & 3 & 2 & 4 & 3 & 3 & 3 \\
\hline 19 & Selenium & * & 12 & * & $\star$ & $\star$ & * \\
\hline 20 & Beryllium & 1 & 1 & 1 & 1 & 1 & 1 \\
\hline 21 & Thallium & 1 & * & * & 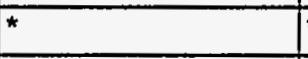 & $\star$ & * \\
\hline 22 & Arsenic & 1 & * & $\star$ & $\star$ & ᄎ & $\star$ \\
\hline 23 & Mercury & 0 & * & 0 & * & * & $\star$ \\
\hline 24 & Antimony & * & * & ${ }^{\star}$ & 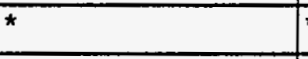 & * & \# \\
\hline & * Below detectable limit & & & & & & \\
\hline & Brine samples are & & & & & & \\
\hline & marked with ${ }^{* \star}$ & & & & & & \\
\hline
\end{tabular}


Table 2.1-1

Analysis of Salt and Brine Samples, Cations

\begin{tabular}{|c|c|c|c|c|c|c|c|}
\hline & DATE: & $12 / 4 / 91$ & $12 / 5 / 91$ & $1 / 5 / 92$ & $1 / 6 / 92$ & 2/22/92 & $2 / 23 / 92$ \\
\hline & SAMPLE ID: & $1-0122$ & $1-0128$ & $1-0315$ & $1-0390$ & $1-0422$ & $1-0421$ \\
\hline & ANALYTE & $(\mathrm{mg} / \mathrm{kg})$ & (mg/kg) & $(\mathrm{mg} / \mathrm{kg})$ & $(\mathrm{mg} / \mathrm{kg})$ & $(\mathrm{mg} / \mathrm{kg})$ & (mg/kg) \\
\hline 11 & Sodium & 153,000 & 154,000 & 144,000 & 155,000 & 198,000 & 212,000 \\
\hline 2 & Potassium & 133,000 & 134,000 & 155,400 & 141,000 & 72,900 & 72,700 \\
\hline 3 & Calcium & 16,100 & 16,300 & 8,160 & 17,800 & 20,900 & 21,400 \\
\hline 4 & Magnesium & 3,550 & 3,430 & 7,170 & 4,280 & 8,000 & 8,260 \\
\hline 5 & Iron & 1,110 & 993 & 3,840 & 2,030 & 1,140 & 1,040 \\
\hline 6 & Aluminum & 748.00 & 723 & $3,790.00$ & 776 & 588.00 & 541 \\
\hline 7 & Zinc & 198.00 & 175 & 345.00 & 173 & 336.00 & 345 \\
\hline 8 & Boron & 212.00 & 168 & 183.00 & 208 & 232.00 & 216 \\
\hline 9 & Nickel & 50 & 32 & 72 & 30 & 98 & 53 \\
\hline 10 & Chromium & 74 & 58 & 30 & 51 & 60 & 32 \\
\hline 11 & Copper & 38 & 34 & 36 & 39 & 42 & 36 \\
\hline 12 & Silver & 62 & 52 & 25 & 38 & 30 & 29 \\
\hline 13 & Barium & 23 & 22 & 91 & 23 & 26 & 26 \\
\hline$\overline{14}$ & Manganese & 17 & 15 & 43 & 24 & 15 & 15 \\
\hline 15 & Vanadium & 10 & 10 & 63 & 10 & 7 & 7 \\
\hline 16 & Lead & 6 & 10 & 6 & 8 & 6 & $\star$ \\
\hline 17 & Cadmium & 10 & 9 & 4 & 8 & 4 & 5 \\
\hline 18 & Cobalt & 3 & 3 & 4 & 3 & 4 & * \\
\hline 19 & \begin{tabular}{|l|} 
Selenium \\
\end{tabular} & $\star$ & $\bar{\pi}$ & ॠ & $\star$ & 15 & $=$ \\
\hline 20 & Beryllium & 1 & 1 & 4 & 1 & 4 & 4 \\
\hline 21 & Thallium & 1 & 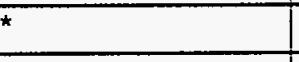 & 1 & * & 1 & 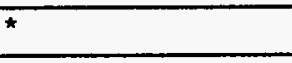 \\
\hline 22 & Arsenic & 1 & $\star$ & 1 & $\star$ & 0 & $\star$ \\
\hline 23 & Mercury & * & 0 & * & 0 & 0 & 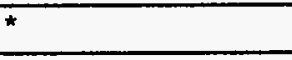 \\
\hline 24 & Antimony & $\overline{-}$ & 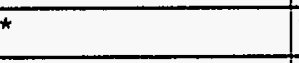 & * & 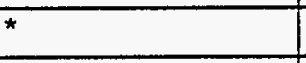 & 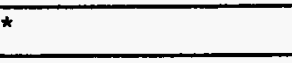 & 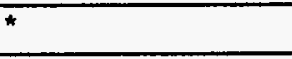 \\
\hline & * Below detectable limit & & & & & & \\
\hline & Brine samples are & & & & & & \\
\hline & marked with ${ }^{\star \star}$ & & & & & & \\
\hline
\end{tabular}

Page 2 - 3 
Table 2.1-1

Analysis of Salt and Brine Samples, Cations

\begin{tabular}{|c|c|c|c|c|c|c|c|}
\hline & DATE: & $2 / 28 / 92$ & $4 / 23 / 92$ & $4 / 24 / 92$ & $5 / 11 / 92$ & $5 / 12 / 92$ & $6 / 15 / 92$ \\
\hline & SAMPLE ID: & $1-0423$ & $1-0616$ & $1-0618$ & $1-0626$ & $1-0627$ & $1-0638$ \\
\hline & ANALYTE & $(\mathrm{mg} / \mathrm{kg})$ & $(\mathrm{mg} / \mathrm{kg})$ & $(\mathrm{mg} / \mathrm{kg})$ & $(\mathrm{mg} / \mathrm{kg})$ & (mg/kg) & (mg/kg) \\
\hline 1 & Sodium & 199,000 & 203,000 & 151,000 & 210,000 & 207,000 & 193,000 \\
\hline 3 & Calcium & 21,000 & 16,300 & 14,300 & 20,100 & 19,800 & 29,000 \\
\hline 4 & Magnesium & 8,040 & 5,570 & 3,400 & 7,310 & 7,310 & 6,680 \\
\hline 5 & Iron & 1,620 & 1,520 & 1,320 & 1,430 & 1,310 & 1,900 \\
\hline 7 & Zinc & 338.00 & 238.00 & 163.00 & 326.00 & 329.00 & 298.00 \\
\hline 8 & Boron & 237.00 & 285.00 & 233.00 & 252.00 & 232.00 & 269.00 \\
\hline 9 & Nickel & 256 & 197 & 45 & 159 & 134 & 125 \\
\hline$\overline{10}$ & Chromium & 180 & 131 & 62 & 101 & 82 & 79 \\
\hline 11 & Copper & 65 & 53 & 36 & 51 & 48 & 44 \\
\hline$\overline{12}$ & Silver & 31 & 21 & 57 & 29 & 27 & 25 \\
\hline 17 & Cadmium & 4 & 3 & 10 & 4 & 4 & 4 \\
\hline$\overline{18}$ & Cobalt & 7 & 7 & 3 & 6 & 5 & 4 \\
\hline 19 & Selenium & 2 & * & 太 & 2 & * & 2 \\
\hline 20 & Beryllium & 4 & 2 & 1 & 3 & 3 & 2 \\
\hline 21 & Thallium & 1 & 1 & 1 & 1 & 1 & 1 \\
\hline 22 & Arsenic & 1 & 0 & 1 & 1 & 1 & 1 \\
\hline 23 & Mercury & 0 & 0 & 0 & 0 & 0 & $\underline{0}$ \\
\hline 24 & Antimony & * & * & 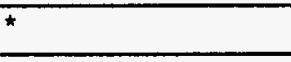 & * & 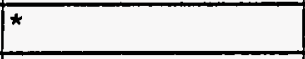 & * \\
\hline & * Below detectable limit & & & & & & \\
\hline & Brine samples are & & & & & & \\
\hline & marked with ** & & & & & & \\
\hline
\end{tabular}


Table 2.1-1

Analysis of Salt and Brine Samples, Cations

\begin{tabular}{|c|c|c|c|c|c|c|c|}
\hline & DATE: & $6 / 16 / 92$ & $7 / 10 / 92$ & $7 / 11 / 92$ & $7 / 16 / 92$ & $10 / 8 / 92$ & $10 / 31 / 92$ \\
\hline & SAMPLE ID: & $1-0639$ & $1-0793$ & $1-0703$ & $1-0792$ & $2-71475$ & $2-71476$ \\
\hline & ANALYTE & $(\mathrm{mg} / \mathrm{kg})$ & $(\mathrm{mg} / \mathrm{kg})$ & $(\mathrm{mg} / \mathrm{kg})$ & (mg/kg) & (mg/kg) & $(\mathrm{mg} / \mathrm{kg})$ \\
\hline 1 & Sodium & 183,000 & 206,000 & 210,000 & 197,000 & 220,000 & 221,000 \\
\hline 2 & Potassium & 85,300 & 113,000 & 98,600 & 115,000 & 87,600 & 78,600 \\
\hline 3 & Calcium & 23,900 & 12,400 & 8,840 & 12,800 & 12,400 & 22,700 \\
\hline 4 & Magnesium & 5,500 & 6,180 & 4,240 & 6,150 & 7,660 & 7,320 \\
\hline 5 & Iron & 1,400 & 830 & 865 & 1,010 & 714 & 1,160 \\
\hline 6 & Aluminum & 1070 & 545 & 442.00 & 623.00 & 450 & 941 \\
\hline 7 & Zinc & 212 & 186 & 180.00 & 183.00 & 194 & 170 \\
\hline 8 & Boron & 234 & 162 & 215.00 & 196.00 & 164 & 164 \\
\hline 9 & Nickel & 34 & 23 & 87 & 79 & 24 & 20 \\
\hline 10 & Chromium & 26 & 20 & 64 & 57 & 14 & 13 \\
\hline 11 & Copper & 24 & 22 & 29 & 30 & 20 & 19 \\
\hline$\overline{12}$ & Silver & 20 & 27 & 21 & 28 & 17 & 16 \\
\hline 13 & Barium & 32 & 20 & 15 & 21 & 20 & 29 \\
\hline 14 & Manganese & 18 & 12 & 11 & 13 & 19 & 39 \\
\hline 15 & Vanadium & 18 & 8 & 4 & 9 & 5 & 12 \\
\hline 16 & Lead & 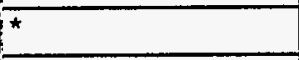 & * & 4 & 4 & $\star$ & * \\
\hline 17 & Cadmium & 3 & 2 & 3 & 2 & 2 & 2 \\
\hline$\overline{18}$ & Cobalt & 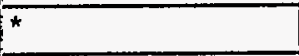 & $\star$ & $\star$ & 4 & * & $\star$ \\
\hline 19 & Selenium & 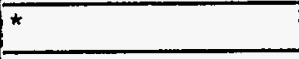 & $\star$ & 2 & $\star$ & $\star$ & * \\
\hline 20 & Beryllium & 1 & * & * & * & $\star$ & $\hbar$ \\
\hline 21 & Thallium & * & * & 1 & 1 & * & * \\
\hline 22 & Arsenic & * & * & 0 & 1 & $\star$ & 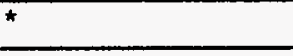 \\
\hline 23 & Mercury & 0 & 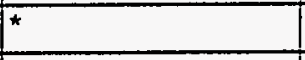 & 0 & 1 & * & * \\
\hline \multirow[t]{4}{*}{24} & Antimony & 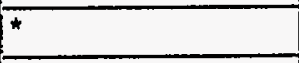 & * & $\star$ & * & $\star$ & * \\
\hline & * Below detectable limit & & & & & & \\
\hline & Brine samples are & & & & & & \\
\hline & marked with ${ }^{\star \star}$ & & & & & & \\
\hline
\end{tabular}


Table 2.1-1

Analysis of Salt and Brine Samples, Cations

\begin{tabular}{|c|c|c|c|c|}
\hline & DATE: & $1 / 7 / 93$ & $1 / 28 / 93$ & $2 / 11 / 93$ \\
\hline & SAMPLE ID: & $2-71477$ & $2-71932$ & $2-71952$ \\
\hline & ANALYTE & $(\mathrm{mg} / \mathrm{kg})$ & (mg/kg) & (mg/kg) \\
\hline 1 & Sodium & 225,000 & 221,000 & 225,000 \\
\hline$\overline{2}$ & Potassium & 74,500 & 72,000 & 74,000 \\
\hline 3 & Calcium & 16,400 & 11,900 & 10,100 \\
\hline 4 & Magnesium & 7,050 & 5,990 & 4,910 \\
\hline 5 & Iron & 933 & 780 & 746 \\
\hline 6 & Aluminum & 677 & 493 & 476 \\
\hline 7 & Zinc & 143 & 116 & 101 \\
\hline 8 & Boron & 162 & 154 & 144 \\
\hline 9 & Nickel & 20 & 19 & 17 \\
\hline 10 & Chromium & 12 & 12 & 11 \\
\hline 11 & Copper & 18 & 17 & 19 \\
\hline 12 & Silver & 17 & 15 & 12 \\
\hline 13 & Barium & 22 & 18 & 16 \\
\hline 14 & Manganese & 29 & 22 & 19 \\
\hline 15 & Vanadium & 8 & 6 & 5 \\
\hline 16 & Lead & $\star$ & $\star$ & * \\
\hline 17 & Cadmium & 2 & 2 & 2 \\
\hline 18 & Cobalt & $\bar{*}$ & $\star$ & * \\
\hline 19 & Selenium & $\bar{\star}$ & t & * \\
\hline 20 & Beryllium & $*$ & 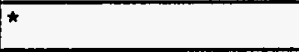 & \pm \\
\hline 21 & Thallium & 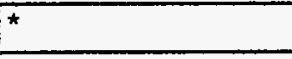 & * & * \\
\hline 22 & Arsenic & ${ }^{*}$ & $\star$ & * \\
\hline 23 & Mercury & 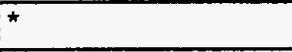 & * & ॠ \\
\hline 24 & Antimony & 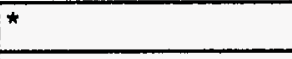 & $\star$ & * \\
\hline & * Below detectable limit & & & \\
\hline & Brine samples are & & & \\
\hline & 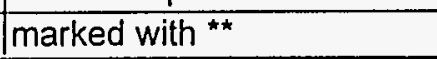 & & & \\
\hline
\end{tabular}


Table 2.1-1

Analysis of Salt and Brine Samples, Cations

\begin{tabular}{|c|c|c|c|c|c|}
\hline & DATE: & $3 / 10 / 93$ & $3 / 10 / 93$ & $3 / 10 / 93$ & $3 / 10 / 93$ \\
\hline & SAMPLE ID: & $44272^{\star \star}$ & $44273^{\star \star}$ & $44274^{\star \star}$ & $44275^{\star \star}$ \\
\hline & ANALYTE & (mg/kg) & $(\mathrm{mg} / \mathrm{kg})$ & (mg/kg) & $(\mathrm{mg} / \mathrm{kg})$ \\
\hline 1 & Sodium : & 81,300 & 83,900 & 82,800 & 86,700 \\
\hline 2 & Potassium & 29,300 & 29,400 & 29,000 & 27,300 \\
\hline 3 & Calcium & 2,370 & 2,380 & 2,480 & 2,550 \\
\hline$\overline{4}$ & Magnesium & 1,720 & 1,730 & 1,800 & 1,830 \\
\hline$\overline{5}$ & Iron & 253 & 252 & 262 & 263 \\
\hline$\overline{6}$ & Aluminum & 1.18 & 117 & 128 & 124 \\
\hline$\overline{7}$ & Zinc & 53.3 & 53.7 & 55.8 & 55.3 \\
\hline$\overline{8}$ & Boron & 45.4 & 47 & 44.8 & 44.8 \\
\hline 9 & Nickel & 6 & 7 & 7 & 7 \\
\hline$\overline{10}$ & Chromium & 5 & 4 & 5 & 5 \\
\hline 11 & Copper & 8 & 8 & 8 & 8 \\
\hline 12 & Silver & 4 & 4 & 4 & 4 \\
\hline 13 & Barium & 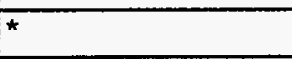 & $\star$ & $\star$ & * \\
\hline$\overline{14}$ & Manganese & 4 & 4 & 5 & 5 \\
\hline 15 & Vanadium & * & $\star$ & 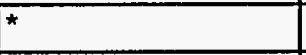 & \# \\
\hline 16 & Lead & * & 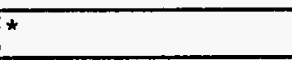 & $\star$ & $\star$ \\
\hline 17 & Cadmium & 1 & 1 & $\star$ & 1 \\
\hline 18 & Cobalt & * & * & * & * \\
\hline 19 & Selenium & ${ }^{\infty}$ & * & * & $\star$ \\
\hline 20 & Beryllium & ${ }^{\star}$ & $\star$ & $\star$ & * \\
\hline 21 & Thallium & * & * & * & * \\
\hline 22 & Arsenic & * & ${ }^{\star}$ & $\star$ & « \\
\hline 23 & Mercury & * & * & * & * \\
\hline \multirow[t]{4}{*}{24} & Antimony & 7 & $*$ & $\star$ & * \\
\hline & * Below detectable limit & & & & \\
\hline & Brine samples are & \#\#RINE & **BRINE & ${ }^{\star \star} \mathrm{BRINE}$ & ${ }^{\star \star} B R I N E$ \\
\hline & marked with ** & SAMPLE & SAMPLE & SAMPLE & SAMPLE \\
\hline
\end{tabular}

Page $2-7$ 
Table 2.1-2

Analysis of Salt and Brine Samples, Anions

\begin{tabular}{|l||r|r|r|r|r|r|r|r|r|}
\hline \multicolumn{1}{|c|}{ DATE: } & \multicolumn{1}{|c|}{$10 / 1 / 91$} & $11 / 9 / 91$ & $11 / 9 / 91$ & $11 / 9 / 91$ & $11 / 9 / 91$ & $11 / 9 / 91$ & $12 / 4 / 91$ & $12 / 5 / 91$ & \multicolumn{1}{|c|}{$1 / 5 / 92$} \\
\hline \multicolumn{1}{|c|}{ SAMPLE ID: } \\
\hline ANALYTE
\end{tabular}


Table 2.1-2

Analysis of Salt and Brine Samples, Anions

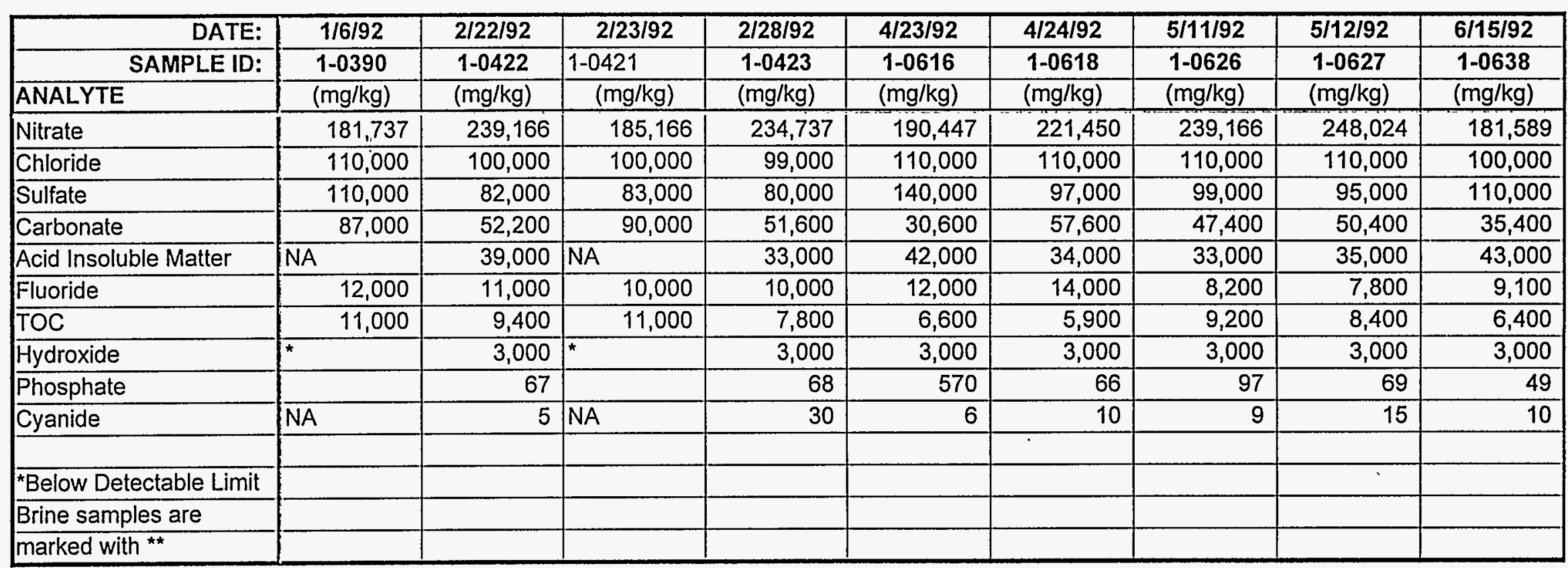


Table 2.1-2

Analysis of Salt and Brine Samples, Anions

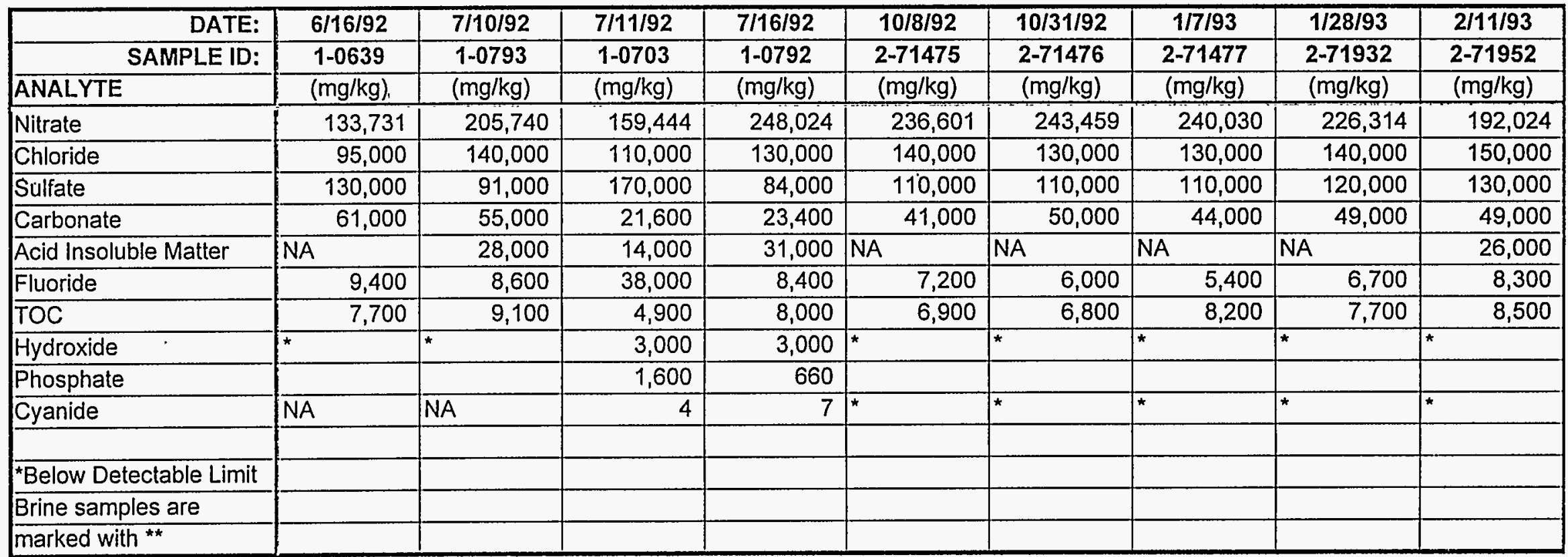


Table 2.1-2

Analysis of Salt and Brine Samples, Anions

\begin{tabular}{|c|c|c|c|c|}
\hline DATE: & $3 / 10 / 93$ & $3 / 10 / 93$ & $3 / 10 / 93$ & $3 / 10 / 93$ \\
\hline SAMPLE ID: & $44272^{\star \star}$ & $44273^{\star \star}$ & $44274^{\star \star}$ & $44275^{\star \star}$ \\
\hline ANALYTE & $(\mathrm{mg} / \mathrm{kg})$ & $(\mathrm{mg} / \mathrm{kg})$ & $(\mathrm{mg} / \mathrm{kg})$ & $(\mathrm{mg} / \mathrm{kg})$ \\
\hline Nitrate & 54,864 & 58,293 & 58,293 & 58,293 \\
\hline Chloride & 52,000 & 53,000 & 54,000 & 53,000 \\
\hline Sulfate & 41,000 & 41,000 & 42,000 & 45,000 \\
\hline Carbonate & 13,000 & 12,000 & 12,000 & 13,000 \\
\hline Acid Insoluble Matter & NA & 8,200 & 10,000 & NA \\
\hline Fluoride & 2,100 & 2,000 & 2,200 & 3,000 \\
\hline TOC & 3,700 & 3,800 & 3,800 & 3,700 \\
\hline Hydroxide & * & * & * & * \\
\hline \multicolumn{5}{|l|}{ Phosphate } \\
\hline Cyanide & 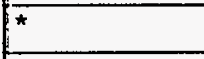 & * & * & * \\
\hline \multicolumn{5}{|l|}{${ }^{\circ}$ Below Detectable Limit } \\
\hline Brine samples are & ${ }^{\star \star} \mathrm{BRINE}$ & ** BRINE & ** BRINE & $\star$ BRINE \\
\hline marked with ** & SAMPLE & SAMPLE & SAMPLE & SAMPLE \\
\hline
\end{tabular}




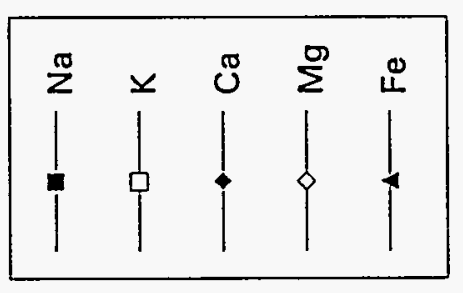

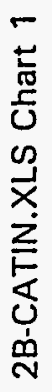

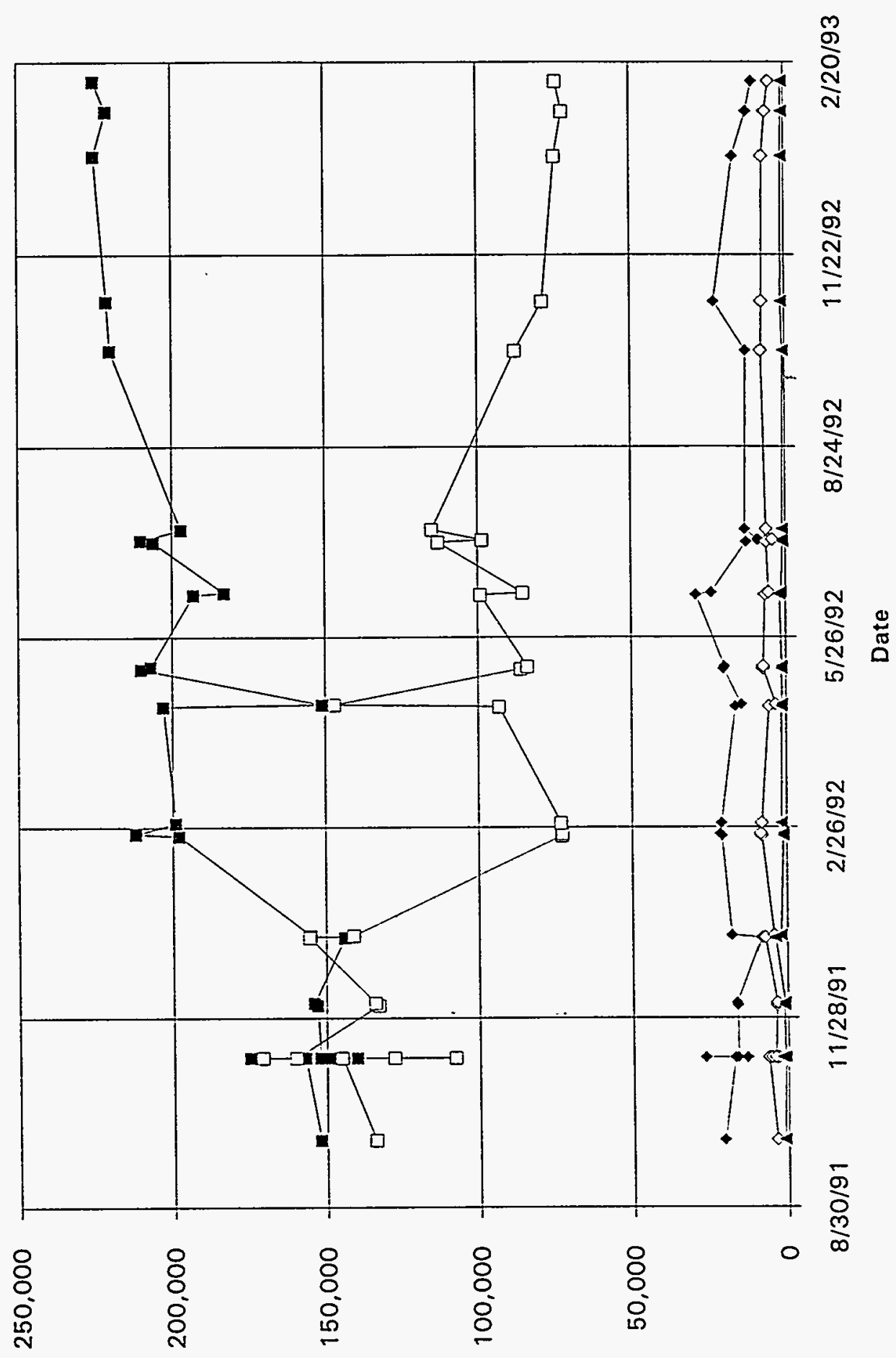

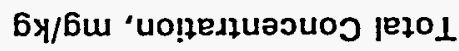




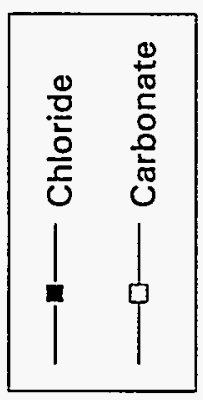

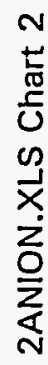
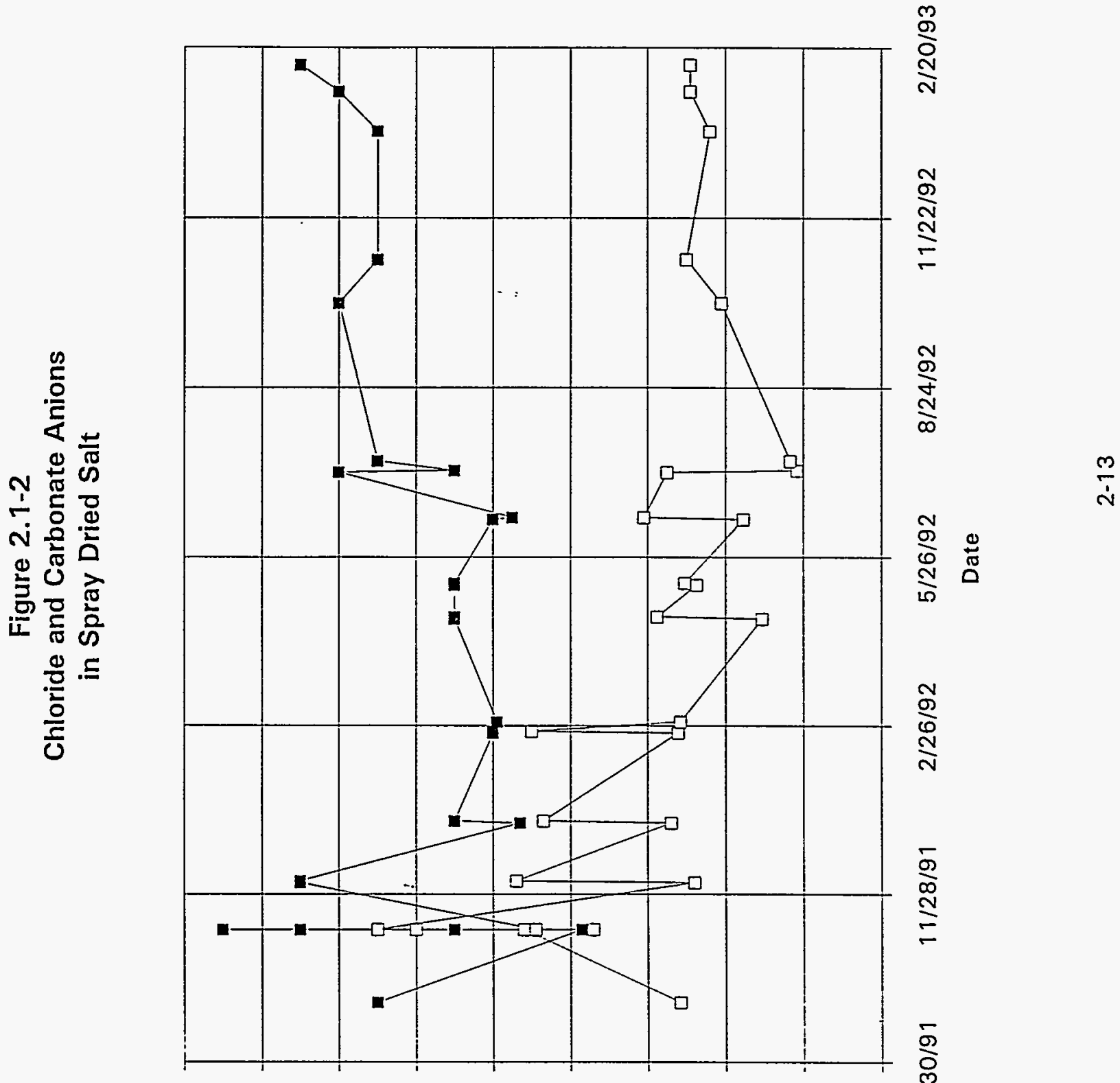

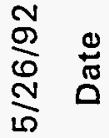

ơ
$\frac{\mathfrak{v}}{v}$

$\bar{\sigma}$
$\infty$
$v$
$\bar{\sigma}$

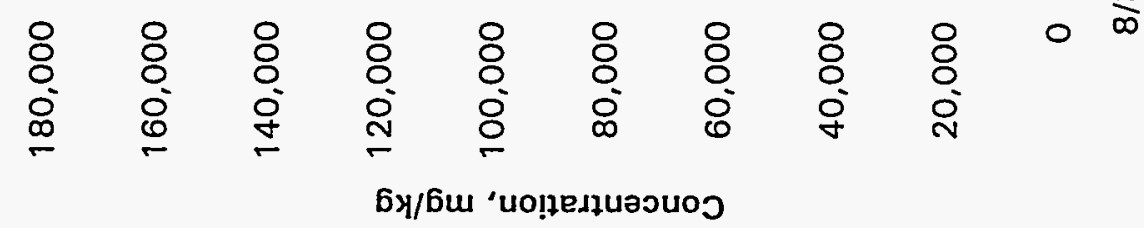

$\frac{\bar{\sigma}}{\frac{\infty}{\infty}}$ 
Figure 2.1-3

Nitrate and Sulfate Anions

in Spray Dried Salt

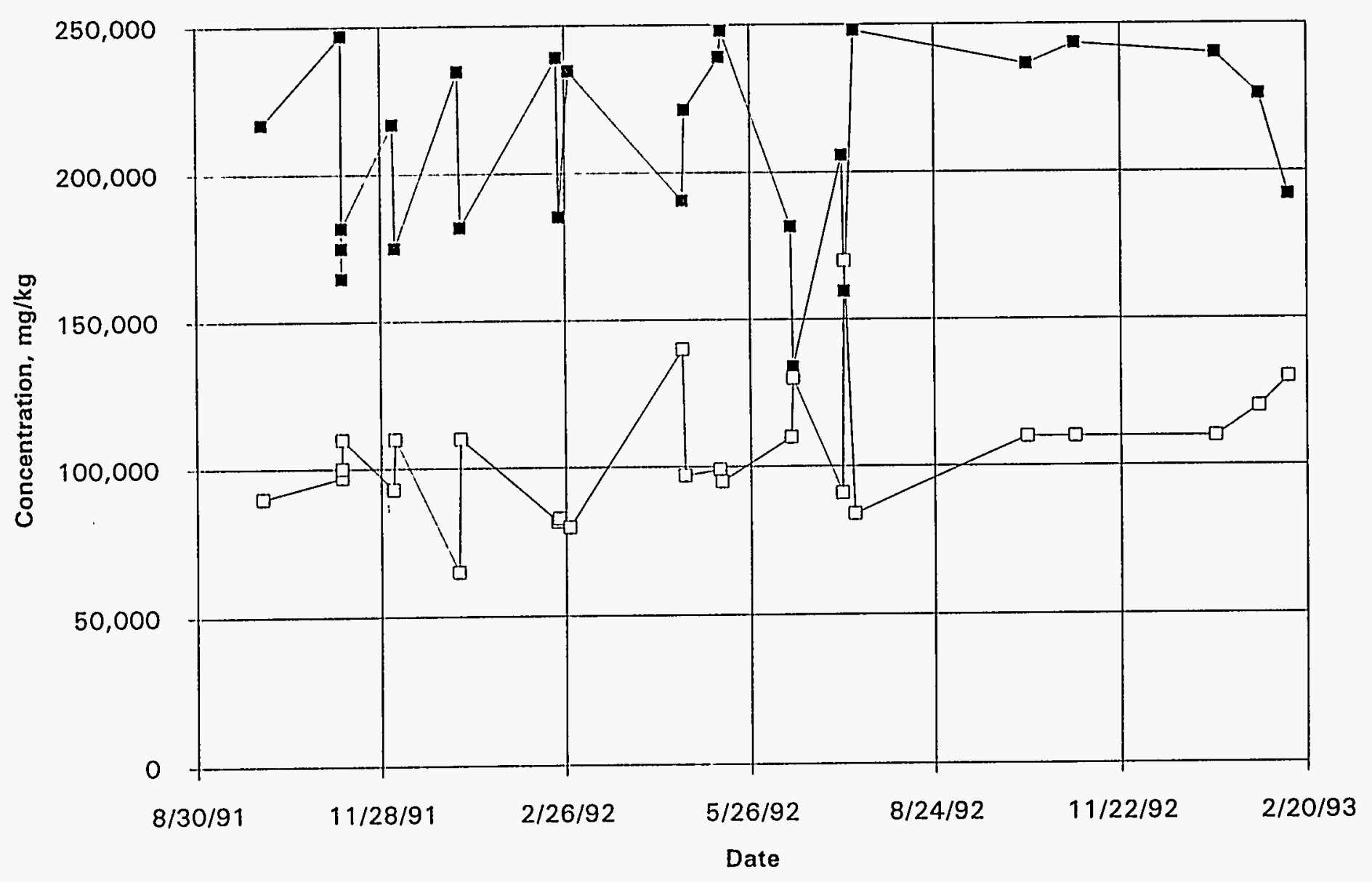


Total Concentration, $\mathrm{mg} / \mathrm{kg}$

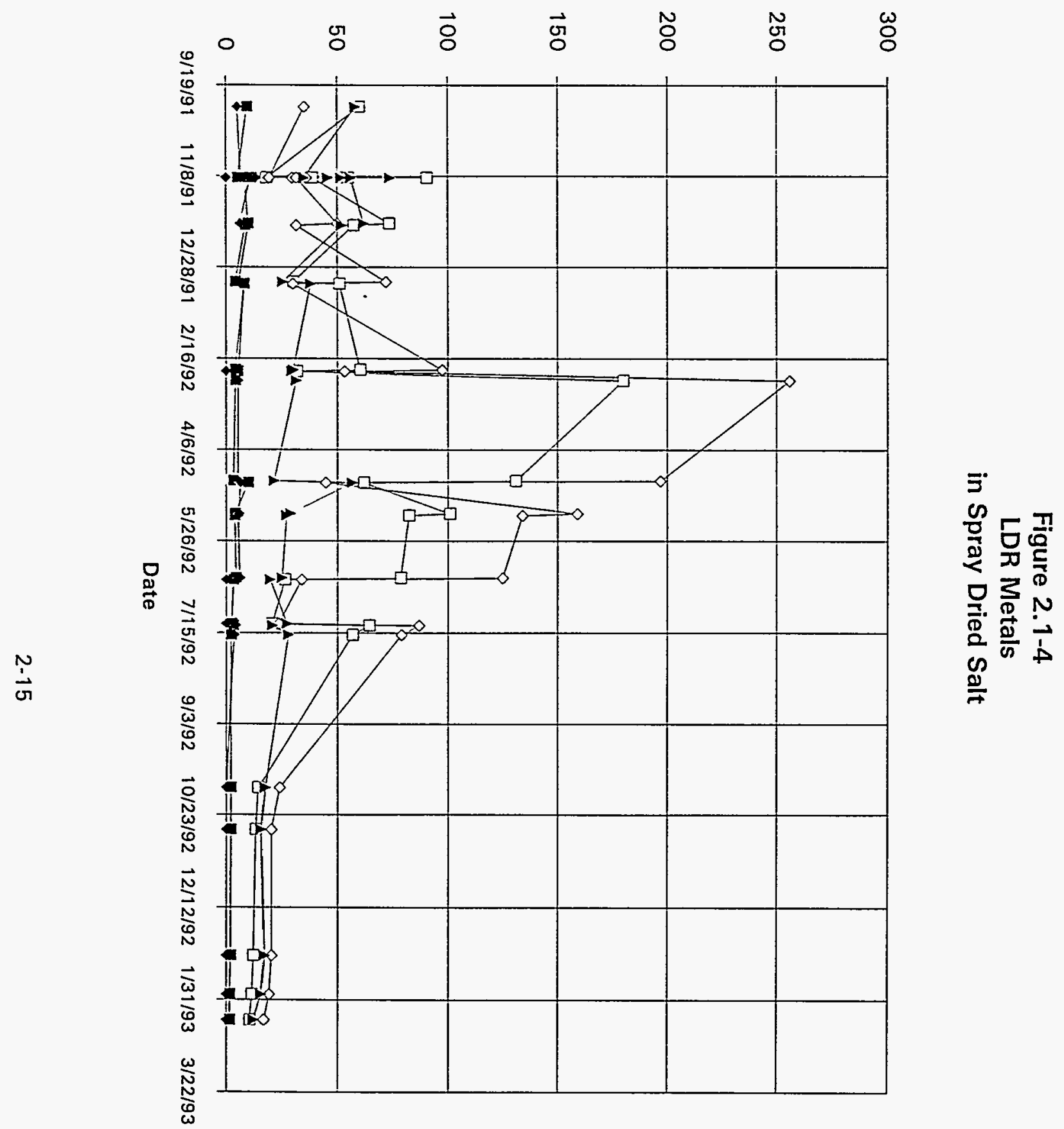

$$
\begin{aligned}
& 1\} \mapsto|1|
\end{aligned}
$$

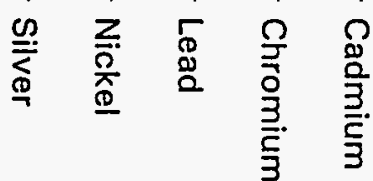




\subsection{Petrology}

The purpose of the petrology study was to determine the reason why the saltcrete expands.

\subsubsection{Experimental}

The approach was to compare samples from saltcrete crates that expanded to saltcrete crates that did not. In addition, samples of saltcrete that were generated in the laboratory and subjected to freeze/thaw testing were examined to determine if the expansion observed in the laboratory was due to the same mechanism as for the crates.

A core was taken from the center and from one end of seven crates with a $2 \frac{1}{2}$-inch core bit. Crates that expanded were cored at the end where the expansion was observed. An unexpanded crate produced during the same production run was cored for a comparison.

Three methods were employed to examine the microstructure: optical microscopy, scanning electron microscope (SEM), and x-ray diffraction (XRD). Optical microscopy was used to identify cement, the degree of cement hydration, porosity, homogeneity, salt crystals, and structural flaws. SEM and XRD were used to identify crystals. The analysis was performed on-site with oversight from consultants. Halliburton Energy Services contracted by EG\&G and the Army Corps of Engineers contracted by DOE advised EG\&G personnel about examining the waste form samples. Their reports are in Appendix 3.

\subsubsection{Conclusions}

The conclusions resulting from this study are:

1. The expansion is largely due to darapskite, which is a nitrate-sulfate hydrate $\left[\mathrm{Na}_{3}\left(\mathrm{NO}_{3}\right)\left(\mathrm{SO}_{4}\right) \cdot \mathrm{H}_{2} \mathrm{O}\right]$.

2. Porosity, salt crystal formation, and expansion occur together.

3. Laboratory samples did not produce darapskite.

4. Calcium-chloro-alumina hydrate is a possible cause of expansion. However, it is not likely to be significant.

5. Expansion is finite, and the rate of expansion will decrease the longer a crate is in storage.

The consensus of opinion among those who analyzed the data is that the expansion of the saltcrete is due to the formation of darapskite. The components of darapskite are derived from the waste rather than the cement. Since the formation of this salt is liable to occur no matter what type of cement is used type cement, type I/II cement, type V cement, or a blend of cement and Class $F$ flyash is suitable for the saltcrete treatment. It is also recommended that the waste loading be reduced from $35 \mathrm{wt} \%$ to $30 \mathrm{wt} \%$ since saltcrete containing less waste will have less darapskite. Waste loading of $30 \mathrm{wt} \%$ is recommended because production history shows that expansion is dramatically less when the waste loading is $30 \mathrm{wt} \%$ or less.

It was also observed that high porosity, crystal formation, and microfractures existed in the crates that expanded. Since porosity is higher in crates that expand, reducing the porosity of the saltcrete matrix may reduce expansion. Three possible causes of expansion are gas generation, 
air entrainment, and excess water. Air entrainment is the only one of these three that has a simple remedy. Gas generation is caused by chemicals in the waste, and the water content has been reduced as much as possible for the existing mixing system.

The maximum amount of expansion and the time when the expansion stops are of concern while the saltcrete is stored at Rocky Flats. The petrology studies provided estimates but not definite quantitative answers. Some of the core samples had darapskite concentrations of $20 \mathrm{wt} \%$. Since the waste loading was $35 \mathrm{wt} \%$, and since nitrate and sulfate ions comprise less than half of the waste, a reasonable estimate is that maximum expansion has occurred in those samples. Considering that the core samples were chosen to represent the crates with the most expansion, maximum expansion can be expected to be approximately two to three inches after one year. Section 2.6 addresses the expansion measurements of the entire saltcrete inventory.

Variation of the darapskite concentration was noted in the petrology study (Appendix 3). The cause could be poor mixing which could be the result of short residence time in the mixer or the formation of large, unmixed cement lumps. Large lumps of cement have been observed during mixing when the viscosity limitation of the mixer is exceeded at the same time as a large amount of cement enters the mixer. The mixer is then unable to agitate the contents of the tank.

\subsection{Time-of-Set}

The time-of-set of saltcrete formulations is a consideration for choosing a cement/admixture composition. This experiment had two objectives. The first objective was to compare the time-ofset for waste forms made with type $1 / 1 \mathrm{l}$ cement (currently produced) to waste forms produced using a blend of type $V$ cement and Class $F$ flyash ( $V-F$ blend). The second objective was to compare the time-of-set of lab-scale samples to full-scale containers. Typically, type I/II Portland cement mixed with the Building 374 salts typically requires seven to 21 days to harden in crates. Both type $V$ cement and Class $F$ flyash generally take longer to set than type I/II. This has been qualitatively observed in the lab on previous occasions.

\subsubsection{Experimental}

The approach was to compare the time-of-set in the full-scale saltcrete blocks made with type $1 / 11$ cement to lab-scale saltcrete blocks made with type $1 / 1 /$ cement and lab-scale saltcrete blocks made with $V-F$ blend by recording the respective temperature profiles. One full-scale block and four lab-scale blocks made with type $1 / 11$, plus one full-scale and four lab-scale blocks made with $\mathrm{V}-\mathrm{F}$ blend were monitored. The lab-scale block was insulated in a polystyrene foam box to reduce heat loss to the atmosphere (as in the August 1993 report). The temperature profile was recorded to monitor the exothermic cement hydration reaction. One full-scale crate of $35 \mathrm{wt} \%$ type $\mathrm{I} / \mathrm{II}$ saltcrete was available for testing and serves as the baseline for the lab-scale tests. The 30 $w t \% \mathrm{~V}-\mathrm{F}$ blend full-scale block was monitored for comparison. Table 2.3-1 gives the composition of the blocks and lab-scale samples that were monitored.

The saltcrete crate made with the V-F blend hardened in approximately the same amount of time (15 days) as the currently produced saltcrete (35 wt\% salt) made type I/II cement. In fact, the 
crate of V-F blend set three days sooner than the crate of type $I / I$ that was monitored for temperature, but other crates in the production run set sooner than either of the crates that were monitored. It is typical for the set times of the crates in a production run to vary by two to three days.

The full-scale V-F crate set sooner than was expected due to the accumulation of heat energy from the cement hydration reaction. Previous experience was with lab-scale samples which took much longer to set than type $I / I I$ lab-scale samples. The difference between type $V$ and type $I / I I$ cement is in the concentration of tricalcium aluminate which reacts more quickly with water than the other cement components. Type I/II has a higher concentration of tricalcium aluminate than type V. Apparently, the type $I / I I$ samples generated early heat quickly enough to accelerate the hydration of the other cement components. The type $V$ lab samples generated heat more slowly so more heat it was lost to the environment and was not available for accelerating the other cement components. The type $\mathrm{V}$ crate, however, accumulated the heat due to its size so the hydration reaction was accelerated in the crate. The lab-scale samples of V-F blend took approximately three times as long to set as the crate of $V-F$ blend. The lab-scale samples of type I/II took $1 \frac{1}{2}$ times as long as the crate of type $1 / I$.

TABLE 2.3-1

$\begin{array}{ccccccc}\text { SAMPLE } & \begin{array}{c}\text { SALT, } \\ \text { WT\% }\end{array} & \text { SCALE } & \begin{array}{c}\text { TYPE OF } \\ \text { CEMENT }\end{array} & \begin{array}{c}\text { CEMENT } \\ \text { FLYASH, } \\ \text { WT\% }\end{array} & \begin{array}{c}\text { WATER, } \\ \text { WT\% } \%\end{array} & \begin{array}{c}\text { TIME OF } \\ \text { SET, } \\ \text { DAYS }\end{array} \\ 1 & 35 \% & \text { Lab } & \text { I/I } & 36 \% & 29 \% & 17 \\ 2 & 35 \% & \text { Lab } & 1 / I 1 & 36 \% & 29 \% & 18 \\ 3 & 35 \% & \text { Lab } & \text { I/II } & 36 \% & 29 \% & 16 \\ 4 & 35 \% & \text { Lab } & \text { I/II } & 36 \% & 29 \% & 18 \\ \text { Crate } & 35 \% & \text { Full } & \text { I/II } & 36 \% & 29 \% & 13 \\ \text { H04747 } & & & & & & \\ 6 & 30 \% & \text { Lab } & \text { V-F blend } & 42 \% & 28 \% & 29 \\ 7 & 30 \% & \text { Lab } & \text { V-F blend } & 42 \% & 28 \% & 28 \\ 8 & 30 \% & \text { Lab } & \text { V-F blend } & 42 \% & 28 \% & 30+ \\ 9 & 30 \% & \text { Lab } & \text { V-F blend } & 42 \% & 28 \% & 30+ \\ \text { Crate } & 30 \% & \text { Full } & \text { V-F blend } & 42 \% & 28 \% & 10 \\ \text { H04749 } & & & & & & \end{array}$

The temperature profiles are shown in Figures 2.3.1-1, 2.3.1-2, and 2.3.1-3. A detailed table of temperatures is in Appendix 6. 
Figure 2.3.1-1

Temperature vs Elapsed Time

Type I/II Cement
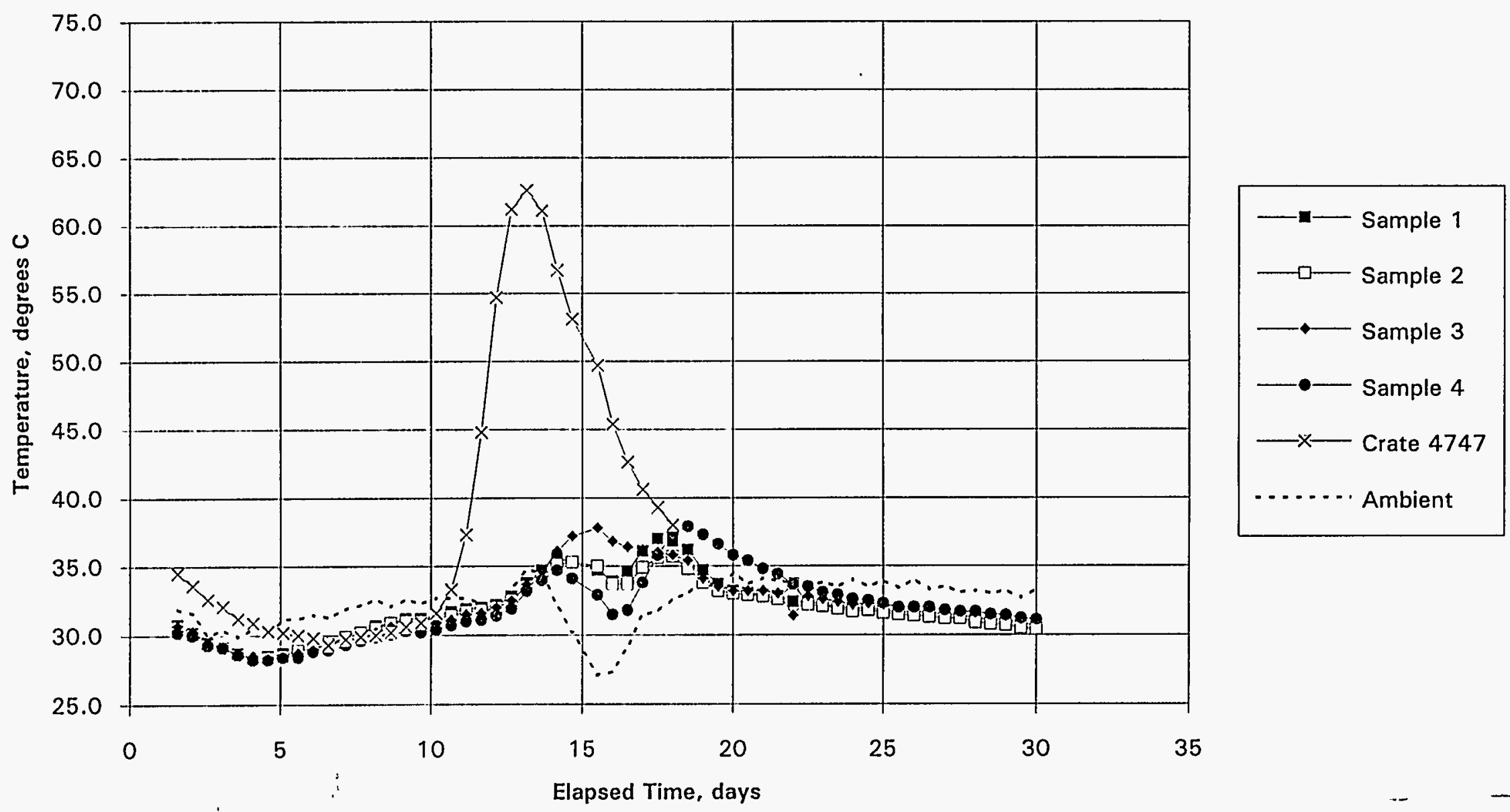
Figure 2.3.1-2

Temperature vs Elapsed Time

Type V Cement, Class F Flyash Blend

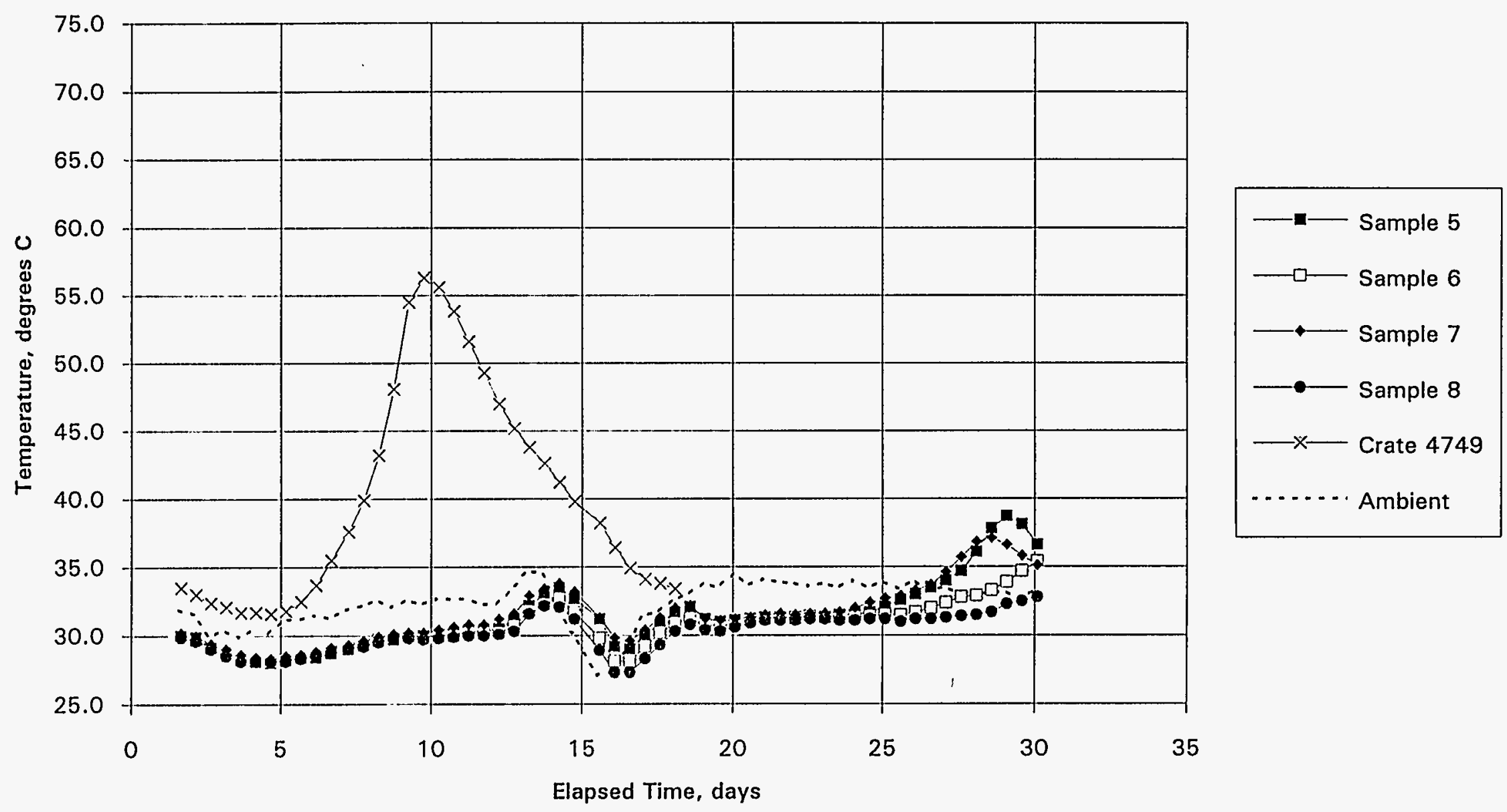


Figure 2.3.1-3

Temperature vs Elapsed Time

Type V Cement-Class F Flyash Blend Compared to Type I/II Cement

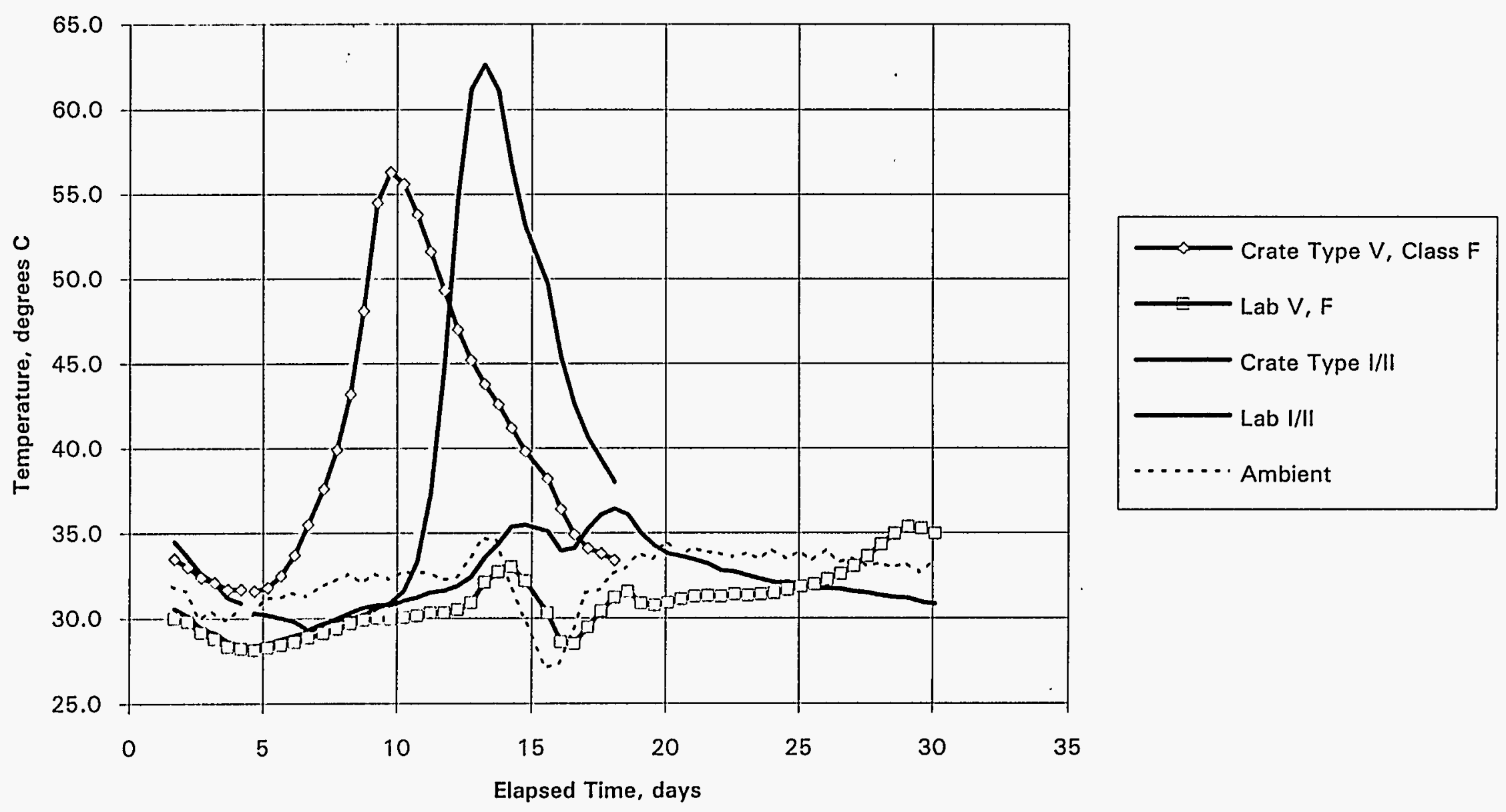




\subsection{Freeze/Thaw Cycling}

The objective of this experiment was to evaluate the durability and stability of saltcrete formulations using actual waste from the treatment process.

Lab-scale samples of saltcrete prepared with various proportions of type $V$ cement, type $1 / 11$ cement, and Class $F$ flyash were cured in an oven then subjected to freeze/thaw cycling. The dimensions and mass of the samples were measured before and after the freeze/thaw cycling.

\subsubsection{Experimental}

Samples of saltcrete were prepared by adding the dry cementitious constituents to the brine. The ratio of water to salt to cement/flyash was 30.5 to 29.5 to 40.5 percent by weight. The cement to flyash ration was 3:1. The water concentration in this test is slightly higher than in the recommended operating envelope (by $0.7 \mathrm{wt} \%$ ) to provide a harsh freeze/thaw test. Cylindrical samples one inch in diameter by two inches high were weighed and measured before and after freeze/thaw cycling. The diameters were measured at three points and the length at two points. The samples were poured into sealed plastic molds then cured in a lab oven at $60^{\circ} \mathrm{C}$ for $21 / 2$ days. The ten different cement dry blends shown in Table 2.4.1-1 were evaluated.

\begin{tabular}{|c|c|c|c|c|c|c|c|c|}
\hline \multicolumn{3}{|c|}{$\begin{array}{c}\text { Sample } \\
\text { no. }\end{array}$} & \multirow{2}{*}{$\begin{array}{c}\text { Water } \\
\text { wt\% } \\
30.8\end{array}$} & \multirow{2}{*}{$\begin{array}{l}\text { Salt } \\
\text { wt\% } \\
28.7\end{array}$} & \multicolumn{2}{|c|}{$\begin{array}{l}\text { Cement } \\
\text { type, wt\% }\end{array}$} & \multirow{2}{*}{$\begin{array}{c}\text { Flyash } \\
\text { wt } \% \\
20.3\end{array}$} & \multirow[t]{2}{*}{$\begin{array}{l}\text { Free } \\
\mathrm{H} 2 \mathrm{O} ?\end{array}$} \\
\hline 2 & A & $1-94$ & & & I/II & 20.3 & & \\
\hline 2 & B & $1-94$ & 30.8 & 28.7 & I/II & 20.3 & 20.3 & \\
\hline 3 & A & $1-94$ & 30.8 & 28.6 & $I / I I$ & 30.4 & 10.2 & \\
\hline 3 & B & $1-94$ & 30.8 & 28.6 & $1 / I I$ & 30.4 & 10.2 & \\
\hline 4 & A & $1-94$ & 30.9 & 28.7 & $|/| I$ & 36.3 & 4.1 & yes \\
\hline 4 & B & $1-94$ & 30.9 & 28.7 & $\mid / / 1$ & 36.3 & 4.1 & \\
\hline 5 & A & $1-94$ & 30.8 & 28.7 & $|/ I|$ & 38.4 & 2.0 & yes \\
\hline 5 & B & $1-94$ & 30.8 & 28.7 & $1 / \mid I$ & 38.4 & 2.0 & yes \\
\hline 1 & A & $1-94$ & 30.8 & 28.7 & $1 / 11$ & 40.5 & 0.0 & yes \\
\hline 1 & B & $1-94$ & 30.8 & 28.7 & $\mid / I I$ & 40.5 & 0.0 & yes \\
\hline 7 & A & $1-94$ & 30.7 & 28.6 & V & 20.3 & 20.4 & \\
\hline 7 & B & $1-94$ & 30.7 & 28.6 & V & 20.3 & 20.4 & \\
\hline 8 & A & $1-94$ & 30.7 & 28.6 & V & 30.4 & 10.3 & \\
\hline 8 & B & $1-94$ & 30.7 & 28.6 & V & 30.4 & 10.3 & \\
\hline 9 & A & $1-94$ & 30.9 & 28.8 & V & 36.2 & 4.1 & yes \\
\hline 9 & B & $1-94$ & 30.9 & 28.8 & V & 36.2 & 4.1 & \\
\hline 10 & A & $1-94$ & 30.9 & 28.7 & V & 38.2 & 2.2 & yes \\
\hline 10 & B & $1-94$ & 30.9 & 28.7 & V & 38.2 & 2.2 & \\
\hline 6 & $A$ & $1-94$ & 30.7 & 28.6 & V & 40.6 & 0.0 & yes \\
\hline 6 & B & $1-94$ & 30.7 & 28.6 & V & 40.6 & 0.0 & yes \\
\hline
\end{tabular}


An unexpected benefit of this test was the observation that flyash immobilizes water when the flyash concentration was between $5 \mathrm{wt} \%$ and $10 \mathrm{wt} \%$ in the final waste form (see Table 2.4.1-1). This concentration of flyash is commonly used in waste treatments (Conner, 1990). The correlation of free water to flyash concentration lead to the recommendation that flyash be used in the treatment at $10 \mathrm{wt} \%$ of the final waste form.

The freeze/thaw tests showed that the type of cement did not affect the expansion nearly as much as the concentration of flyash. The previous study showed that the type of cement had a significant effect on the expansion. The different results suggest that the freeze/thaw test is not a reliable predictor of expansion. The petrology study in Section 2.2 indicates that the expansion mechanism in the lab-scale samples is different from the mechanism in the full-scale crates.

\subsubsection{Conclusions}

The freeze/thaw test is not a reliable predictor of the expansive properties of a cement formulation.

Flyash helped immobilize water in lab-scale samples.

\subsection{Instrumentation}

There are two reasons for recommending more instrumentation for the saltcrete process. The first is to provide documentation that the process is operated within a set of specifications, the second is to improve the accuracy and consistency of measurements.

\subsubsection{Rationale}

Documentation of the process will help provide evidence that the waste is treated according to the standard operating procedure (SOP), which is a certification requisite for the Nevada Test Site (NTS). The necessity for documentation is derived from NVO-325 (an NTS document). Envirocare of Utah, another disposal site, has no requirements for process documentation, but relies on chemical analysis of the treated waste. Currently, the weight of the components in saltcrete (brine, salt, and cement) are manually recorded. A method to automatically record this information would provide confirmation of the manual transcription.

The process parameters of interest are:

1. The water content of the untreated brine.

2. The weight of each component, brine, salt, and cement, added to a batch of saltcrete.

3. When the saltcrete is set.

Currently the water content of the untreated brine is calculate from its specific gravity as measured by a hydrometer. The precision of the hydrometer is \pm 0.01 specific gravity units and an error of 0.02 specific gravity units has been observed in practice. This amounts to an error of approximately $1 \%$ by weight of the final waste form ( $3 w t \%$ of the untreated brine). Since the process has a $2 \mathrm{wt} \%$ range, the hydrometer error can be significant. Technology Development 
personnel have used a moisture balance to make water content determinations. The moisture balance has consistently produced results that are $0.2 \%$ by weight of the final waste form $(0.5$ $w t \%$ of the brine).

The weights of the saltcrete components are measured by load cells on the mixing tank. A digital display of the weight is manually transcribed after each component is transferred to the tank. The weighing system has no automated recorder, but data acquisition instruments are on-site and will be installed soon to provide an automatic redundant record.

Currently, the completion of the cement hydration reaction is determined by inspection. Visual observation is used to determine that there is no free water and no free particulate matter. The waste form is poked with a rod to determine if the waste form is hard. A method to record the completion of the hydration reaction would help demonstrate whether the treatment of a given container of waste is successful.

\subsubsection{Recommendations}

Two Hydra Data Buckets, manufactured by Fluke, are recommended to record data. One recorder dedicated to monitoring the weights of the saltcrete components and the specific gravity of the brine will provide documentation of composition of the waste form. A second recorder to monitor the temperature of the crates while they are curing will provide documentation of the cement hydration.

A nuclear densitometer to continuously monitor the specific gravity of the brine and provide data for documentation of waste certification is recommended. A Texas Nuclear model 5201 is available from plant inventory. The densitometer data can be recorded by a Data Bucket.

The letter report prepared by A. A. Marlowe, included as Appendix 8, gives more detail about the recommended instrumentation.

A moisture balance should be used for determining the water content of the untreated brine.

\subsection{Measurement of Expanded Crates}

Saltcrete crates produced since April 1990 with noticeable bulges were measured for expansion in April 1993 and again January 1994. Approximately one out of seven crates in inventory were bulged. The average expansion in April 1993 was 0.84 inches. When those same crates were measured the second time the average expansion was 1.03 inches. Since the difference was less than the estimated accuracy of the measurements, the expansion during the period was considered negligible.

\subsection{DOT Oxidizer Test}

The test to determine if a material is an oxidizer (49 CFR 173 Appendix F) according to the Department of Transportation (DOT) was performed on samples of spray-dried salt. (A letter report is in Appendix 1.) Salt waste generated from Building 374 liquid waste treatment containing 
less than 31 wt\% nitrate ion is not an oxidizer by this test. However, this does not imply that salt waste generated in the future will not be. Higher nitrate concentrations and the combined effects of the other constituents in the waste may cause the salt to fail the oxidizer test.

$$
1
$$

Since the test is simple to perform, the determination can be made on each saltcrete production run if the decision is made to store untreated salt. 


\subsection{Formulation}

3.1 Operating Envelope, Lab-Scale Tests

The objective was to determine the proportions of water, salt, and cement that exhibit the properties that allow the full-scale mixer to stir the paste and not produce free water.

\subsubsection{Experimental}

Tests were performed in the laboratory to find the minimum and maximum concentrations of water with a $30 \mathrm{wt} \%$ waste loading (30 wt\% salt) and a $26 \mathrm{wt} \%$ waste loading. The maximum waste loading of $30 \mathrm{wt} \%$ was chosen because it was found that the likelihood of waste form expansion greatly increases at higher waste loading due to the darapskite formation (see Section 2 in the August 1993 report). The minimum waste loading of $26 \mathrm{wt} \%$ was chosen because it allows reasonable room for process variation. Once the bounding water and salt concentrations were found, the bounding cement concentration was calculated.

A high concentration of water in the paste reduces viscosity which allows better mixing. If the water concentration is too high, free water accumulates on the top surface of waste form. The free water must then be removed for the waste to be certifiable because it is a violation of the WAC (removal of free water can be included in the standard operating procedure). Once the proportions were determined in the laboratory, the formula was tested with the full-scale equipment.

Detailed data, graphs and explanations of them are in Appendix 4. A summary of the results is presented in Table 3.1.1-1 and Figure 3.1.1-1.

Table 3.1.1-1

\begin{tabular}{|c|c|c|c|}
\hline & $\begin{array}{c}\text { Water } \\
\text { wt \% }\end{array}$ & $\begin{array}{l}\text { Salt } \\
\text { wt\% }\end{array}$ & $\begin{array}{c}\text { Cement } \\
w t \%\end{array}$ \\
\hline $\begin{array}{l}\text { Maximum water at maximum } \\
\text { salt loading }\end{array}$ & 29.7 & 30.0 & 40.3 \\
\hline $\begin{array}{l}\text { Minimum water at maximum } \\
\text { salt loading }\end{array}$ & 29.0 & 30.0 & 41.0 \\
\hline $\begin{array}{l}\text { Minimum water at } \\
26 \text { wt } \% \text { salt }\end{array}$ & 27.2 & 26.0 & 46.8 \\
\hline $\begin{array}{l}\text { Maximum water at } \\
26 \text { wt } \% \text { salt }\end{array}$ & 28.3 & 26.0 & 45.7 \\
\hline
\end{tabular}


Figure 3.1-1

Lab-Scale Operating Envelope
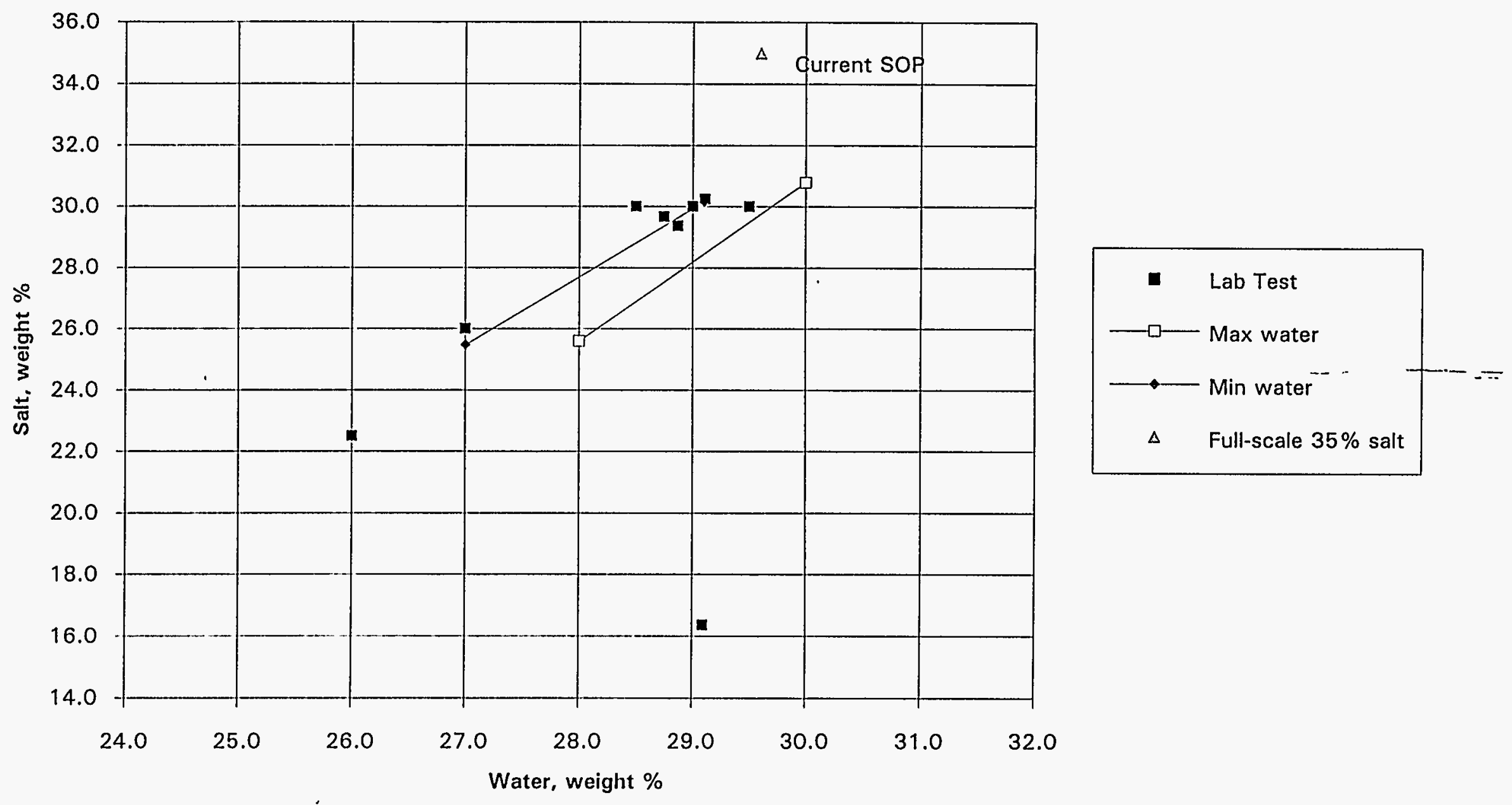


\subsubsection{Conclusions}

When the salt concentration is $30.0 \mathrm{wt} \%$, the laboratory-scale tests indicate that the maximum and minimum concentrations of water in the final waste form are 29.7 and $29.0 \mathrm{wt} \%$ respectively. When the salt concentration is $26.0 \mathrm{wt} \%$, the maximum water concentration is $28.3 \mathrm{wt} \%$ and the minimum water concentration is $27.2 \mathrm{wt} \%$. (See the next section for the full-scale test of these concentrations.)

The minimum cement concentration ( $40.3 \mathrm{wt} \%$ ) was calculated from the maximum salt concentration ( $30.0 \mathrm{wt} \%$ ) and the maximum water concentration (30 wt\%). The maximum cement concentration ( $46.8 \mathrm{wt} \%$ ) was calculated from the minimum water concentration $(27.2 \mathrm{wt} \%)$ and the minimum salt concentration (26.0 wt\%).

The information from lab-scale tests was used to develop the tests for the full-scale tests. The lab-scale tests indicated that the bounding conditions were very restrictive. Since there was very little difference between the maximum and minimum water concentrations and "problems with scale-up are legion" (Uhl, 1986), there was concern that there would be problems when this formulation was used with the full-scale mixer. However, the saltcrete paste is a shear-thinning fluid and there is a greater average shear rate in the full-scale mixer (Oldshue, 1983). This means that saltcrete paste with less water would exhibit acceptable viscosities in the full-scale mixer, as was shown in the full-scale tests (refer to Section 3.2).

\subsubsection{Contingency Formulation}

Tests were also performed on brine with no spray-dried salt added. The results from this test can be used as an emergency formulation in the event that the spray-drier fails. At 16 wt\% salt, the range of water concentration was $25 \mathrm{wt} \%$ to $29 \mathrm{wt} \%$. This water-content range has not been tested on the full-scale equipment. Verification of this water-content range should be tested on the full-scale equipment for free water formation and viscosity during the early part of a production run in the event the spray-drier fails.

\subsection{Operating Envelope, Full-Scale}

The objective was to determine the proportions of water, salt, and cement that exhibit the properties that allow the full-scale mixer to stir the paste and not produce free water. The tests used were the same as laboratory-scale tests. The limiting conditions established in this test can be used by LWTO to produce certifiable waste.

Explanation of terms used in this section:

Production run - One run produces approximately fifteen crates during a two day period. Production runs are made approximately once per month.

Batch - Three 1,200-pound batches are poured into one halfcrate.

Halfcrate - A plywood box 7' $\times 4^{\prime} \times 2^{\prime}$ lined with fiberboard and plastic. 
Bleed water - A layer of water that forms on the top of the saltcrete before the paste hardens. Bleed water must be removed because waste containing free waste cannot be disposed.

Predicted water content - results from the laboratory-scale test.

Actual water content - results from the full-scale test.

Viscosity limitation of the mixer - saltcrete paste with viscosity values greater than the line in equation (1) is too viscous to agitate. A semi-solid mass forms that must be pushed out of the mixer with hand tools.

$$
\theta=60+1 / 2(\mathrm{rpm})
$$

(equation 1)

Where $\theta$ is the angle of deflection, and rpm is the rotation speed of the viscometer. If the vortex is observed for a visual determination, the limitation of the mixer is where the vortex is less than two inches. (Markers on the mixer shaft may help make visual determinations.)

\subsubsection{Experimental}

The boundary conditions were based on the waste loading and water content. The maximum waste loading was established by reviewing historical production records (August 1993 report). The maximum water content was based on formation of bleed water. Formulations that produced bleed water were judged to have too much water. The minimum water content was established by the limitations of the mixer (the lower the water content, the higher the viscosity).

The approach was to test the corners of the envelope that was developed in the laboratory. To find the maximum water concentration the full-scale mixer could tolerate, the lab-scale maximum was tested. Two test crates were made to test for free water, one at the highest water concentration with $30.0 \mathrm{wt} \%$ salt concentration and one at the highest water concentration with $26.0 \mathrm{wt} \%$ salt concentration. These crates were visually monitored for formation of bleed water. Samples of these batches were placed in $50 \mathrm{ml}$ graduated cylinders and were monitored for free water formation. To find the minimum water concentration that the full-scale mixer could tolerate, high-water-content batches were made first and then cement was added. Several tests were made to test for high viscosity by adding cement until the viscosity reached the limitations of the mixer.

Several steps were taken to ensure the accuracy of the test. During the test, the vacuum line (for dust control) to the mixer was closed, and the mixer motor was stopped after each component was added to minimize forces extraneous to the mixer weighing system. The digital weight readout was zeroed after the brine was added, after the salt was added, and after each batch was poured into a crate. This was done to prevent carrying over error from one weight determination to another. For example, an over run on the brine weight was not carried over to the salt measurement. The mixer load cells were calibrated with certified weights prior to the production run. The moisture balance, an instrument for thermal gravimetric determinations, was calibrated 
with certified weights prior to the test. The viscometer was calibrated with the manufacturer's calibration kit before and after the test.

The parameters measured were the water content of the brine, the weight of the components in the saltcrete, the specific gravity and temperature of the brine, and the viscosity of the saltcrete slurry. Visual observations were made for free water in the crates. Observations for free water were also made by collecting samples in $50 \mathrm{ml}$ test tubes. The test tubes were checked over a period of several hours.

The results are presented in Table 3.2-1 and in Figures 3.2-1, 3.2-2, and 3.2-3. The minimum and maximum water content lines were derived by performing linear regressions on the respective data points.

The full-scale test validated the laboratory-scale tests. The actual maximum water content was similar to the predicted value, but the predicted minimum water content was lower than the actual water content. see Figure 3.2.4 The fact that the full-scale envelope is larger than the lab-scale envelope is not surprising since the saltcrete paste is a shear-thinning fluid and the full-scale mixer has greater range of shear rate than the lab-scale mixer. The lab-scale impeller rotates at $400 \mathrm{rpm}$ and has a diameter of one inch while the full-scale impeller rotates at $360 \mathrm{rpm}$ and has a diameter of 12.6 inches. The higher shear rate produces more shear thinning, or in other words, the full-scale mixer thins the fluid more than the lab-scale mixer.

The full-scale envelope was found to have $1 \frac{1}{2}$ times the water content latitude as the lab-scale envelope. The lab-scale tests indicated that for a given salt concentration, the water concentration can vary by approximately $11 / 2$ wt\%. The full-scale tests indicated that the water concentration can vary by approximately $21 / 4 \mathrm{wt} \%$. This is significant because the size of the envelope is small, compared to the inherent variation of the process, such as the accuracy of the measuring system ( $1 / 4 \mathrm{wt} \%$ to $1 / 2 \mathrm{wt} \%$ ). Also consider that the pneumatic transfer systems deliver salt and cement in increments of 12 and 25 pounds respectively. These weights correspond to 1 $w t \%$ and $2 w t \%$ of a batch. 


\begin{tabular}{|c|c|c|c|c|c|c|c|c|c|c|c|c|c|c|c|c|c|c|c|c|c|c|c|c|c|c|c|c|}
\hline & & & & & & & & & & & & & & & & & & & & & & & & & & & & \\
\hline Cement & Flyash & Date & Time & Crate & Run & Specif & Grav. & $W_{t} \%$ & & unds I & & & Nt\% In & & & & & & & & :ome & erRes & dings & & & & & \\
\hline Type & Class & & & & & Meast & ed by & Water & & Iterete & & & altcrett & & $\mathrm{pmm}$ & 1 & 21 & 3 & 6 & 10 & 20 & 30 & 60 & 100 & 200 & 300 & 600 & Free \\
\hline & & & & & & LWTO & TD & In Brine & Brine & Salt & $\mathrm{Cmt}_{\mathrm{t}}$ & Water & Salt & Cement & degref & 5 of & deflec & IIon & & & & & & & & & & $\mathrm{H} 2 \mathrm{O} ?$ \\
\hline $100 \% \mathrm{~V} / \mathrm{lt}$ & & $12 / 8 / 93$ & $11: 24$ & 4683 & 1 & 1.32 & 1.32 & 59.5 & 608 & 114 & 478 & 30.1 & 30.0 & 39.8 & & 10 & 10 & 11 & 11 & 15 & 18 & 21 & 30 & 41 & 67 & 89 & 143 & trace \\
\hline $100 \% \mathrm{VIII}$ & & $12 / 8 / 93$ & $13: 00$ & 4683 & 2 & 1.32 & 1.325 & 59.5 & 608 & 107 & 469 & 30.6 & 29.8 & 39.6 & & 9 & 9 & 9 & 9 & 10 & 12 & 14 & 20 & 26 & 43 & 58 & 97 & \\
\hline $100 \% \mathrm{VIII}$ & & $12 / 8 / 93$ & $13: 45$ & 4683 & 3 & 1.32 & 1.32 & 59.6 & 608 & 124 & 484 & 29.8 & 30.4 & 39.8 & & 14 & 20 & 21 & 20 & 21 & 24 & 26 & 33 & 41 & 62 & 80 & 124 & \\
\hline $100 \% \mathrm{IIII}$ & & $12 / 8 / 93$ & $16: 50$ & 4682 & 1 & 1.32 & 1.32 & $60 . \overline{6}$ & 577 & 129 & 514 & 28.7 & 29.2 & 42.1 & & 15 & 20 & 19 & 19 & 20 & 24 & 28 & 37 & 49 & 75 & 97 & & \\
\hline $100 \% \mathrm{inI}$ & & $12 / 8 / 93$ & $16: 50$ & 4682 & 1 & 1.32 & 1.32 & 60.6 & 577 & 129 & 535 & 28.2 & 28.7 & 43.1 & & 13 & 16 & 14 & 15 & 17 & 21 & 24 & 34 & 45 & 72 & 97 & & \\
\hline $100 \% \mathrm{Wi11}$ & & $.12 / 8 / 93$ & $16: 50$ & 4682 & 1 & 1.32 & 1.32 & 60.6 & 577 & 129 & 580 & 27.2 & 27.7 & 45.1 & & 14 & 20 & 20 & 20 & 22 & 26 & 30 & 42 & 56 & 89 & 112 & & \\
\hline $100 \% \mathrm{VInI}$ & & $12 / 8 / 93$ & $16: 50$ & 4682 & 1 & 1.32 & 1.32 & 60.6 & 577 & 129 & 636 & 26.1 & 26.6 & 47.4 & & 20 & 26 & 30 & 31 & 35 & 38 & 44 & 60 & 78 & 120 & 156 & & \\
\hline $100 \% 1 / 11$ & & $12 / 8 / 93$ & $16: 50$ & 4682 & 1 & 1.32 & 1.32 & 60.6 & 577 & 129 & 674 & 25.3 & 25.8 & 48.8 & & 25 & 31 & 35 & 43 & 43 & 50 & 56 & 76 & 99 & 155 & 207 & & \\
\hline $100 \%$ lini & & $12 / 14 / 93$ & $8: 05$ & 4663 & 1 & 1.32 & 1.32 & $60 . \overline{8}$ & 563 & 99 & 554 & 28.2 & 26.3 & 45.6 & & 15 & 20 & 20 & 20 & 20 & 20 & 25 & 30 & 37 & 56 & 75 & 125 & \\
\hline $100 \% 1 \mathrm{inI}$ & & $12 / 14 / 93$ & $8: 45$ & 4663 & 2 & 1.32 & 1.32 & 60.8 & 587 & 100 & 580 & 28.2 & 26.1 & 45.8 & & 8 & 10 & 9 & 10 & 11 & 13 & 15 & 21 & 29 & 47 & 64 & 110 & \\
\hline $100 \% \mathrm{ini}$ & & $12 / 14 / 93$ & $9: 20$ & 4663 & 3 & 1.32 & 1.32 & 60.8 & 562 & 104 & 558 & 27.9 & 26.5 & 45.6 & & 12 & 12 & 12 & 12 & 13 & 15 & 18 & 25 & 34 & 54 & 74 & 121 & \\
\hline $100 \% \mathrm{I} / \mathrm{MI}$ & & $12 / 14 / 93$ & $10: 30$ & 4663 & 1 & 1.32 & 1.32 & 60.8 & 554 & 112 & 560 & 27.5 & 26.8 & 45.7 & & 15 & 16 & 15 & 16 & 16 & 19 & 22 & 30 & 41 & 65 & 88 & $\frac{152}{152}$ & \\
\hline $100 \% / / 11$ & & $12 / 14 / 93$ & $11: 00$ & 4663 & 2 & 1.32 & 1.32 & 60.8 & 594 & 112 & 560 & 28.5 & 27.2 & 44.2 & & 11 & 12 & 91 & 11 & 12 & 14 & 17 & 23 & 39 & 51 & 69 & 115 & \\
\hline $100 \% \mathrm{IIII}$ & & $12 / 14 / 93$ & $11: 05$ & 4663 & 3 & 1.32 & 1.32 & 60.8 & 556 & 105 & 561 & 27.7 & 26.4 & 45.9 & & 11 & 12 & 12 & 12 & 13 & 16 & 18 & 24 & 34 & 55 & 74 & $\frac{122}{122}$ & \\
\hline $100 \%$ I/III & & $12 / 8 / 93$ & $10: 55$ & 4689 & 9 & 1.32 & 1.325 & 60.5 & 565 & 104 & 584 & 27.3 & 26.1 & 46.6 & & 30 & 40 & 42 & 60 & 67 & 80 & 92 & 125 & 160 & 235 & 290 & 300 & \\
\hline $100 \% \mathrm{I} / \mathrm{II}$ & & $12 / 8 / 93$ & $14: 35$ & 4689 & 2 & 1.32 & & 60.5 & 529 & 124 & 560 & 26.4 & 27.4 & 46.2 & & 22 & 27 & 27 & 25 & 26 & 32 & 36 & 47 & 61 & 93 & 120 & 192 & \\
\hline $100 \% \mathrm{IIII}$ & & $12 / 8 / 93$ & $15: 45$ & 4689 & 3 & 1.32 & & 60.5 & 537 & 98 & 568 & 27.0 & 25.8 & 47.2 & & 15 & 18 & 18 & 18 & 19 & 23 & 27 & 38 & 52 & 82 & 110 & 182 & \\
\hline $100 \% \mathrm{I} / \mathrm{II}$ & & $12 / 8 / 93$ & $15: 45$ & 4689 & 3 & 1.32 & & 60.5 & 537 & 98 & 592 & 26.5 & 25.3 & 48.2 & & 17 & 19 & 19 & 18 & 20 & 25 & 30 & 42 & 58 & 94 & 126 & 212 & \\
\hline $100 \% / / 11$ & & $12 / 8 / 93$ & $15: 45$ & 4689 & 3 & 1.32 & & 60.5 & 537 & 98 & 611 & 26.1 & 24.9 & 49.0 & & 19 & 22 & 22 & 22 & 23 & 29 & 34 & 49 & 66 & 108 & 143 & 239 & \\
\hline $100 \% 1 / 1 / 1$ & & $12 / 8 / 93$ & $15: 45$ & 4689 & 3 & 1.32 & & 60.5 & 537 & 98 & 643 & 25.4 & 24.3 & 50.3 & & 21 & 27 & 30 & 30 & 33 & 40 & 47 & 65 & 87 & 134 & 173 & 280 & \\
\hline $100 \% \mathrm{l} / \mathrm{II}$ & & $12 / 14 / 93$ & $13: 00$ & 4687 & 1 & 1.32 & & 59.6 & 691 & 166 & 500 & 30.3 & 32.8 & 36.8 & & 60 & 75 & 80 & 100 & 100 & 100 & 100 & 105 & 125 & 205 & 255 & 300 & \\
\hline $75 \% \mathrm{~V}$ & $25 \% \mathrm{~F}$ & $4 / 27 / 94$ & & 4749 & 1 & 1.32 & & 60.7 & 544 & 114 & 460 & 29.5 & 29.3 & 41.1 & & & & & & & 15 & 15 & 15 & 20 & 30 & 40 & 67 & \\
\hline $75 \% \mathrm{~V}$ & $25 \% F$ & 4/27/94 & & 4749 & $\overline{2}$ & 1.32 & & 60.7 & 508 & 130 & 462 & 28.0 & 30.0 & 42.0 & & & & & & & & & & 28 & 44 & 53 & 86 & \\
\hline $75 \% \mathrm{~V}$ & $25 \% F$ & $4 / 27 / 94$ & & 4749 & 3 & 1.32 & & 60.7 & 472 & 159 & 481 & 25.8 & 31.0 & 43.3 & & & & & & & & & & & & $>300$ & $>300$ & \\
\hline
\end{tabular}




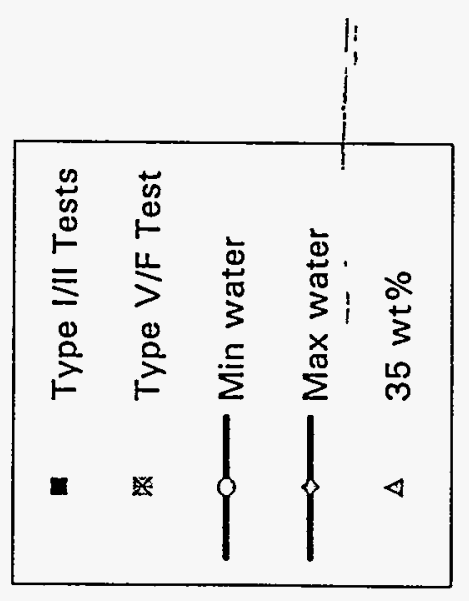

范

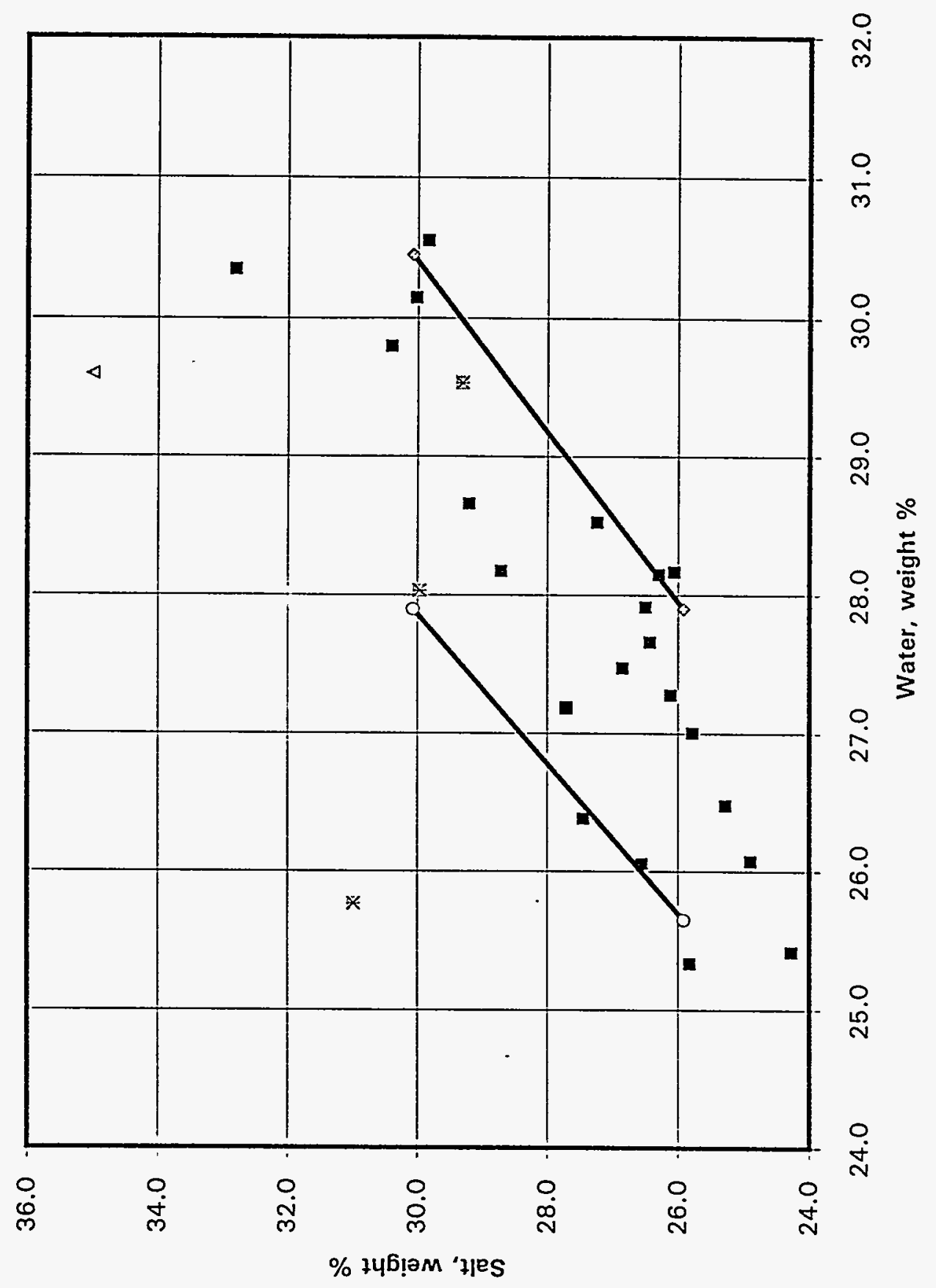




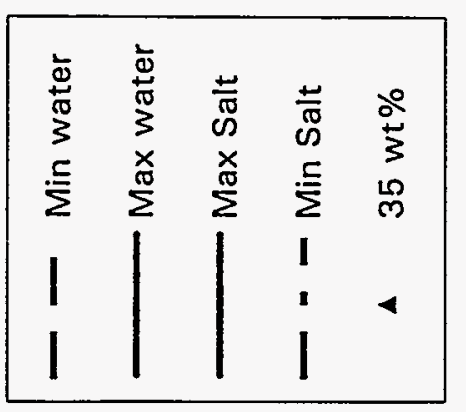

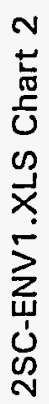

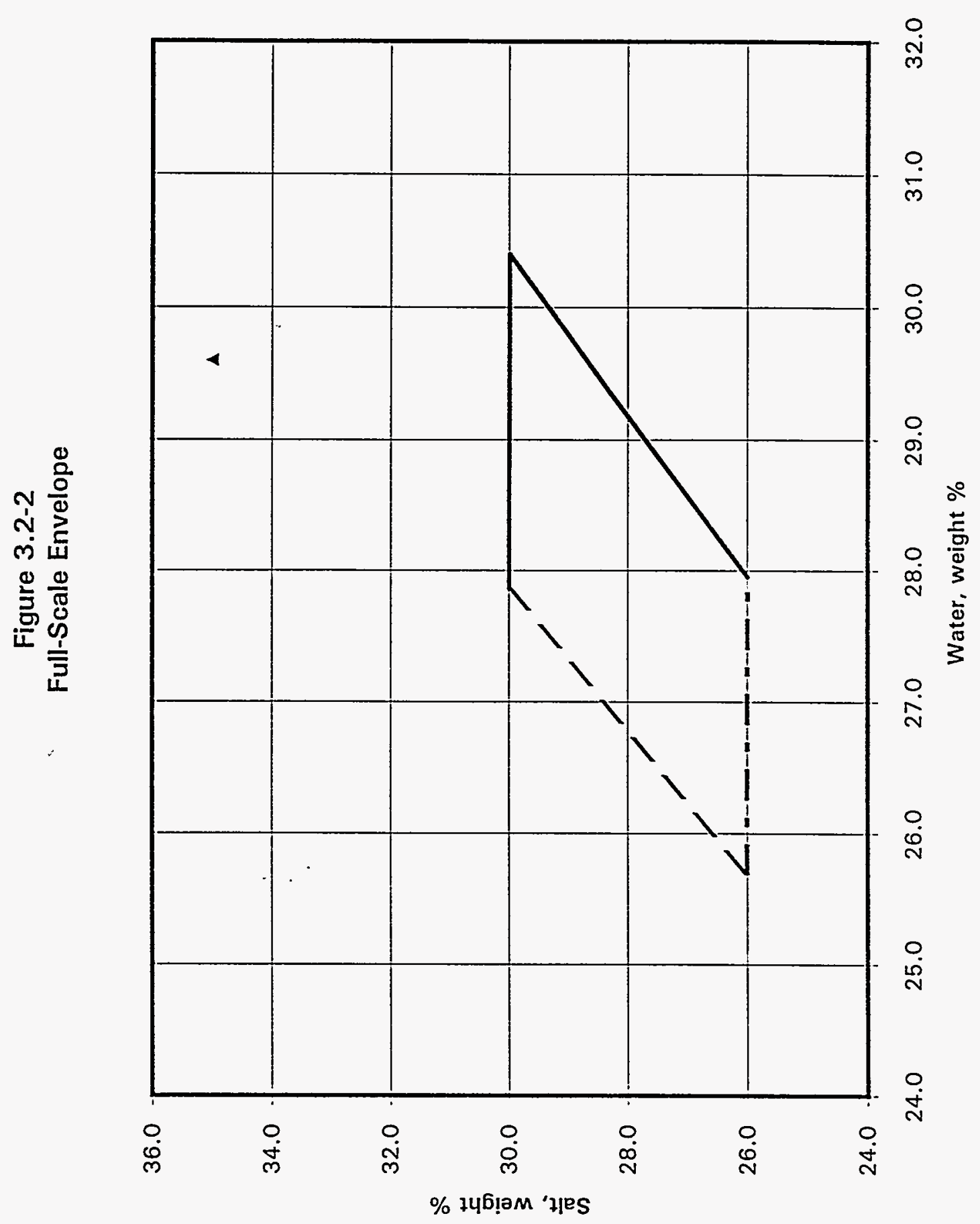




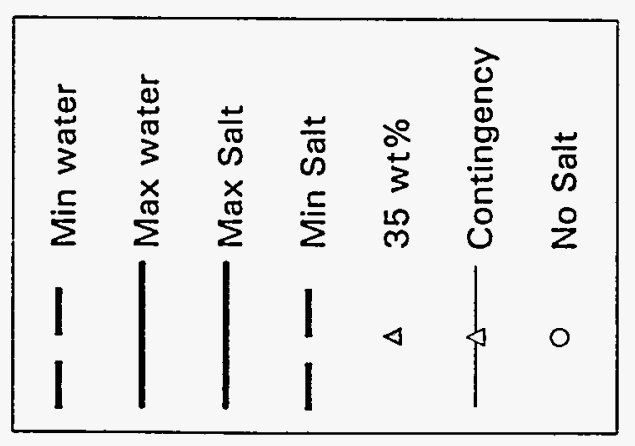

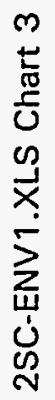

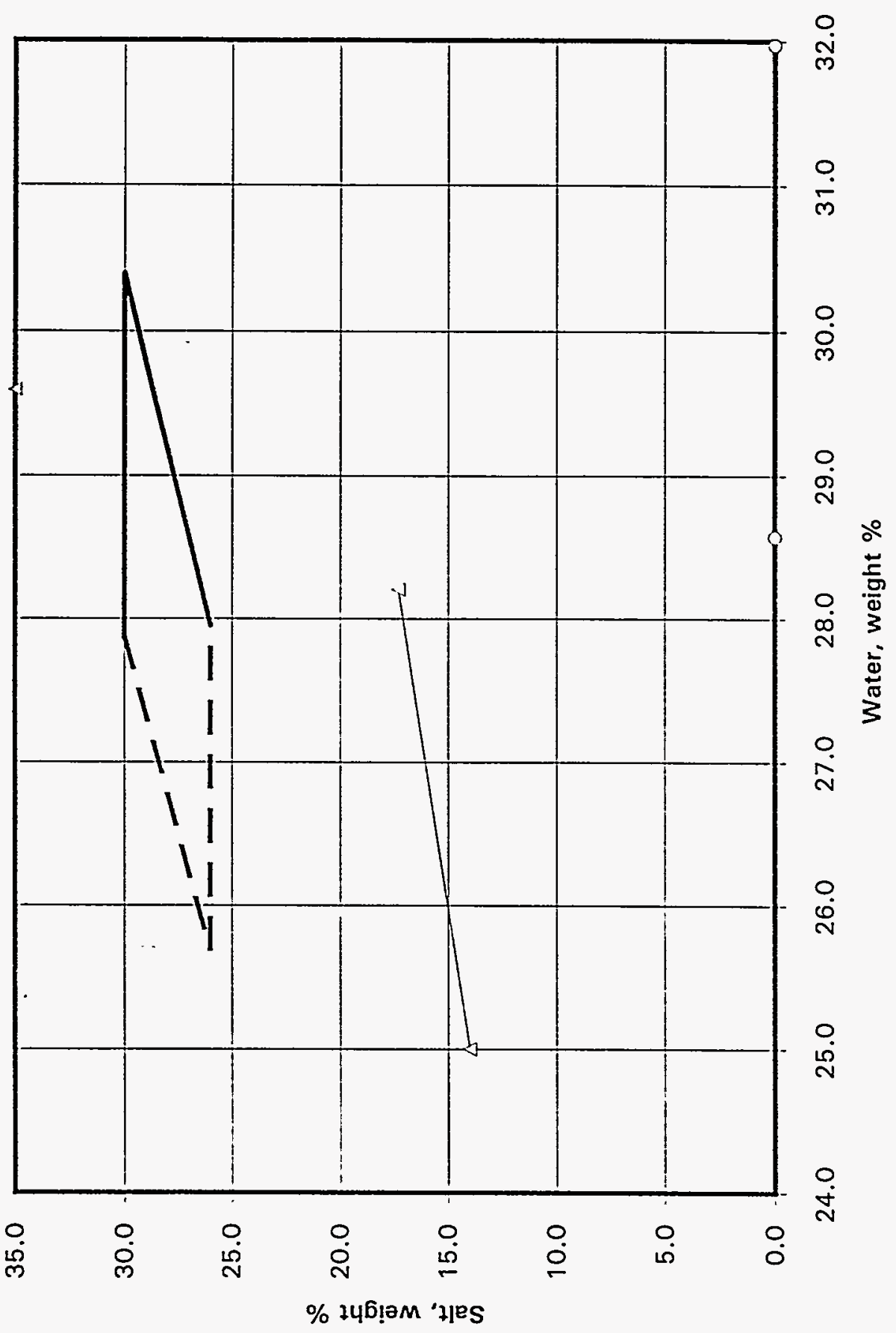


Figure 3.2-4

Comparison of

Lab-Scale to Full-Scale

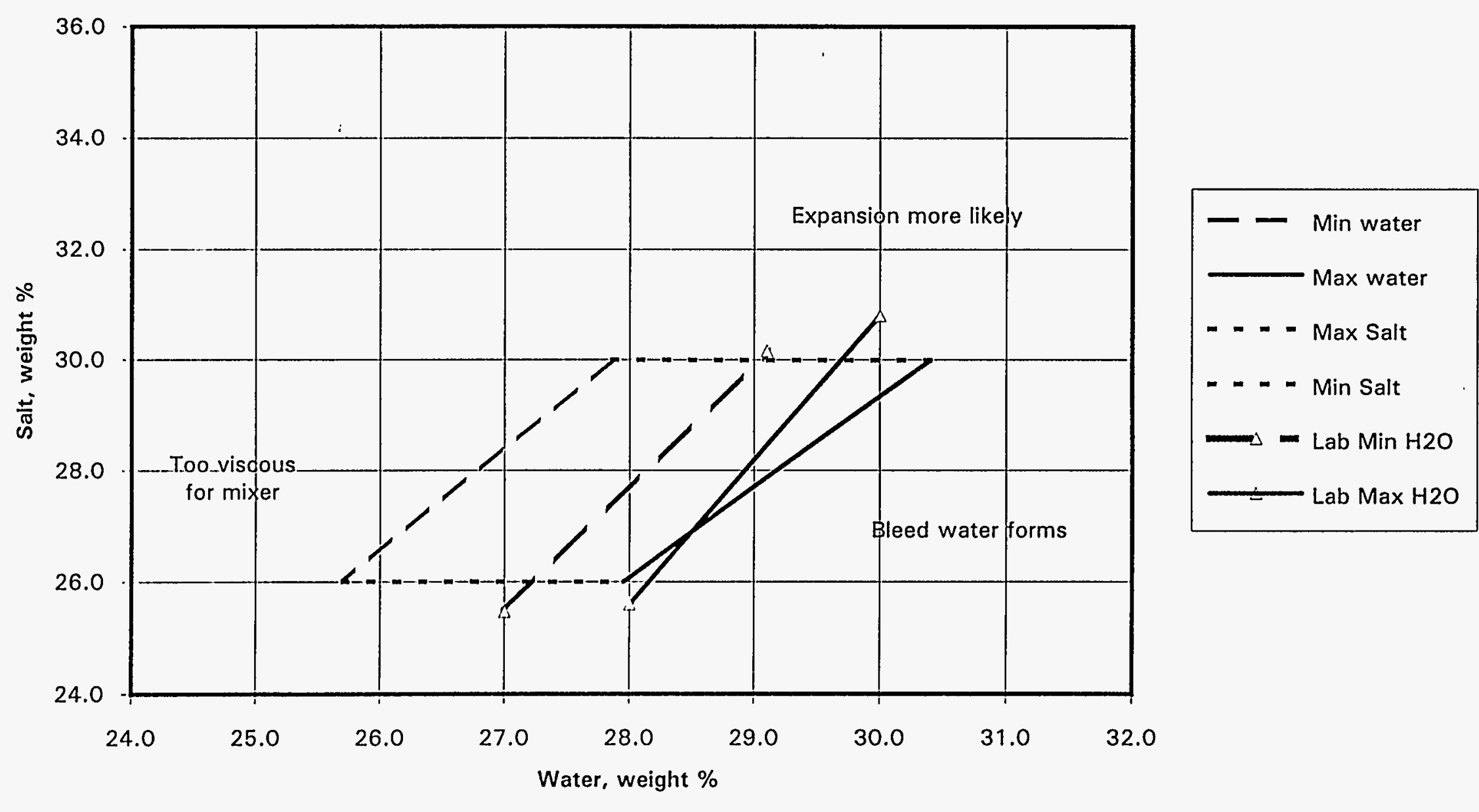


Table 3.2-2

\begin{tabular}{|c|c|c|c|c|}
\hline & \multicolumn{2}{|c|}{$\begin{array}{c}\text { Minimum } \\
\text { Water }\end{array}$} & \multicolumn{2}{|c|}{$\begin{array}{l}\text { Maximum } \\
\text { water }\end{array}$} \\
\hline & $\begin{array}{l}\text { Salt } \\
w t \%\end{array}$ & $\begin{array}{c}\text { Water } \\
w t \%\end{array}$ & $\begin{array}{l}\text { Salt } \\
w t \%\end{array}$ & $\begin{array}{c}\text { Water } \\
w t \%\end{array}$ \\
\hline \multicolumn{5}{|l|}{ Normal Conditions } \\
\hline Maximum salt & 30.0 & 27.9 & 30.0 & 30.4 \\
\hline Minimum salt & 26.0 & 25.7 & 26.0 & 28.0 \\
\hline \multicolumn{5}{|l|}{ Contingency } \\
\hline Saturated brine & 14.0 & 25.0 & 17.3 & 28.2 \\
\hline
\end{tabular}

\subsubsection{Conclusions and Recommendations}

The operating envelope reported here can be used as an effective formulation for treating the Building 374 salt and brine because waste acceptance criteria (WAC) are satisfied. WAC are met because the waste form has no free water, less than $1 \mathrm{wt} \%$ particulate matter (to satisfy NVO-325 only), and it is assumed from the chemical analysis that the LDR treatment standards will be met (sampling and analysis is in progress to gather the legally defensible data to support this assumption).

There are different reasons for recommending each minimum and maximum, yet no waste form should be rejected solely because it was produced outside the envelope. The process can be operated such that operating outside of the envelope should be the exception rather than the rule. An explanation of the limits follows:

- The maximum water content line was recommended because adding more water will cause bleed water to form. Bleed water can be removed before the container is sealed. So if the maximum water content is exceeded, the waste form can still be certified for disposal if the bleed water (if any) is removed and the other WAC are satisfied. Waste forms with less than the minimum water content can be certified with no further testing or treatments as long as the WAC are satisfied.

- The minimum water line is recommended because on the full scale tests, the viscosity limitation of the mixer was nearly exceeded. However, it is generally true that the less water there is in a waste form, the better. So if Liquid Waste Treatment Operations (LWTO) is able to effectively mix saltcrete with less water than is recommended here, then that practice should be adopted.

- The maximum salt content line was selected because the risk of waste form expansion is greater above that line. Waste forms with greater than the maximum recommended salt concentration have been expanding and damaging containers. However, these waste forms can still be certified as long as the WAC are satisfied.

- The minimum salt content line was selected arbitrarily. The only problem with waste forms with less than 26 wt\% salt is lower waste loading efficiency. 
The operating envelope can be used for type I, type I/II, or type $V$ cements with or without Class $F$ flyash because saltcrete paste made with these cements and the flyash have very similar viscosities. The fluid properties are important because they affect whether the waste form meets the WAC (specifically free water) and the compatibility of the paste with the existing equipment. The chemical properties of these cements are of less importance because the chemical nature of the waste lends itself to satisfying the WAC.

The recommended approach for mixing waste forms that lies within the operating envelope is to produce a paste that is $30 \mathrm{wt} \%$ water, $30 \mathrm{wt} \%$ salt and $40 \mathrm{wt} \%$ cement/flyash. Mix this thoroughly (five minutes of mixing is recommended), then add cement in 40 to 50 pound increments until the paste is at the viscosity limitation of the mixer. The limitation can be determined with a viscometer or by observing the vortex in the mixer. If the viscometer is used to determine the limitation of the mixer, the viscosity of the paste should not exceed:

$$
\theta=60+1 / 2(\mathrm{rpm})
$$

(equation 1)

Where $\theta$ is the angle of deflection, and $\mathrm{rpm}$ is the rotation speed of the viscometer. The vortex that is formed in the mixer is used by chemical operators as an indication of the viscosity of the saltcrete paste. When only salt and brine are in the mixer, the vortex is 12 " to 18 " deep. When the viscosity limit of the mixer is reached, the vortex is less than a few inches. If the vortex is observed for a visual determination, the limitation of the mixer is where the vortex is less than two inches. (Markers on the mixer shaft may help make visual determinations.)

The purpose for doing lab-scale tests was to predict how the full-scale process would behave. The lab-scale tests for free water agreed with the full-scale tests for the determination of the maximum water content. However, the minimum water content determinations differed significantly. The full-scale minimum water content is $2 \mathrm{wt} \%$ less than the maximum water content, whereas the predicted minimum from the lab-scale studies was $1 \mathrm{wt} \%$ less. Enough information can be obtained from the first three batches of a production run to establish a new operating envelope.

\subsubsection{Contingencies}

Contingencies for two improbable events were considered: first the failure of the spray-drier, and second, the unlikely lack of a disposal site for a long period of time. These represent the extremes in the water content of the formulation. In the event that the spray-drier fails and requires repairs lasting several months, saltcrete can be made with saturated brine and cement (the formulation is given in Table 3.2-2 and Figure 3.2-3). In the event that no disposal site is available for several years, there are alternatives to making saltcrete such as the storage of concentrated brine or compacted spray-dried salt (see Appendix 9). Both the pure salt and the concentrated brine can be made into saltcrete. These alternatives require the purchase of capital equipment and changes to RCRA permits. 


\subsection{Conclusions and Recommendations}

\subsection{Conclusions}

The general conclusion is that the current process needs very little change to produce a welldocumented, certifiable product. The recommendations are meant to make minor improvements to the testing, documentation, and operation of the process. The methods to cope with waste that does not meet waste acceptance are also included. Another conclusion is that the waste will change with time. Means to adapt the process to a changing waste stream are also recommended.

\subsubsection{Cementation is an Adequate Treatment}

Cementation is an adequate treatment for the solidification of Building 374 salt because the waste acceptance criteria (WAC) for disposal at the Nevada Test Site (NTS) and Envirocare of Utah are satisfied. The WAC that are affected by the saltcrete mixing process are free water, particulate matter, and EPA treatment standards. The EPA treatment standards are met according to a report by HNUS (HNUS, 1992). This report is scientifically valid though not legally defensible because some of the documentation and data validation were not performed. No free water has been observed in any of the sampling efforts (petrology study, and HNUS sampling). No significant amounts of dust or particulate matter have been reported either (petrology study, HNUS sampling).

Alternatives to treating the waste, such as storing the untreated brine or the untreated salt, were evaluated (Appendix 9). Storing the untreated waste is feasible if no disposal site is available or possibly if the wastes were reclassified from low level mixed waste (LLMW) to strictly low level waste (LLW).

\subsubsection{The Untreated Waste Nearly Meets EPA Treatment Standards}

Chemical analysis of the pure, untreated salt shows that the untreated waste nearly meets treatment standards and does not have the toxic characteristic. (Lockheed data, Appendix 2) These analyses were not done for the purpose of providing legally defensible data, so definitive statements cannot be made about legal issues. When the toxicity characteristic leaching procedure (TCLP) was performed on two samples, nickel was the only metal above the treatment standard with an average concentration of $0.380 \mathrm{mg} / \mathrm{l}$ in the TCLP leachate. The TCLP limit is $0.320 \mathrm{mg} / \mathrm{l}$ in the leachate.

\subsubsection{Expansion is the Main Technical Issue}

A portion of the saltcrete wasteforms expands after the cement has hardened and the container is sealed. The expansion can cause the plywood containers to bulge and breach the caulked seal. Containers with breached seals do not meet the Rocky Flats Plant (RFP) standard SX-211, and thereby do not meet the criteria for "strong, tight containers", a DOT requirement, in the judgment of plant personnel. 
The observations by personnel in charge of storing the waste indicate that expansion occurs three to six months after treatment. Measurements of the waste forms indicate that expansion from year to year is insignificant after the initial expansion.

There are two phenomena that occur in conjunction with the expansion, porosity and the formation of darapskite. Porosity can be controlled to an extent by minimizing water content. The formation of the darapskite is a complex chemical process which can be reduced by limiting the waste loading to $30 \mathrm{wt} \%$ and thereby limiting the chemicals required to form darapskite.

Controlling the chemical reactions that cause darapskite to form is more complex than making allowances for the expansion.

\subsubsection{Documentation and Test Procedures Need Improvement}

- Determining the water content of the brine by using a hydrometer leads to errors in the water content of the final waste form. The hydrometer error has been observed to be approximately $0.67 \mathrm{wt} \%$ of the final waste form. Since the minimum water content of the waste form is 2 percent less than the maximum water content, the hydrometer error can amount to $1 / 3$ of the range.

- Setting of the final wasteform is qualitatively tested by resistance to penetration of a steel rod that is pressed against the waste by hand. Since all of the sampled wasteforms were solid, this method does not detract from the quality of the wasteform. However, no record is made of the test.

- No record of observation for free water of particulate material is made either.

- All records are generated manually. This does not compromise the quality of the data, but a data acquisition system for the key parameters would lend credence to the records by providing a redundant set of records.

\subsubsection{The Waste Forms Are Not Always Homogeneous}

Some cores extracted from the saltcrete were not well mixed based on the darapskite concentration and visual observations. However the sampling and analysis shows that the waste meets WAC for NTS and Envirocare, so this is not critical as long as concentrations of hazardous chemicals remains low.

\subsubsection{The Chemical Nature of the Waste will Change}

The chemical constituents of the waste have changed since the mission of the plant has changed. Since the plant operations will change in the future, the chemistry will likely change again.

\subsubsection{The Optimum Formulation May Change}

The best treatment may change as the chemistry of the waste changes. 


\subsection{Recommendations}

4.2.1 Solidify the waste with cement using the formulation given here as a baseline treatment.

Water

Salt

Type I/II cement

Class $\mathrm{F}$ flyash
30 percent by weight of the final waste form

30 percent by weight of the final waste form

30 weight percent of the final waste form

10 weight percent of the final waste form

Mix this thoroughly (five minutes of mixing is recommended), then add cement in 40 to 50 pound increments until the paste is at the viscosity limitation of the mixer. The limitation can be determined with a viscometer or by observing the vortex in the mixer. If the viscometer is used to determine the limitation of the mixer, the viscosity of the paste should not exceed:

$$
\theta=60+1 / 2(\mathrm{rpm})
$$

(equation 1)

Where $\theta$ is the angle of deflection, and rpm is the rotation speed of the viscometer. If the vortex is observed for a visual determination, the limitation of the mixer is where the vortex is less than two inches. (Markers on the mixer shaft may help make visual determinations.)

4.2.2 Modify the piping in Building 374 to allow two tanks, tank 826-C and 826-A, to be isolated as independent feed tanks for the saltcrete process. A full tank is enough to supply the process for approximately eight months.

\subsubsection{Lab-scale tests.}

Perform lab-scale tests for saltcrete water content, viscosity, and set time once for each tank of brine that is treated. Then test the formulation with full-scale equipment. The methods for the recommended tests are in Appendix 11. The results from these can be used to confirm the baseline formulation or to modify it slightly.

4.2.3.1 Determine the maximum water content by testing for the formation of bleed water. If no visible layer of water forms in a $50 \mathrm{ml}$ test tube, then water will not likely form in the full-scale crates. Perform this test with the following .

$\begin{array}{lcccccc}\text { Component } & & \text { Wt } \% & \text { Wt \% } & \text { Wt \% } & \text { Wt \% } & \text { Wt \% } \\ \text { Water } & & 29.0 & 29.5 & 30.0 & 30.5 & 31.0 \\ \text { Salt } & & 30.0 & 30.0 & 30.0 & 30.0 & 30.0 \\ \text { Cement + Flyash } & 41.0 & 40.5 & 40.0 & 39.5 & 39.0\end{array}$

Cement + flyash is 3 parts cement, 1 part flyash.

Estimate the minimum water content by subtracting $2 \%$ from the maximum water content. To determine the true minimum water content, a full-scale test is necessary. 
4.2.3.2 Perform the set time test to estimate the time required for the full-scale crates to harden. Lab-scale samples of type $1 / I$ cements require $1 \frac{1}{2}$ times as long as the full-scale crates. Lab-scale samples of type $V$ cement require 3 times as long as the fullscale crates. Perform the set time test with three samples made with the maximum amount of water.

4.2.3.3 If the lab-scale tests indicate the formulation will effectively solidify the waste, perform a full-scale test. Mix two batches with the maximum water content, then add cement until the viscosity limitation of the mixer is reached. Mix one batch at the minimum water concentration and one at the maximum salt concentration for verification.

4.2.3.4 If the lab-scale tests indicate problems, test other formulations varying the concentrations of salt, water, cement, flyash, and by using type $V$ cement. $A$ maximum waste loading of $30 \mathrm{wt} \%$ is strongly recommended.

4.2.4 Recommendations to improve the mixing operation.

4.2.4.1 "Base the amount of the individual components on the solids content of the brine. Currently, the components are based on a calculation of the solids content of the brine. A direct determination of the solids content is more accurate. Perform this test once per shift.

4.2.4.2 Mixing can be improved by lengthening the mixing time and by adding the last $100-200$ pounds in stages. Add the baseline formula to the mixer. Mix this thoroughly (five minutes of mixing is recommended), then add cement in 40 to 50 pound increments until the paste is at the viscosity limitation of the mixer. Mix thoroughly after each addition of cement.

4.2.4.3 Install a larger motor and impellers to improve mixing.

4.2.5 Recommendations to improve documentation and testing.

4.2.5.1 A hydrometer can be used to detect changes in the solids content of the brine. Perform this test once per crate.

4.2.5.2 Use an in-line nuclear densitometer to detect changes in the specific gravity of the brine. This instrument can be used to continuously.

4.2.5.3 Since the moisture balance is more accurate than the densitometer and the hydrometer, but requires several minutes to obtain data, the recommendation is to rely on it for accuracy, but perform the test once per shift. Since the densitometer monitors specific gravity continuously and can be used to provide a permanent record when used in conjunction with a data acquisition device, it is intended to provide a means to detect changes in solids content and to provide data to verify the written records. The hydrometer is recommended to provide redundant information. 
4.2.5.4 Use a data logger to record the weight of the saltcrete components to provide documentation of the process and to provide a redundant record.

4.2.5.5 Manually record the weight of the saltcrete components, as is currently done so the process will have two sets of records.

4.2.5.6 Zero the saltcrete mixing system weight indicator after each component is added. This is so over runs or under runs of one component are not compensated by the next component to be added.

4.2.5.7 Monitor the temperature of the crates to determine when the cement has hydrated. Wait three days after the temperature peak or until the temperature returns to $40^{\circ} \mathrm{C}$ whichever takes longer. This is to provide a record that the treatment was complete. It also is a better indicator of the condition of all three batches in a crate than testing the hardness of the top layer as is currently done. Testing the hardness of the top layer is recommended to provide redundant records.

4.2.6 Recommendations to reduce the effects of wasteform expansion.

4.2.6.1 Place a 2-inch spacer in each end of the crates. The spacer (engineering drawing \# 51224-0001) allows the saltcrete to expand without damaging the ends of the box.

4.2.7 Recommendations to improve out-of-specification wasteforms.

4.2.7.1 If bleed water collects on the top of the wasteform during the curing period, use a vacuum to remove the excess water.

4.2.7.2 If more than one percent of the total weight of the wasteform is fine particulate matter, use a vacuum to remove the particulates.

4.2.7.3 If the crate is damaged, repair or overpack the crate.

4.2.8 If wasteform expansion continues to be a problem perform another petrology study.

\subsubsection{Sample Collection}

4.2.9.1 Install a sample splitter in a pneumatic transfer line for collecting spray-dried salt.

4.2.9.2 Install a sample splitter in a pneumatic transfer line for collecting cement.

4.2.9.3 Implement the sampling and analysis plan \#1-100000-EWQA-1.6.1 Addendum 2, Rev. 2 to determine LDR compliance. 


\subsection{References}

Oldshue, J. Y., "Fluid Mixing Technology," McGraw-Hill Publications, New York, 1983

Uhl, V. W., and Von Essen, J. A., Mixing Theory and Practice Vol III," Academic Press, 1986

Conner, J. R., "Chemical Fixation and Solidification of Hazardous Wastes," Van Nostrand Reinhold, 1990

HNUS report "Saltcrete Waste Characterization Report, deliverable 224C-Rev. )", October 1992

U. S. Department of Energy Nevada Field Office and Reynolds Electric \& Engineering Co., Inc., "Nevada Test Site Defense Waste Acceptance Criteria, Certification, And Transfer Requirements, NVO325 (Rev. 1)," June 1992

Code of Federal Regulations 40 CFR 261 


\section{APPENDICES}

APPENDIX 1 Department of Transportation (DOT) Oxidizer Determination

APPENDIX 2 Lockheed Analytical Laboratory, Table of Chemical Data

APPENDIX 3 Petrology Study, Reports from:

D. A. Armentrout, EG\&G, Halliburton Energy Services, and

U. S. Army Corps of Engineers

APPENDIX 4 Lab-Scale Operating Envelope Data

APPENDIX $5 \quad$ Full-Scale Operating Envelope Data

APPENDIX $6 \quad$ Time of Set Data

APPENDIX 7 Freeze/Thaw

APPENDIX $8 \quad$ Recommended Instrumentation

APPENDIX $9 \quad$ Saltcrete Alternatives Study

APPENDIX 10 Measurements of Expanded Crates

APPENDIX 11 PUBLISHED UNDER A SEPARATE COVER

TEST METHODS A Draft Procedure for Determining:

Specific gravity by hydrometer

Moisture content of brine using a moisture balance

Viscosity

Free water formation

Time of set

Freeze/thaw cycling

Monitoring the deformation of wooden crates

Department of Transportation Oxidizer Test 


\section{APPENDIX 1}

\section{DEPARTMENT OF TRANSPORTATION (DOT) OXIDIZER DETERMINATION}




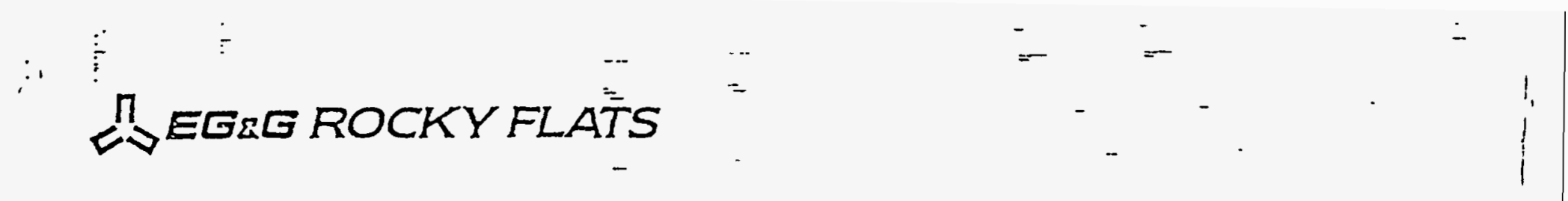

\section{INTEROFFICE CORRESPONDENCE}

DATE: November 18,1993 :

TO: $\quad$ E. C. Garcia, Technology Development, Bldg. T130C, X5980

FROM: R. H. Getty, Materials and Surface Technology, Bldg. $881, \times 4632$ C//C

S. C. Jorgensen, Waste Projects, Bldg. $881, \times 5393$ \& $\mathrm{Cg}$

SUBJECT: SALTCRETE DOT OXIDIZER TEST - SCJ-024-93

\section{INTRODUCTION}

The salt waste stream generated by Building 374 liquid waste treatment using a spray-drying process was found to be a Department of Transportation (DOT) oxidizer when the plant was in production. Recent characterization of the waste since curtailment of production operations indicates it has a lower concentration of nitrate ion, the constituent that caused the salt to be an oxidizer. The DOT test (Appendix F to 49 CFR 173 - Guidelines for the Classification and Packing Group Assignment of Division 5.1 Materials) was performed to see if the salt waste is still an oxidizer. The reason for the oxidizer determination is to see if the material will promote combustion if there were a transportation accident that caused a fire.

The implication of the test is two-fold. If the salt is an oxidizer, the untreated material must be stored in a special building. If the salt is a DOT oxidizer, then it is considered by EPA to have the reactive characteristic under RCRA. The option to store the untreated salt could save storage space if a disposal site does not open.

\section{EXPERIMENTAL}

The official DOT determination has been changed since the last time that the spray-dried salt was tested. The oxidizer test reported in RFP-3919, "Nitrate Salt Immobilization Process Development and Implementation, November 1986," is not the official test now. The previous test required a five pound mixture and a flame source. The current official DOT test is a scaled down version. The current test is performed by igniting a 30 gram mixture of material and sawdust with an electric hot wire. The rate at which a reference material and sawdust burns is compared to the rate at which the salt waste mixed with sawdust bums. The reference material is mixed $1: 1$ by weight with the sawdust, while the salt waste is mixed at $1: 1$ and at $4: 1$. Each mixture is tested three times, for a total of nine tests. The ambient temperature and relative humidity have bounds for the test to be valid. 
DOT OXIDIZER TEST

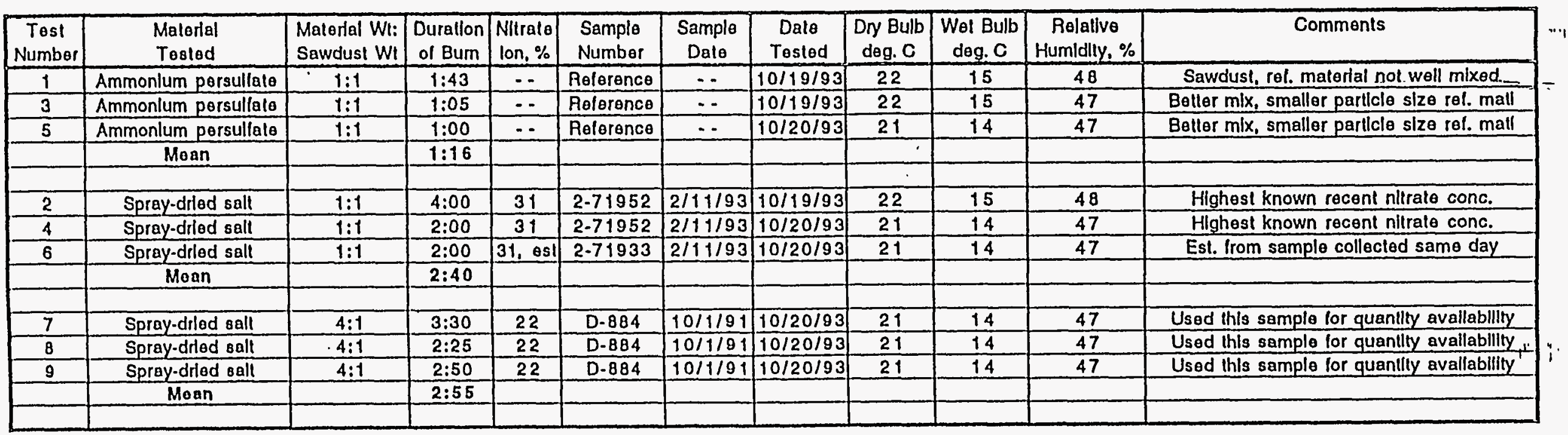

Relatlve humldlty calculations from Brent Bowen, X3222, RFP cllmalologlst 
APPENDIX 2

LOCKHEED ANALYTICAL LABORATORY, TABLE OF CHEMICAL DATA 


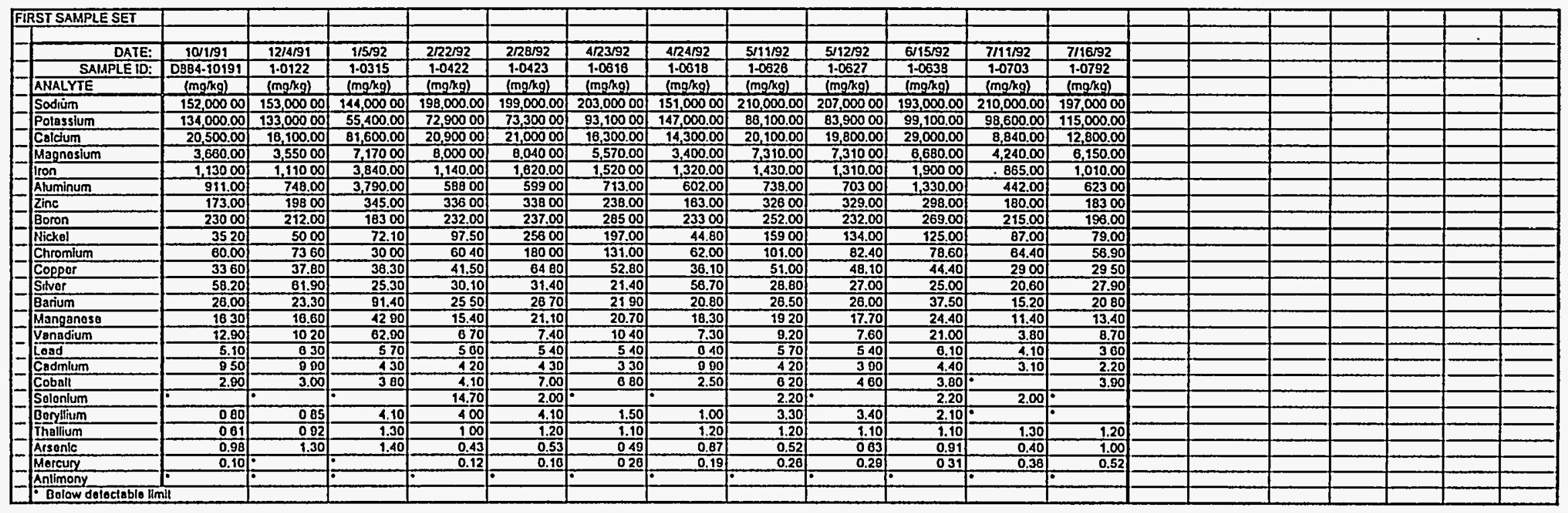




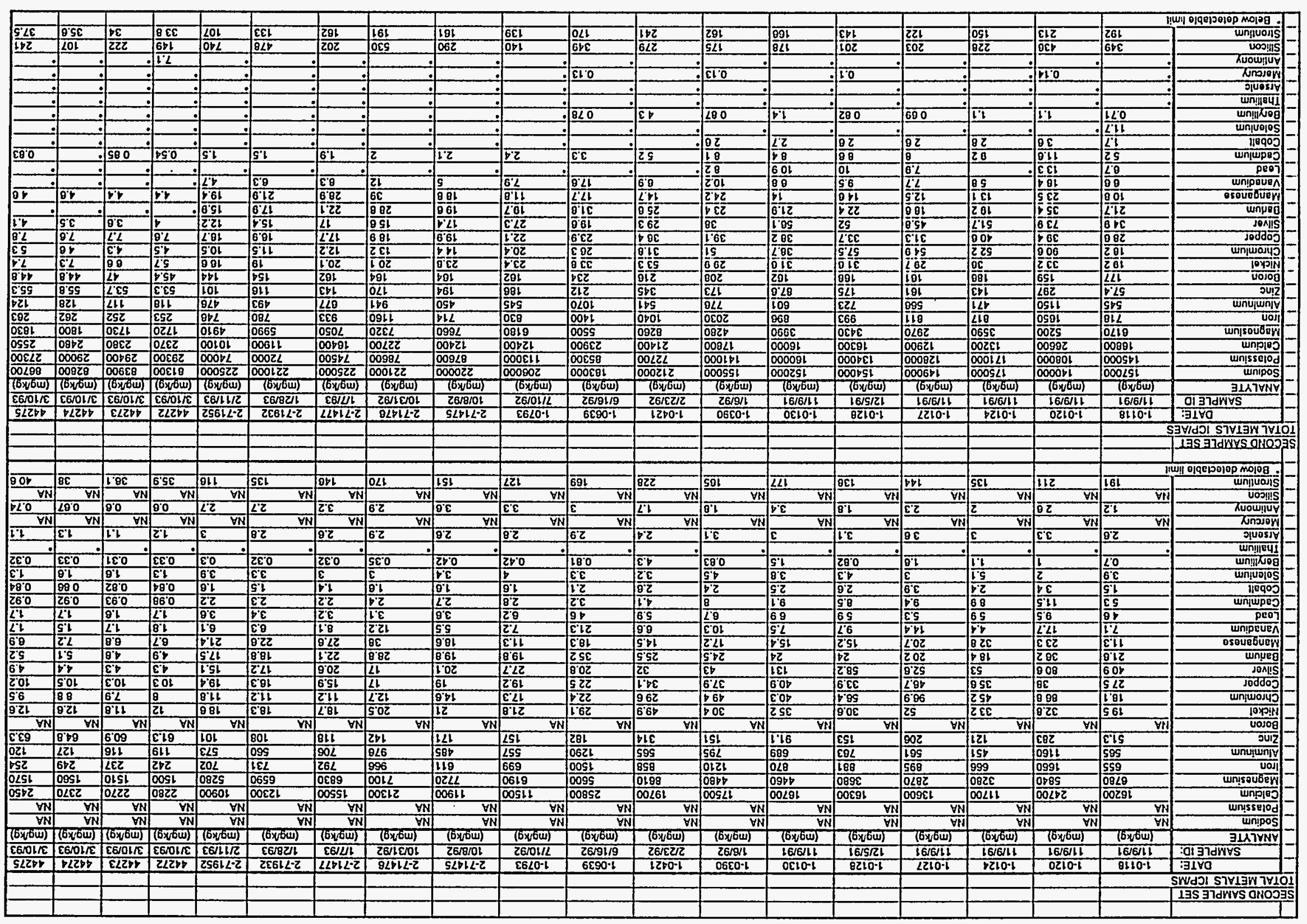




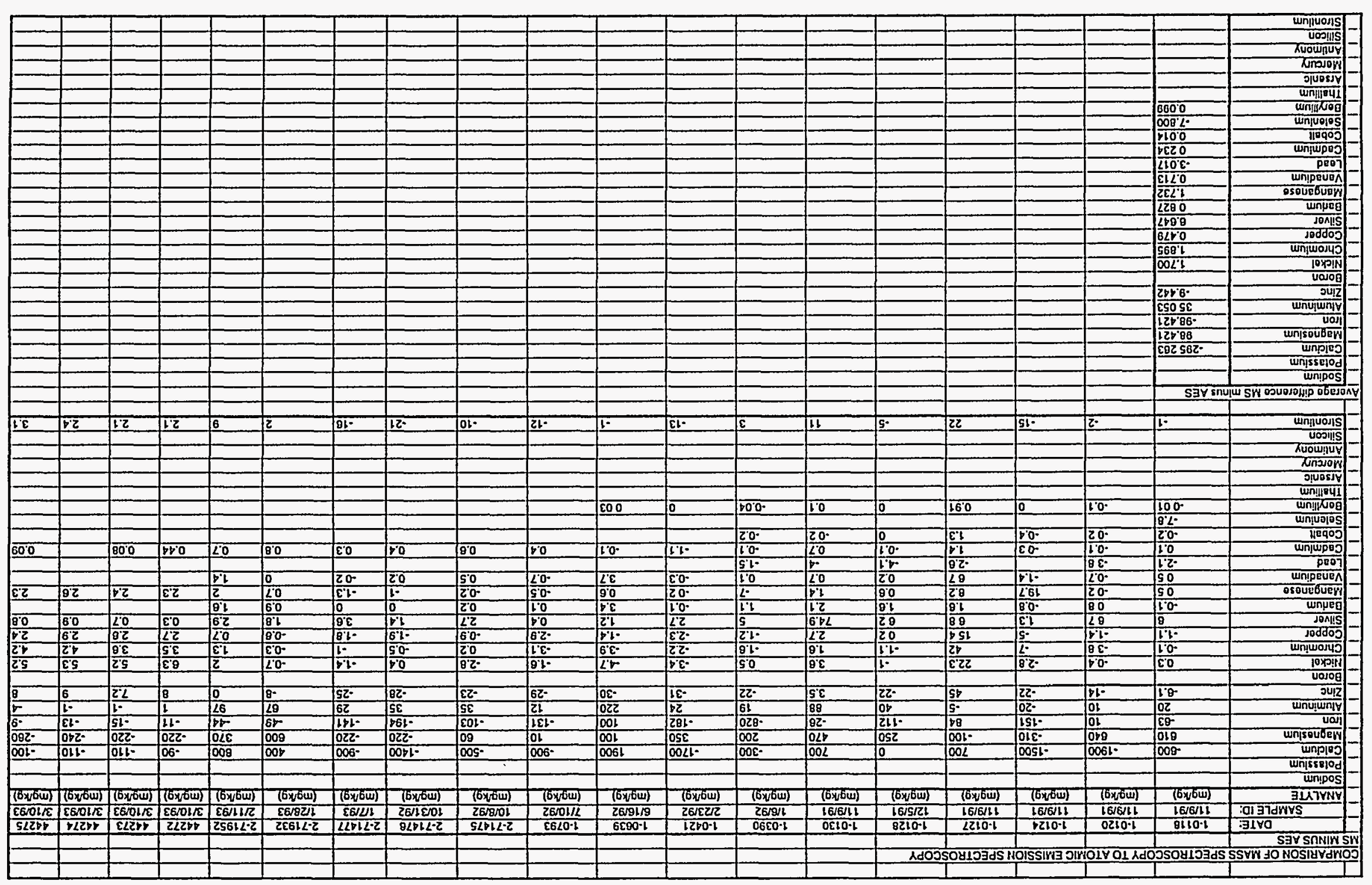

51x IHIVove 
APPENDIX 3

PETROLOGY STUDY, REPORTS FROM:

D. A. ARMENTROUT, EG\&G,

HALLIBURTON ENERGY SERVICES,

AND,

U.S. ARMY CORPS OF ENGINEERS 


\section{Technology Development}

\section{ANALYSES OF SALTCRETE}

by

D. L. Armentrout

TD94-DDT-001

August 16, 1994

EG\&G Rocky Flats

\section{$\Leftrightarrow$ EGIG ROCKY FLATS}

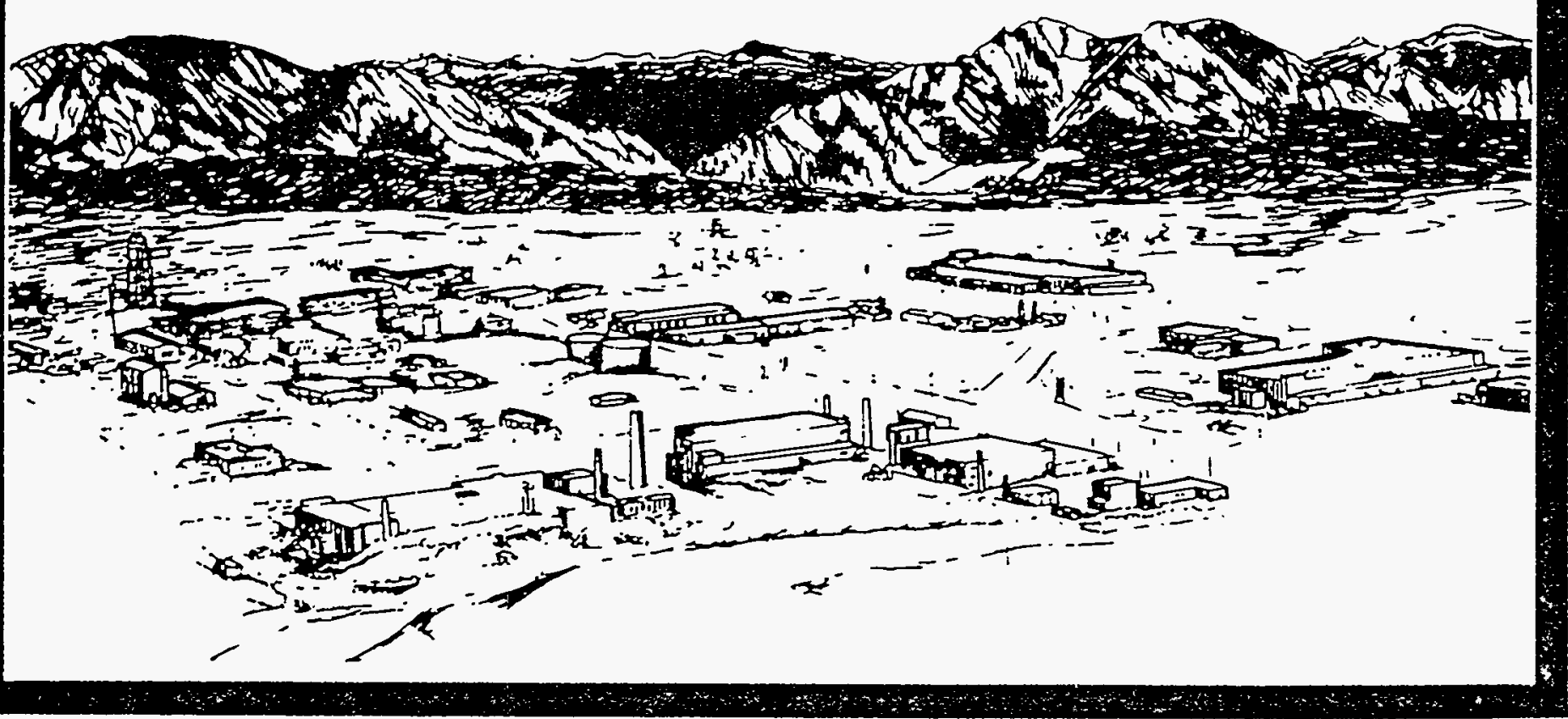




\section{ANALYSES OF SALTCRETE}

by

D. L. Armentrout

TD94-DDT-001

August 16, 1994

EG\&G Rocky Flats

: $\quad$ Prepared Under Contract No. DE-AC34-90RF62349 Rocky Flats Operations Office U.S. Department of Energy

Approved:

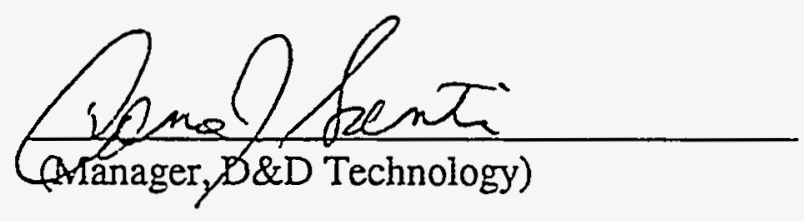

Date: $8-16-94$

Distribution

J.M. Connell

E.C. Garcia

S.C. Jorgensen

J.C. Petersell

D.J. Santi

Library
KWIC Index

Saltcrete

$\mathrm{X}$-ray Diffraction

Scanning Electron

Microscope

)

INTERNAL REPORT NOT CLEARED FOR PUBLICATION OR REFERENCE EXTERNAL TO DOE 


\section{INTRODUCTION}

The-Building 374 evaporator at Rocky Flats Environmental Technology Site (RFETS) processes low level mixed waste solutions to produce a slightly contaminated mixed waste salt. The mixed waste brine produced by the evaporator contains a mixture of many different salts that change in concentration from day to day. Some of the brine is further processed in a spray drier. For disposal, the brine, spray dried salt, and cement are mixed together to form saltcrete in concentrations that are approximately equivalent to $30 \%$ water, $35 \%$ salt and $35 \%$ cement. The saltcrete is poured into half-crates and allowed to cure. The cement binds together both the RCRA and the radioactive waste components. Contamination is not smearable from the surface of this waste form.

A problem has occurred during the curing process of some of the saltcrete. In a few instances, saltcrete expands and breaks the seals on half-crates. Decontamination and Decommissioning Technology (DDT) personnel were asked to perform analyses on this waste form. This report will describe the findings of the optical microscope analysis, the $\mathrm{X}$-ray diffraction (XRD) analysis and the scanning electron microscope (SEM) analysis.

\section{SPECIMEN PREPARATION}

Sixteen core samples were taken from seven half-crates. Samples were obtained from three half-crates without a bulge, three half-crates with a bulge in the side, and one halfcrate bulged at one end on the bottom. The cores are approximately $2.75^{\prime \prime}$ diameter by 15 " long. A total of 54 sections were removed from the sixteen cores since the cores could not be removed in one piece from the half-crates. The samples were taken from three different batches, poured on October 7-8, 1992, January 4-5, 1993, and January 1112, 1994.

In addition to the 16 core samples, eight lab-scale samples were received. Salts were used in approximately the same salt loading as used in the full-scale process. Samples were made from three different types of cement and two different types of fly ash. The lab-scale samples were poured into 1 " diameter by $2^{\prime \prime}$ high cylindrical molds and cured at $55^{\circ} \mathrm{C}$ for 2.5 days. These samples were then subjected to either wet/dry cycling or freeze/thaw cycling.

\section{Optical Specimen Preparation}

Core samples were cut on a diamond wafering saw using methanol for a coolant. Specimens were cut about 2-5 mm thick. Outer edges of the core slices were usually removed to avoid damaged areas from the original coring process. Glass microscope slides were labeled and then the specimens were mounted on the slides with super glue. Specimens were allowed to cure for several minutes before the start of grinding and polishing. The petrographic specimen mounts were ground in a grinding machine with a $15 \mu \mathrm{m}$ diamond plate for a few minutes, using anhydrous ethanol as coolant. Specimens were ground down to a thickness of about $30 \mu \mathrm{m}$ (rough approximation since no accurate measuring system was available). Specimens were cleaned with ethanol and polished with $6 \mu \mathrm{m}$ diamond paste on a nylon polishing cloth. Polishing time was about 15 minutes or until visible scratches were mostly removed. Specimens were cleaned with ethanol. Final 
polish was with $1 \mu \mathrm{m}$ diamond paste on a nylon polishing cloth until fine scratches were not observed in the microscope

Specimens were cleaned with ethanol after the final polish and were etched for 60 seconds with a CDTA-ethanol solution (cyclohexanediaminetetraacetic acid disodium salt) and rinsed immediately with ethanol and dried. The CDTA solution chelates or reacts with the calcium to form a colored film over the specimen that greatly enhances the visibility of the cement crystals and non-crystalline phases. The samples were stored in a desiccator until ready for microscopic examination.

\section{XRD Specimen Preparation}

Core samples were cut on a diamond wafering saw using methanol for a coolant. A small piece from the center of the core was crushed with a mortar and pestle into sand size pieces. The saltcrete specimen was allowed to dry in a hood for several hours. After the specimen was dry, it was crushed again until no grit could be felt through surgeon's gloves. The specimen was packed into a glass sample holder for the Rigaku rotating anode X-ray diffractometer. A thin cover was used to prevent contamination of the instrument by saltcrete dust from the specimen. Either a mylar or a Teflon cover was placed carefully over the specimen to minimize the interference with the $\mathrm{X}$-rays caused by the cover.

Two different conditions were used for the XRD data given in this report. For a general scan the following conditions were used:

Copper target (rotating anode), $40 \mathrm{kV}, 40 \mathrm{~mA}$, line focus

Graphite diffracted beam monochromator

Scintillation counter

One degree divergence and scatter slits

0.034 degree receiving slit

Mylar cover $3.6 \mu \mathrm{m}$ thick

Step scan $2-65^{\circ}$ at $0.05^{\circ}$ increments $2.0 \mathrm{sec} / \mathrm{step}$

A number of peaks were observed between 20 and $40^{\circ}$ two theta. Detailed scans were made between 20 and $40^{\circ}$ two theta under the following conditions:

Copper target (rotating anode), $40 \mathrm{kV}, 80 \mathrm{~mA}$, line focus

Graphite diffracted beam monochromator

Scintillation counter

One degree divergence and scatter slits

0.034 degree receiving slit

Teflon cover $5 \mu \mathrm{m}$ thick

Step scan $20-40^{\circ}$ at $0.02^{\circ}$ increments $4.0 \mathrm{sec} / \mathrm{step}$

\section{SEM Specimen Preparation}

Core samples were cut on a diamond wafering saw using methanol for a coolant. A rectangular piece from the center of the core was cut and labeled. The saltcrete specimen was allowed to dry in a vacuum of better than $1 \cdot 10^{-3}$ Torr overnight. The rectangular 
specimen was fractured in two pieces, and one of the fracture surfaces was etched in a maleic acid and methanol solution. The two fracture surfaces were mounted side by side for examination in the SEM. After mounting, the samples were coated with a thin layer of gold in a sputter coater. All specimens were stored under a vacuum of better than $1 \cdot 10^{-4}$ Torr.

The SEM has an energy dispersive X-ray (EDX) detector that can be used for obtaining semi-quantitative elemental analysis for elements with an atomic number higher than nine. The EDX detector was used to identify phases in the field of view and to obtain the element compositions of the specimens. The EDX elemental composition analysis program assumes that the specimen is flat. In order to obtain an accurate elemental analysis the flat powder sample from XRD analysis was used for the elemental analysis. A conductive foil was placed around the outside of powder sample to improve electrical conduction, and no cover was used. Containment of the specimen was achieved by packing the powder in a glass slide and examining the specimen in a secured horizontal position.

\section{RESULTS}

The three different types of analyses used in this report were decided upon as reasonable for evaluating the expansion problem by DDT, Halliburton Energy Service, and U.S Army Engineer Waterways Experiment Station scientists and engineers. These methods compliment each other to provide a detailed description of the cement hydration and identification of expansive phases. Optical microscopic examination can reveal amounts of cement hydration, presence of microcracking and micropores, and the identification of some crystalline phases. XRD is used strictly for phase identification. The SEM can identify crystalline phases in cracks, which is very helpful in recognizing expansive phases. Results from each type of analysis with be discussed separately below.

\section{Optical Microscope Results}

Microscopic examination of the specimens generally consisted of two methods, polarized transmitted light and reflected light. Both of these examinations were performed on the same microscope that was equipped with both types of light systems. Polarized transmitted light examination uses a polarizer above the specimen and another below the specimen in the transmitted light path. Reflected light examinations were used with the vertical illuminator that projects a focused beam of high intensity light through the objective lens onto the surface of the specimen. This technique is particularly useful for examining the degree of hydration of the cement and showing some of the microcracks or micropores in the sample.

Microscopic examinations of 22 specimens were performed with photomicrographs taken of most specimens. Photomicrographs were taken with a video camera mounted on the phototube of the microscope. The video camera sends the signal through a computer with image processing and character generator to a video printer and a monitor. Photomicrographs were prepared by the video printer and images were also stored in the 
computer. Magnifications were calibrated yielding images on the video printer that were approximately twice the microscope magnification.

A large number of color micrographs from saltcrete were presented and discussed in Reference 1. Polished sections of saltcrete showed some degree of cement hydration in all of the specimens. The amount of cement hydration appeared to increase with the age of the saltcrete half-crates. None of the samples showed complete hydration of the cement. Many microcracks were also observed in the saltcrete sections. Inside many of the cracks were crystalline phases that appear to be the cause of the cracks. Many microvoids and micropores were found in the specimens.

\section{XRD Results}

Although care was taken to minimize the effects of the two different covers used, there were some diffraction peaks resulting from the covers. A diffraction pattern from just the Teflon cover is shown in Figure 1. The two small peaks in Figure 1 overlapped two peaks from the saltcrete. For all data a correction was made for the two Teflon peaks by subtracting the intensities from the saltcrete data. A diffraction pattern from just the mylar cover is shown in Figure 2. There is a large mylar peak at approximately $26^{\circ}$ two theta. Since this peak overlaps several saltcrete peaks, data from a Teflon cover was used instead of $20-40^{\circ}$ two theta data using a mylar cover. X-ray diffraction patterns of a specimen from a bulging half-crate with pour date of October 7, 1992 are shown in Figures 3 \& 4. Table 1 contains a summary of the XRD peaks observed and their intensities for a number of different half-crates and lab-scale samples. The $D$-spacing values are given in Angstroms and the intensity values are given in counts/second referenced to $40 \mathrm{~mA}$. Identification of most of the XRD peaks is included in Table 1. No match was found for the minor peaks with no identification listed in Table 1.

One of the most common expansive phases in cement is ettringite $\left[\mathrm{Ca}_{6} \mathrm{Al}_{2}\left(\mathrm{SO}_{3}, \mathrm{SiO}_{4}\right.\right.$, $\left.\mathrm{CO}_{3}\right)_{3}(\mathrm{OH})_{12} \cdot 26 \mathrm{H}_{2} \mathrm{O}$ ]. Etrringite is has a large $\mathrm{D}$-spacing peak at $9.67 \AA$ and $\mathrm{XRD}$ is particularly sensitive to this phase. No ettringite was observed in any of the XRD patterns obtained from the saltcrete half-crates or lab-scale samples. 

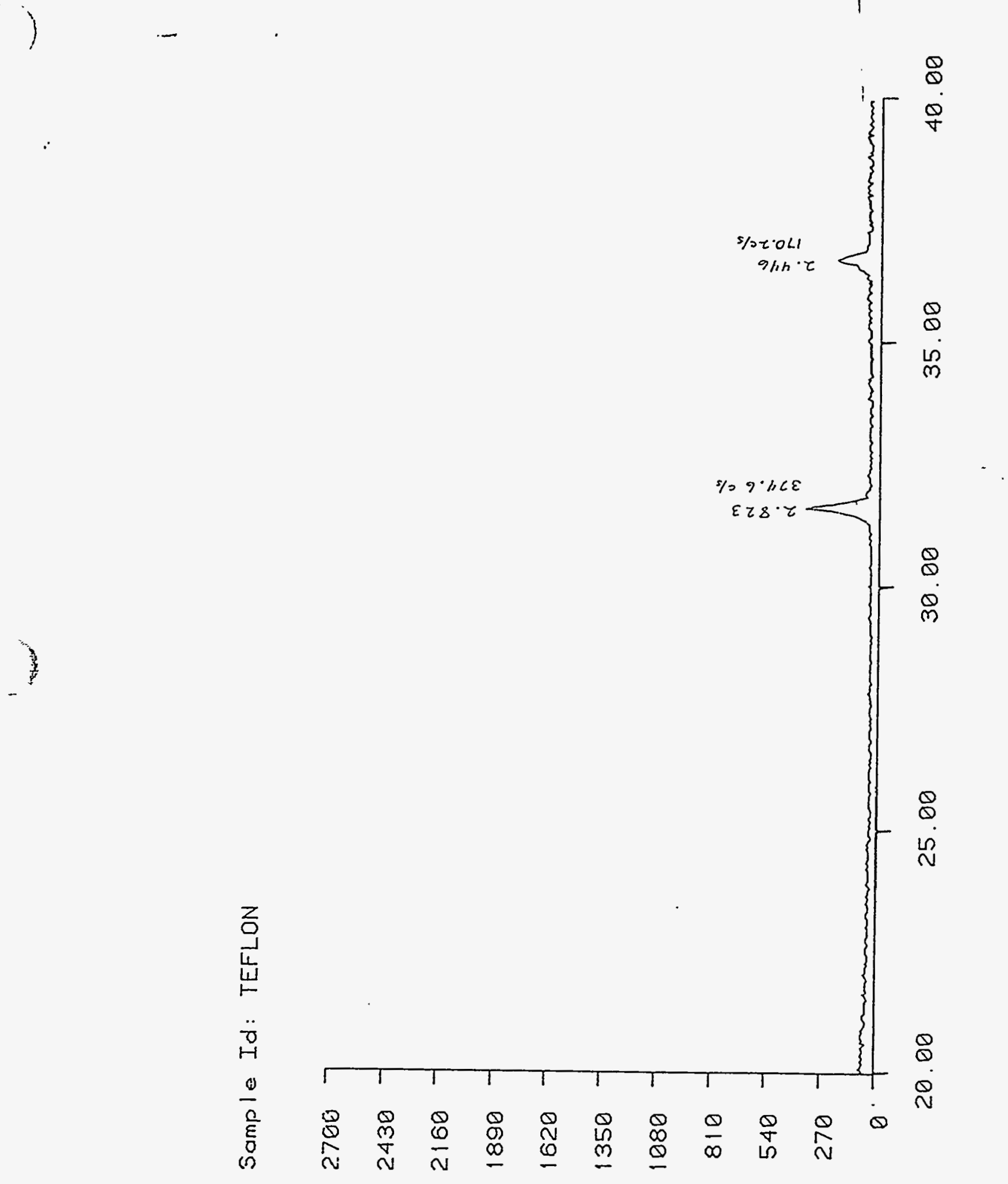

Figure 1 - X-ray diffraction pattern of a Teflon cover used in this report. The two peaks are labeled with $\mathrm{D}$-spacing values and intensities. 


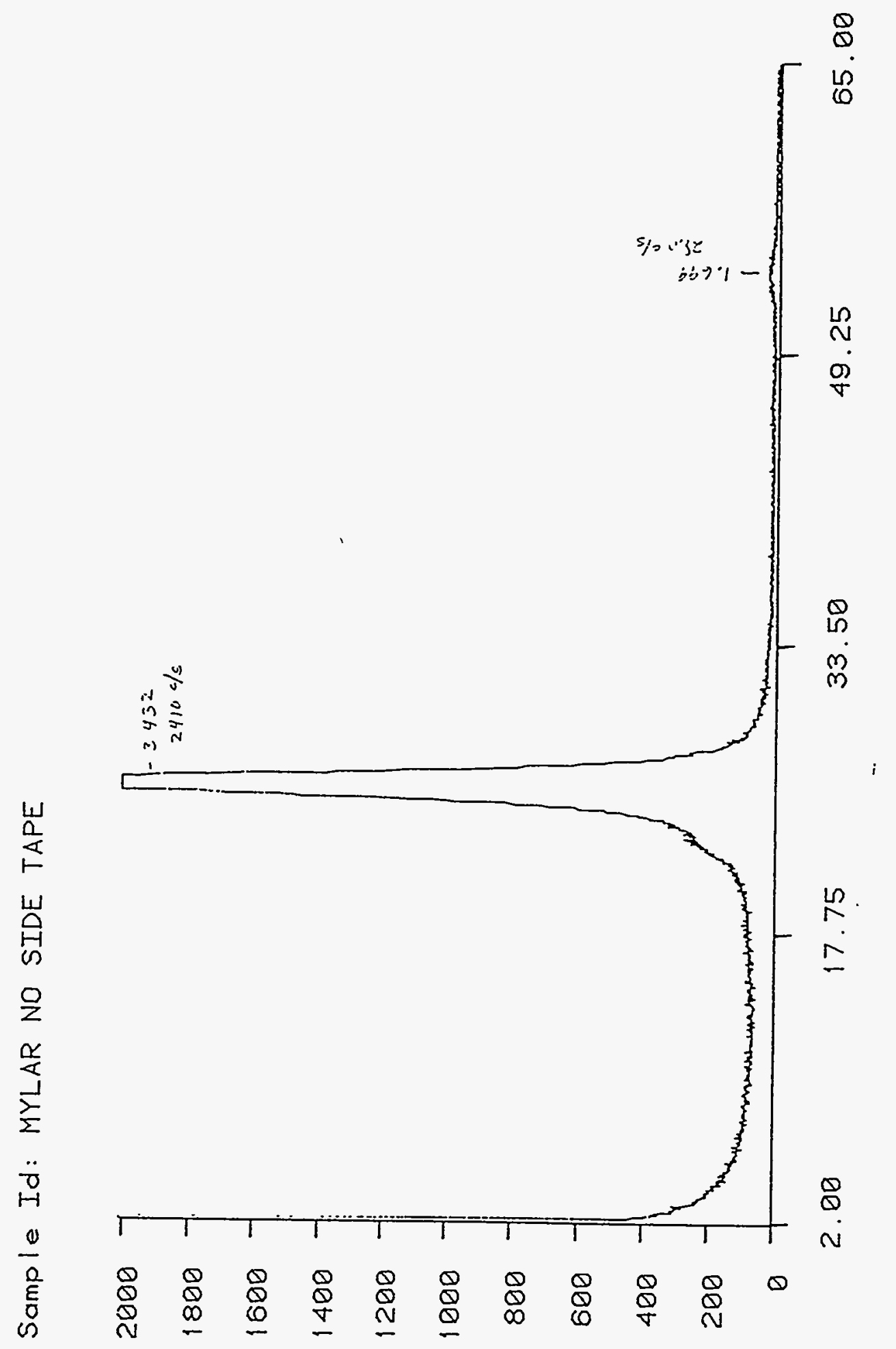

Figure 2 - X-ray diffraction pattern of a mylar cover used in this report. The two peaks are labeled with $D$-spacing values and intensities. 

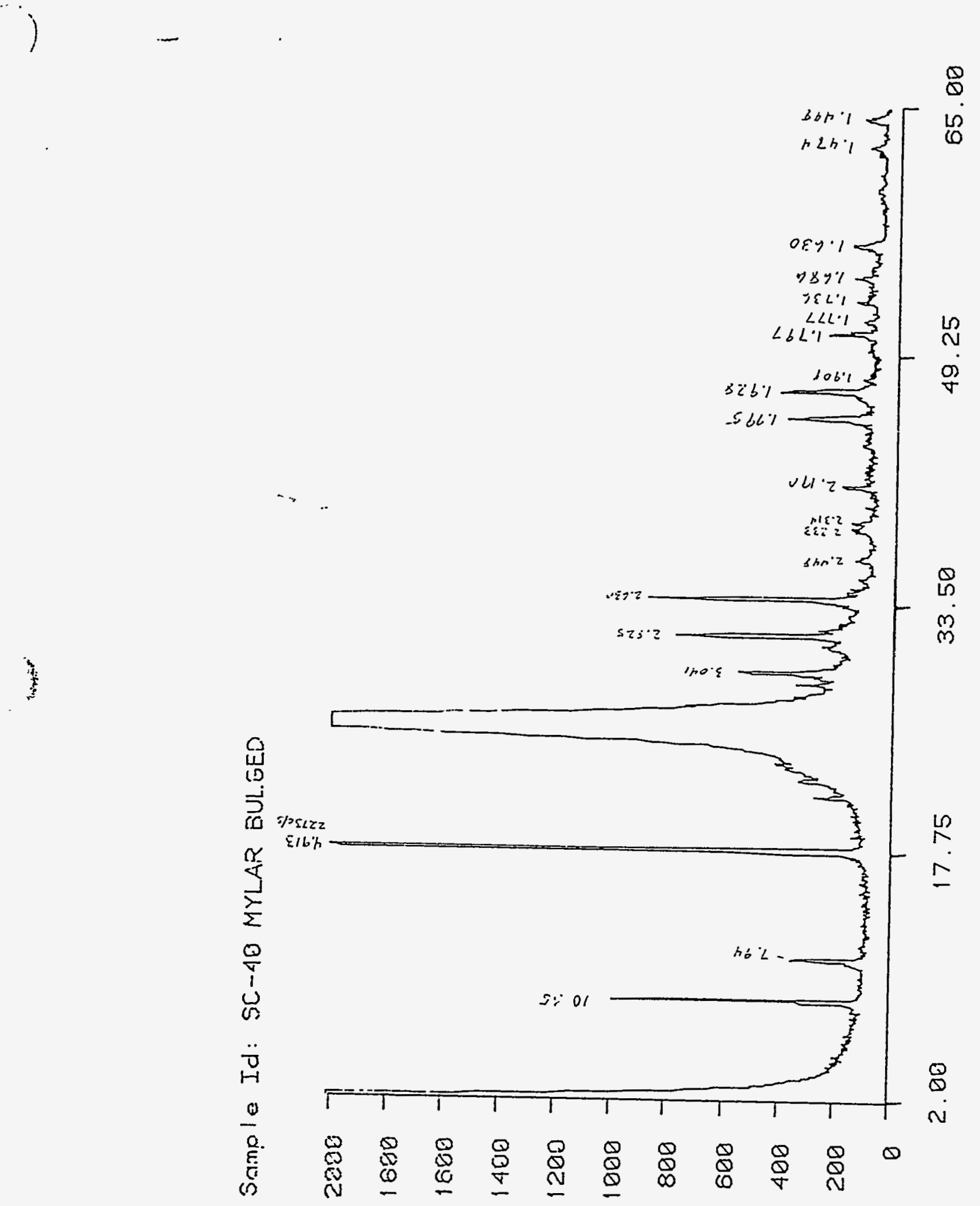

Figure 3 - X-ray diffraction pattern from a bulged area of a half-crate made $10 / 7 / 92$. A mylar cover was used and the peaks are labeled with $\mathrm{D}$-spacing values. 
TD94-DDT-001

일

i

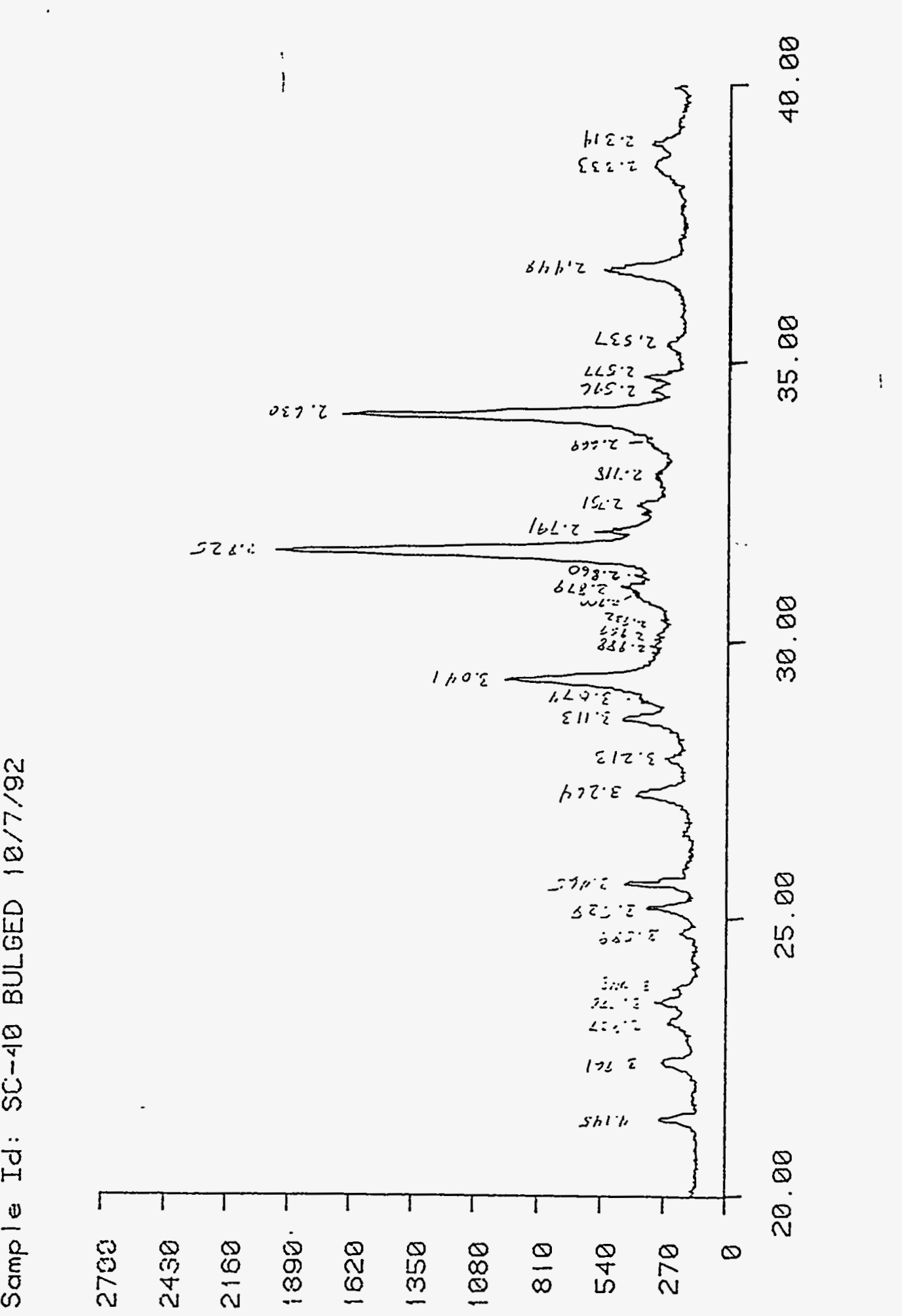

Figure 4 - X-ray diffraction pattern from a bulged area of a half-crate made 10/7/92. A Teflon cover was used and the peaks are labeled with $\mathrm{D}$-spacing values. 
Table 1

$X$-ray Diffraction Lines for Saltcrete Samples

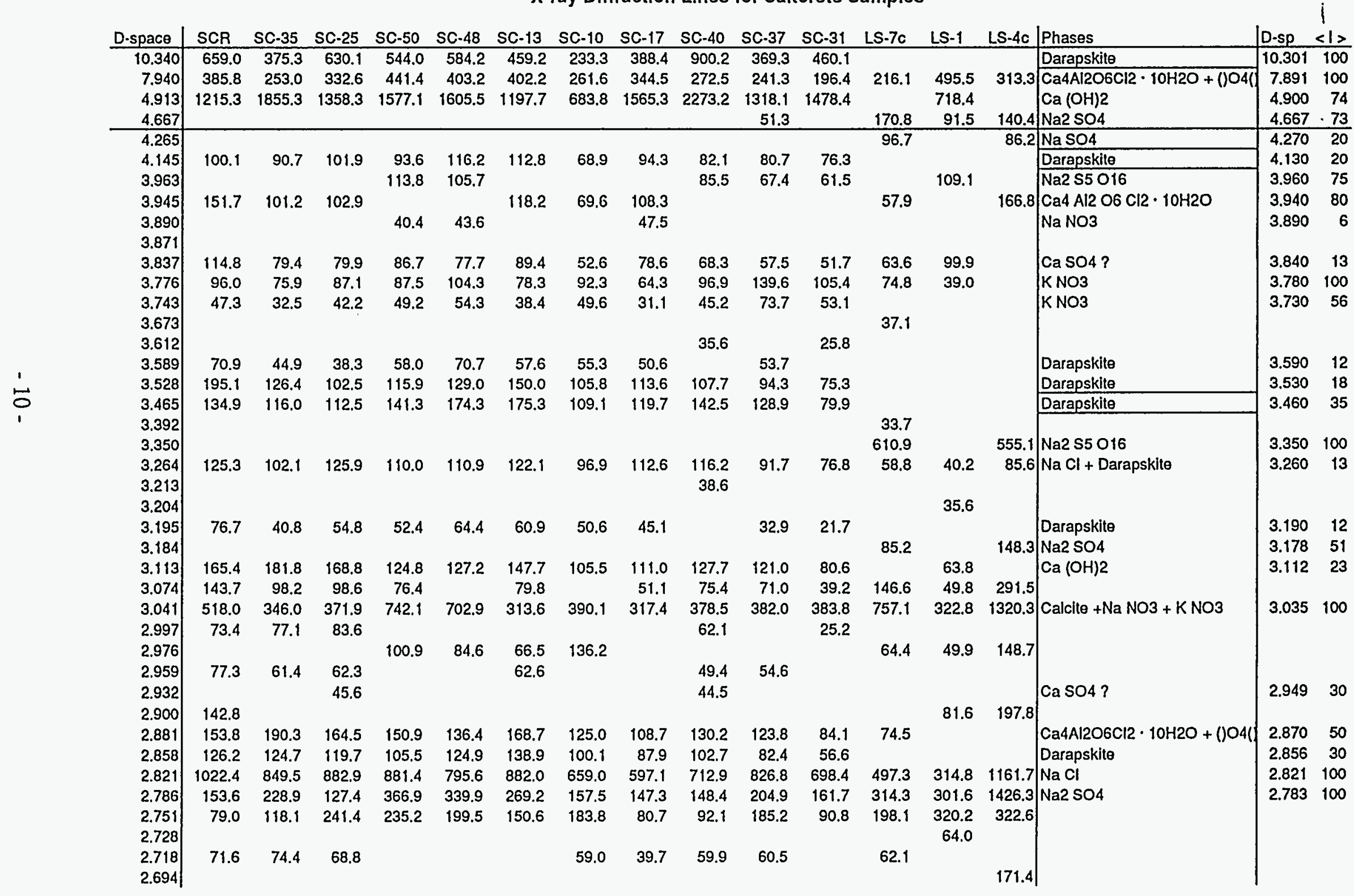


Table 1 Continued

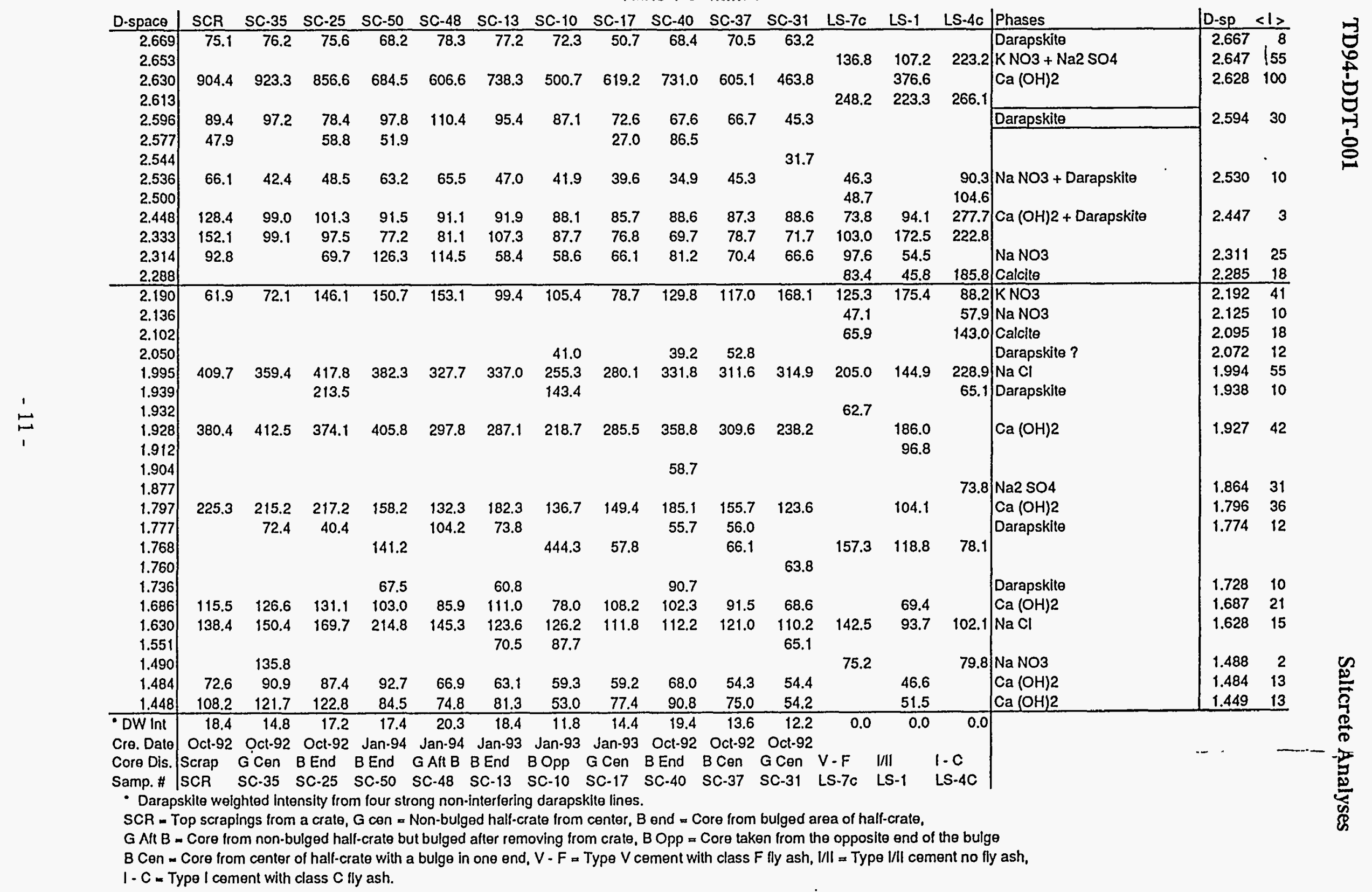




\section{SEM Results}

The SEM has a high resolution capability with a large depth of field that makes it well suited for examination of fracture surfaces. The EDX detector on the SEM allows for identification of phases from the elemental composition. Examination of saltcrete focused mainly on: 1) identifying phases in microcracks on the fracture surface, 2) locating some of the phases identified with XRD, and 3) performing elemental analysis on flat powder specimens used in XRD. The first part of the examination showed repeatedly that the mineral phase Darapskite $\left[\mathrm{Na}_{3}\left(\mathrm{NO}_{3}\right)\left(\mathrm{SO}_{3}\right) \cdot \mathrm{H}_{2} \mathrm{O}\right]$ could be found in many microcracks Figures 5-7. Darapskite could also be found growing in microvoid caused by small pockets of unmixed brine shown in Figure 8. Microvoids from brine formed crystals along the surface of the microvoid while microvoids from gas generation had no crystal growth in the void. In some cases Darapskite was found with potassium nitrate $\left(\mathrm{KNO}_{3}\right)$ shown in Figures 9 and 10 or with calcium aluminate chloride hydrates $\left(\mathrm{Ca}_{4} \mathrm{Al}_{2} \mathrm{O}_{6} \mathrm{Cl}_{2} \cdot 10 \mathrm{H}_{2} \mathrm{O}\right.$ or $\mathrm{Ca}_{4} \mathrm{Al}_{2} \mathrm{O}_{4} \mathrm{Cl}_{2} \cdot 10 \mathrm{H}_{2} \mathrm{O}$ ) shown in Figure 11. Other phases found include $\mathrm{Ca}(\mathrm{OH})_{2}$ in Figure 12, $\mathrm{NaCl}$ in Figure 13, and $\mathrm{CaSiO}_{4}$ in Figure 14. Results from the elemental analysis on flat powder specimens used in XRD is given in Table 2.

Analyses of the lab-scale specimens were also important since these samples were expansive and no Darapskite was found in these samples. The calcium aluminate chloride hydrates $\left(\mathrm{Ca}_{4} \mathrm{Al}_{2} \mathrm{O}_{6} \mathrm{Cl}_{2} \cdot 10 \mathrm{H}_{2} \mathrm{O}\right.$ or $\left.\mathrm{Ca}_{4} \mathrm{Al}_{2} \mathrm{O}_{4} \mathrm{Cl}_{2} \cdot 10 \mathrm{H}_{2} \mathrm{O}\right)$ are suspected to cause the expansion in the lab-scale specimens. These two phases cannot be distinguished with the EDX since oxygen is not detected. Figure 15 shows calcium aluminate chloride hydrates in a lab-scale specimen. In Figure 16 a microvoid is shown in a lab-scale specimen with a large number of cracks. Microvoids in the saltcrete can either be trapped water or gas. If the microvoid contain salt crystals then it probably contained a water salt mixture. 


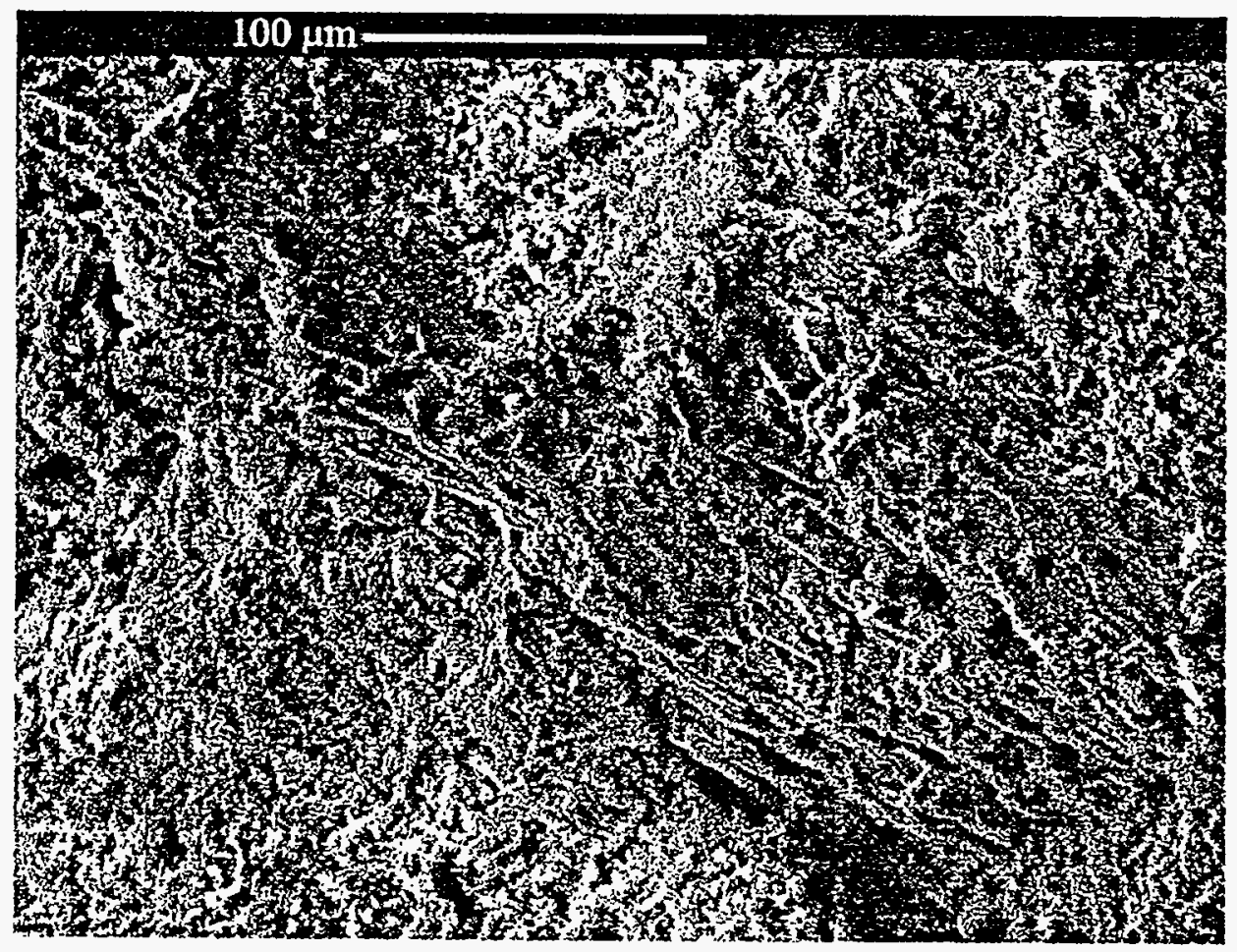

Figure 5 - The center of this picture shows darapskite crystals growing in a cement matrix. The micrograph is an secondary electron images from an SEM.

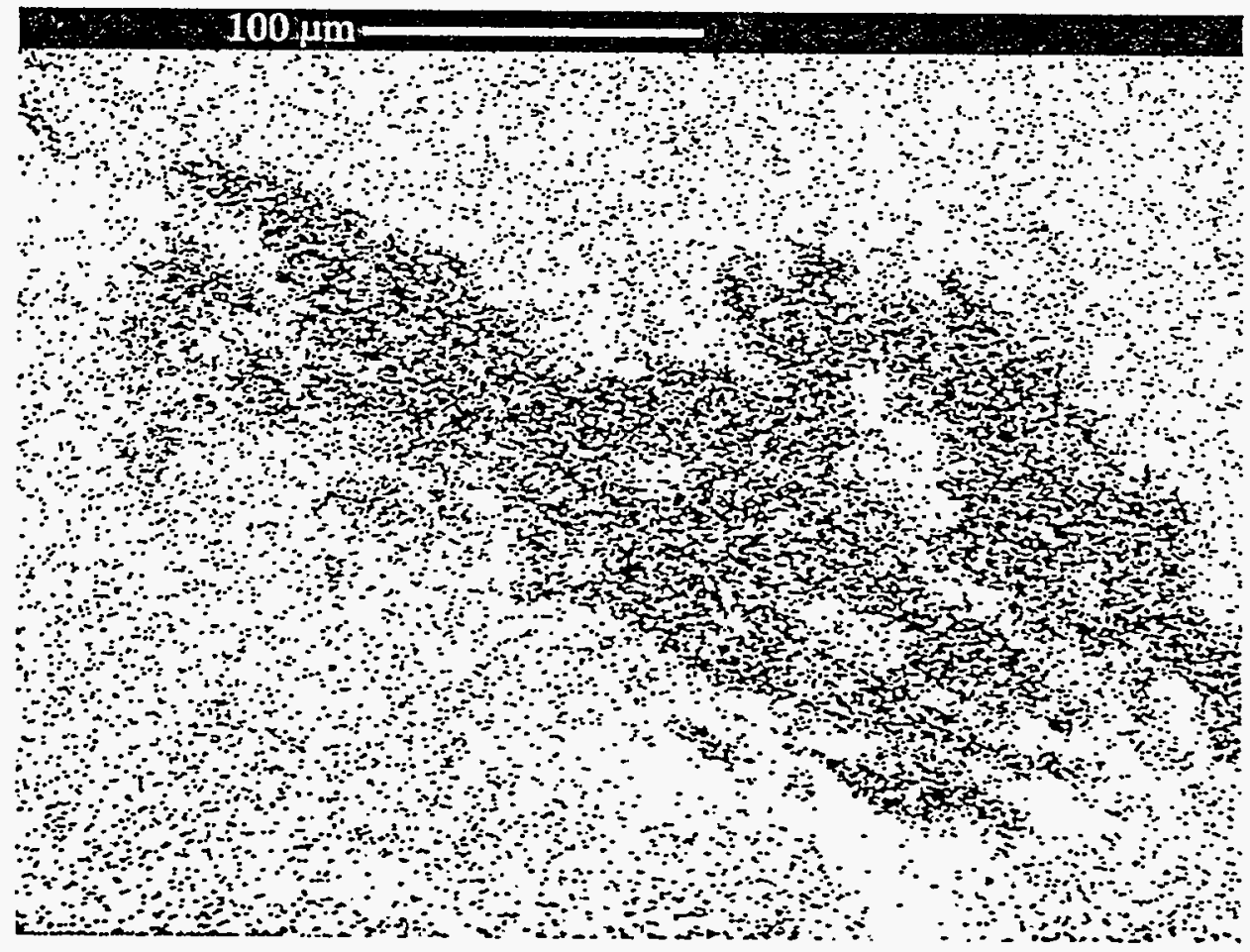

Figure 6 - The same area as Figure 5 is shown in this sulfur X-ray map. The darkness of the dots increases as more sulfur is detected in a region. The majority of the dots away from the darapskite are a result of background radiation. 


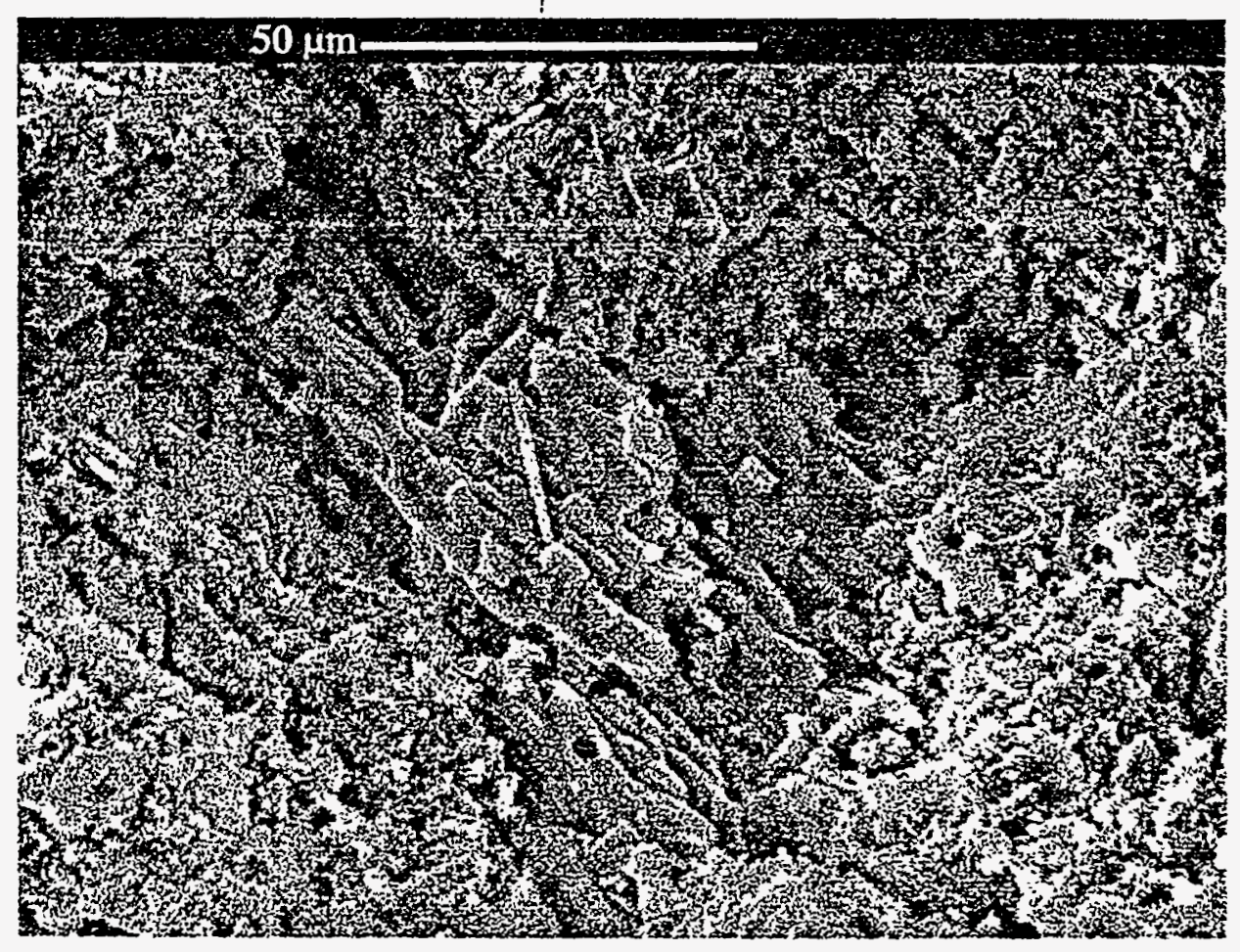

Figure 7 - In this secondary electron image many cracks are shown in the cement matrix around some darapskite.

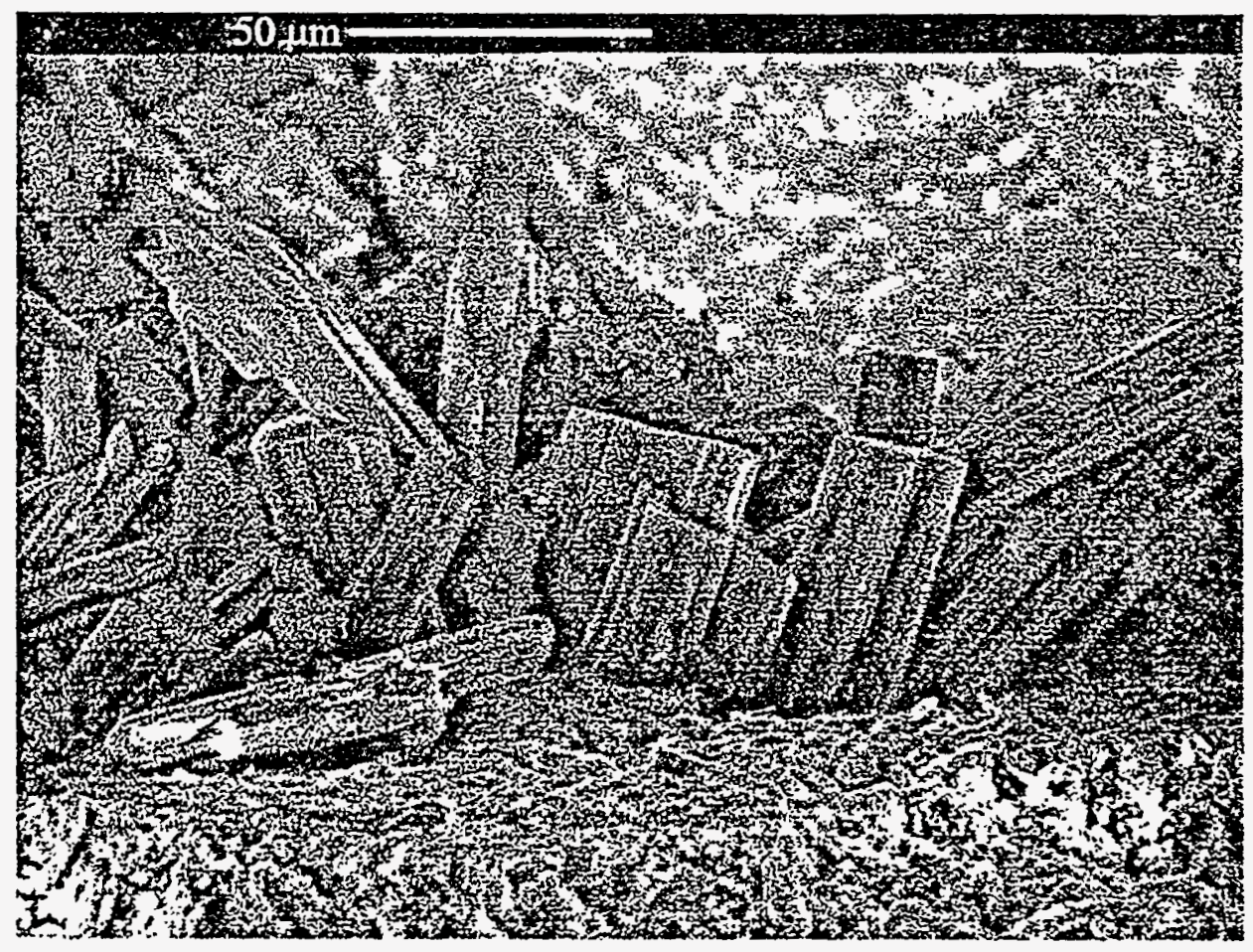

Figure 8 - Darapskite, shown in this secondary electron image, has grown into a microvoid that was once filled with brine. 


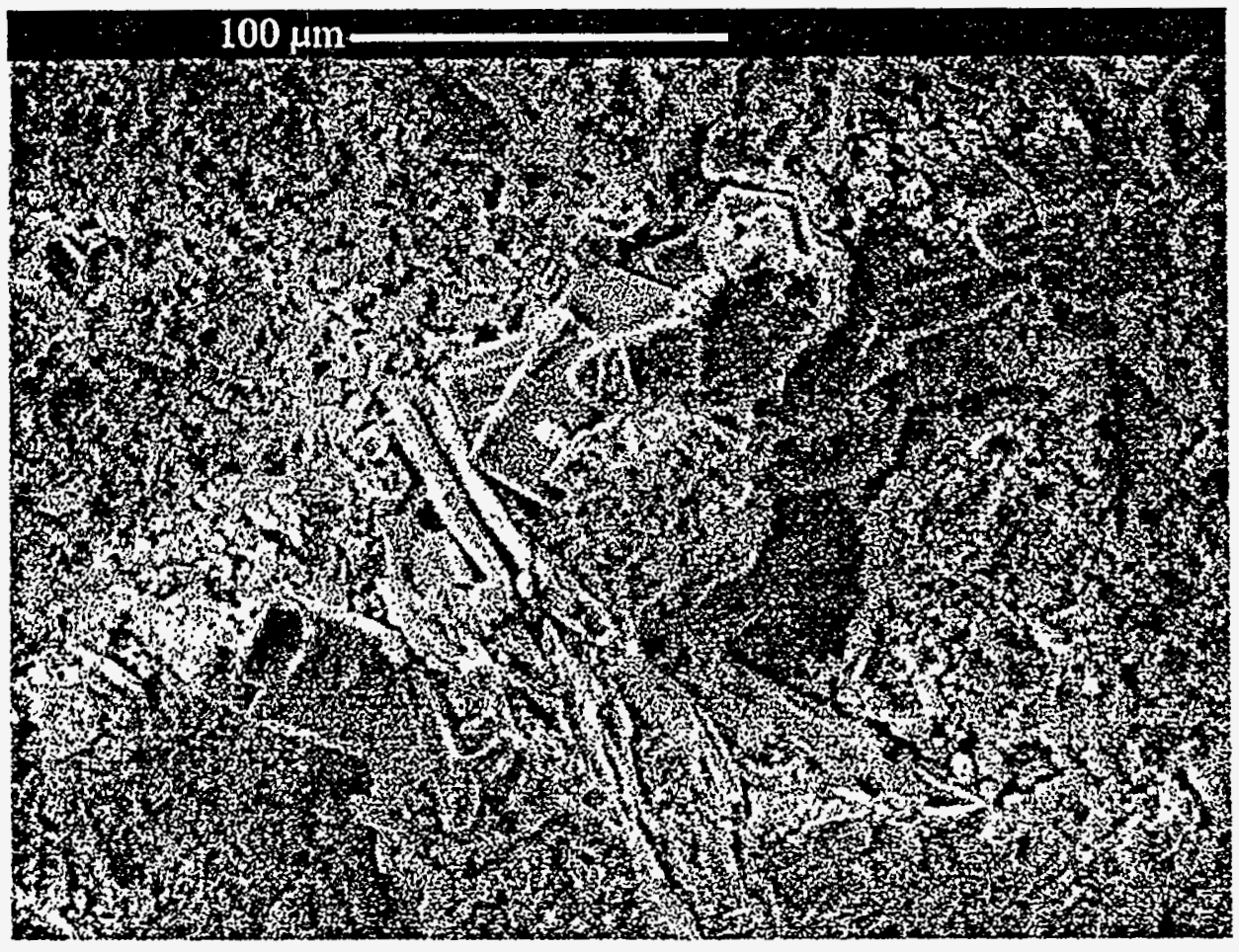

Figure 9 - Darapskite crystals are shown with some potassium nitrate crystals growing in a cement matrix. The micrograph is an secondary electron images from an SEM.

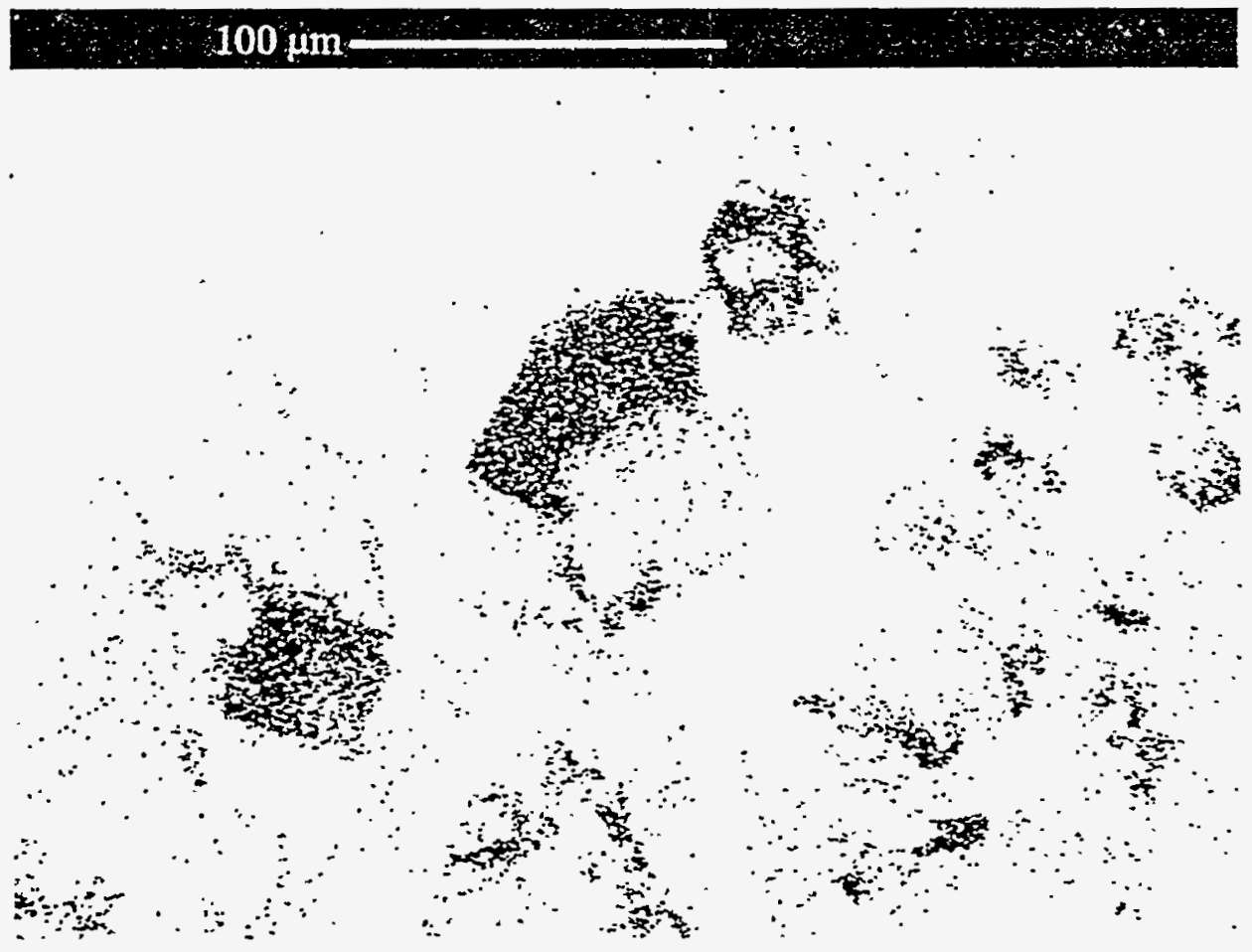

Figure 10 - The same area as Figure 9 is shown in this potassium X-ray map. The darkness of the dots increases as more potassium is detected in a region. The map shows the location of the potassium nitrate phase. 


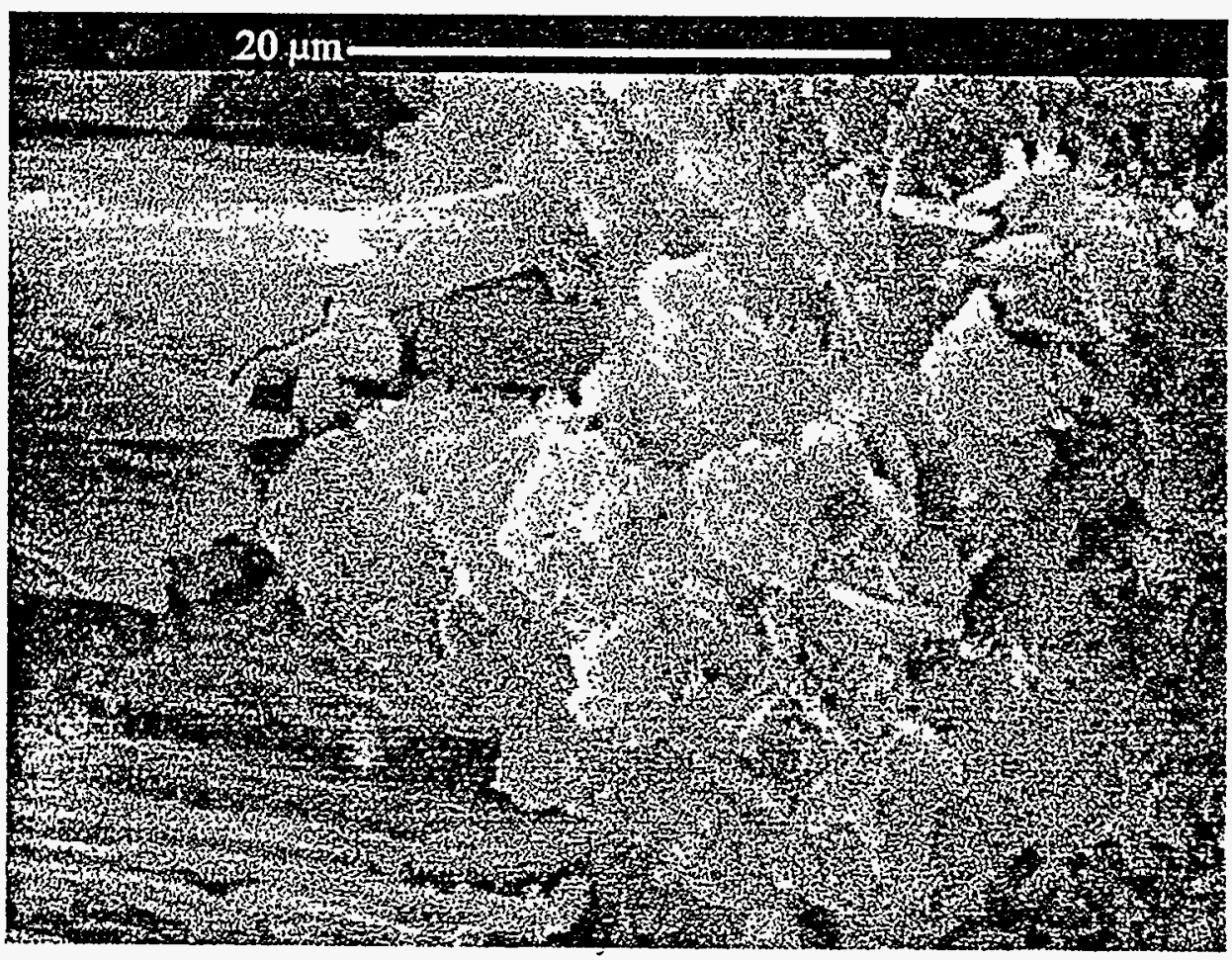

Figure 11 - Darapskite is shown on the left with some flakes of calcium aluminate chloride hydrates on the right. This sample was etched with maleic acid.

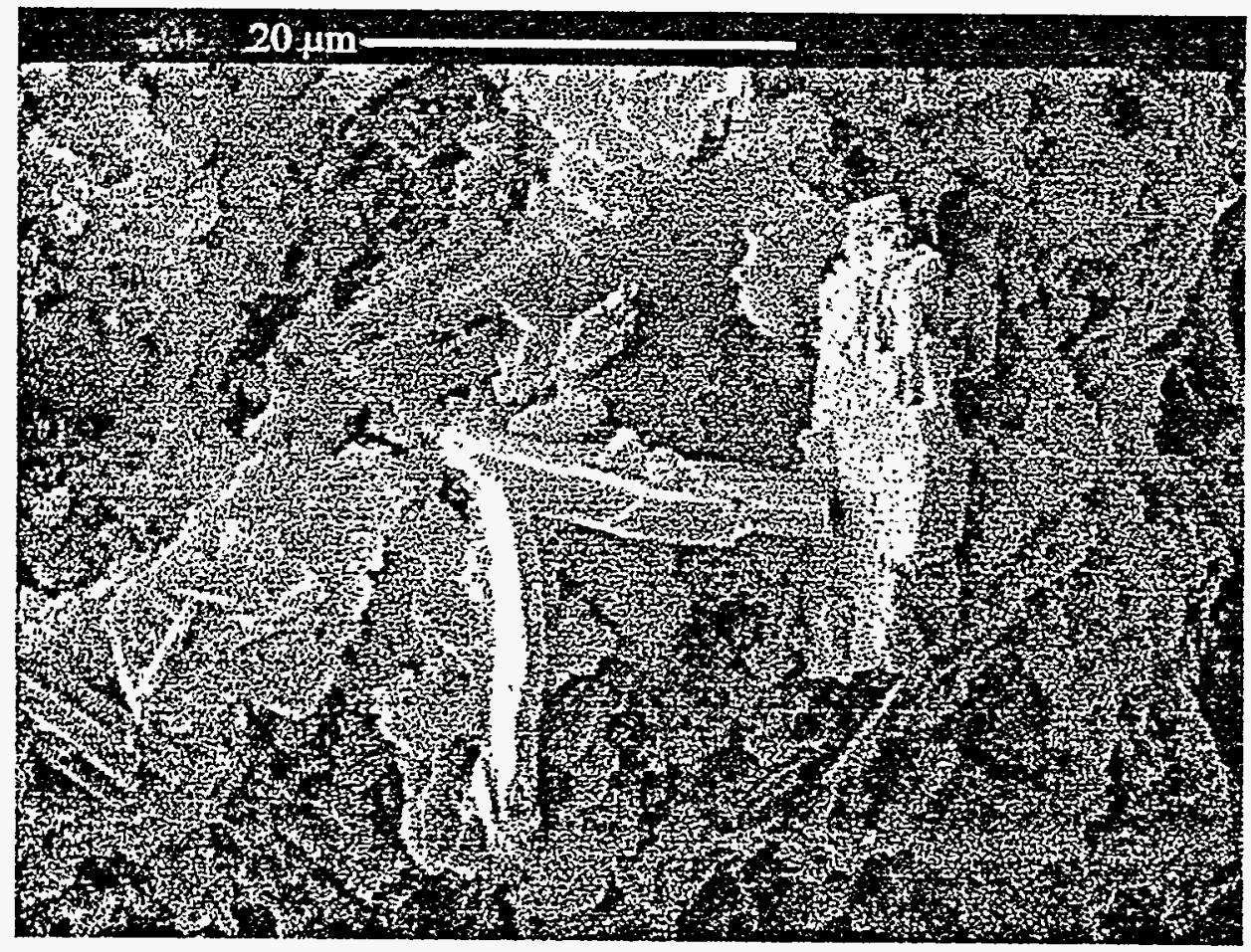

Figure 12 - The plate like crystals shown in this micrograph protruding out of the surface are calcium hydroxide crystals. 


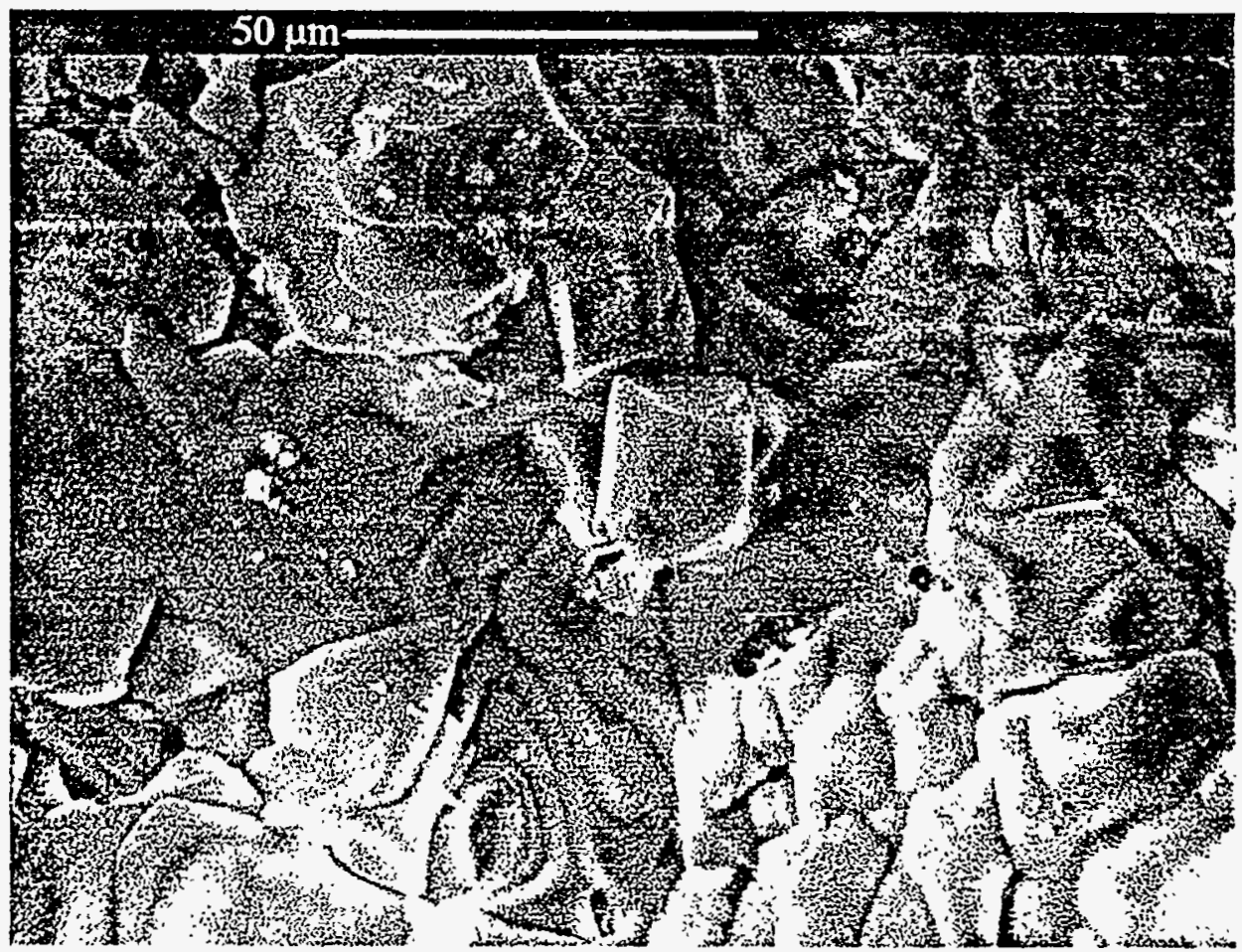

Figure 13 - A microvoid is shown in this micrograph that is completely lined with sodium chloride. The void shown was once filled with a sodium chloride brine that later formed these crystals.

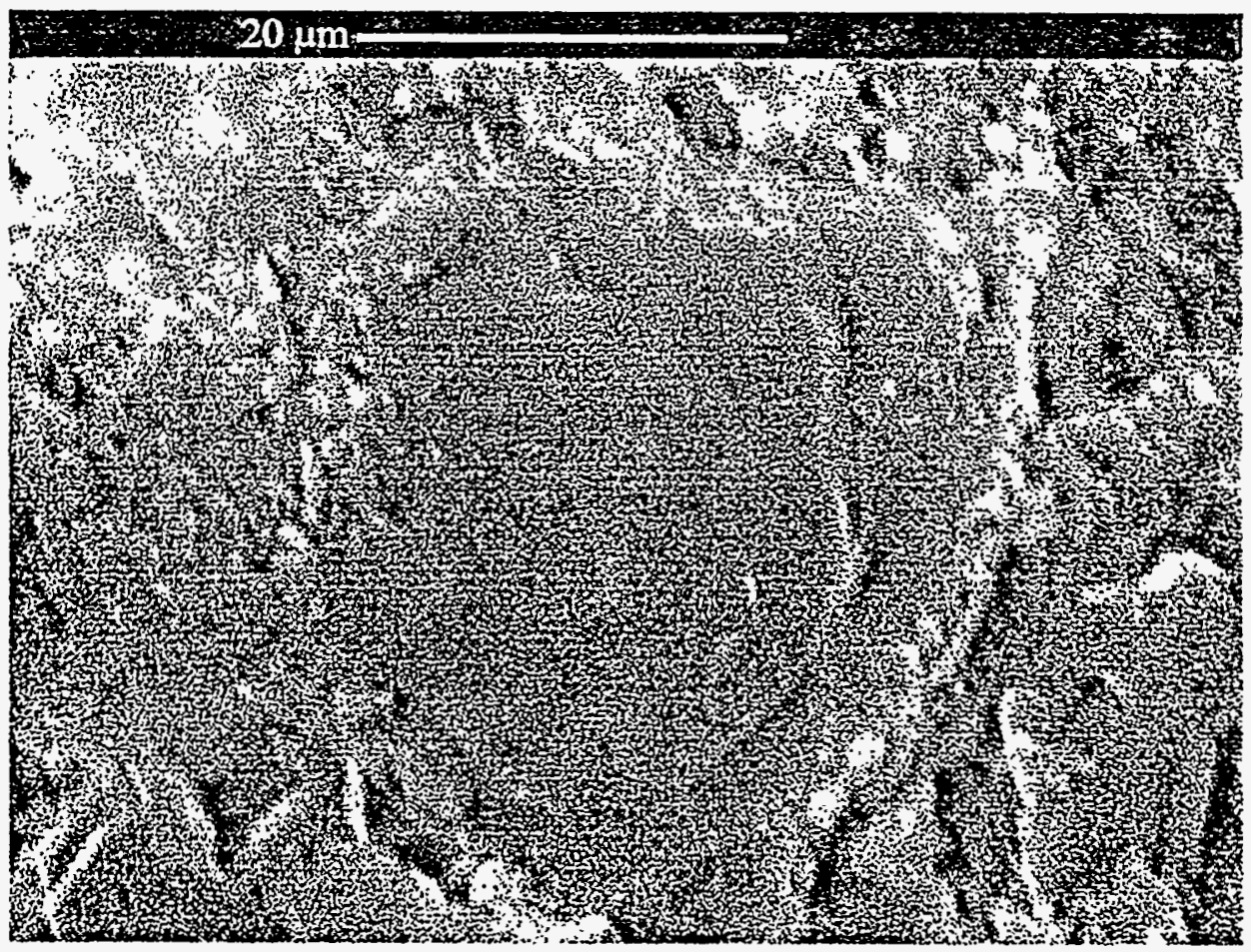

Figure 14 - The round particle in the center of this micrograph is a calcium silicate particle. 


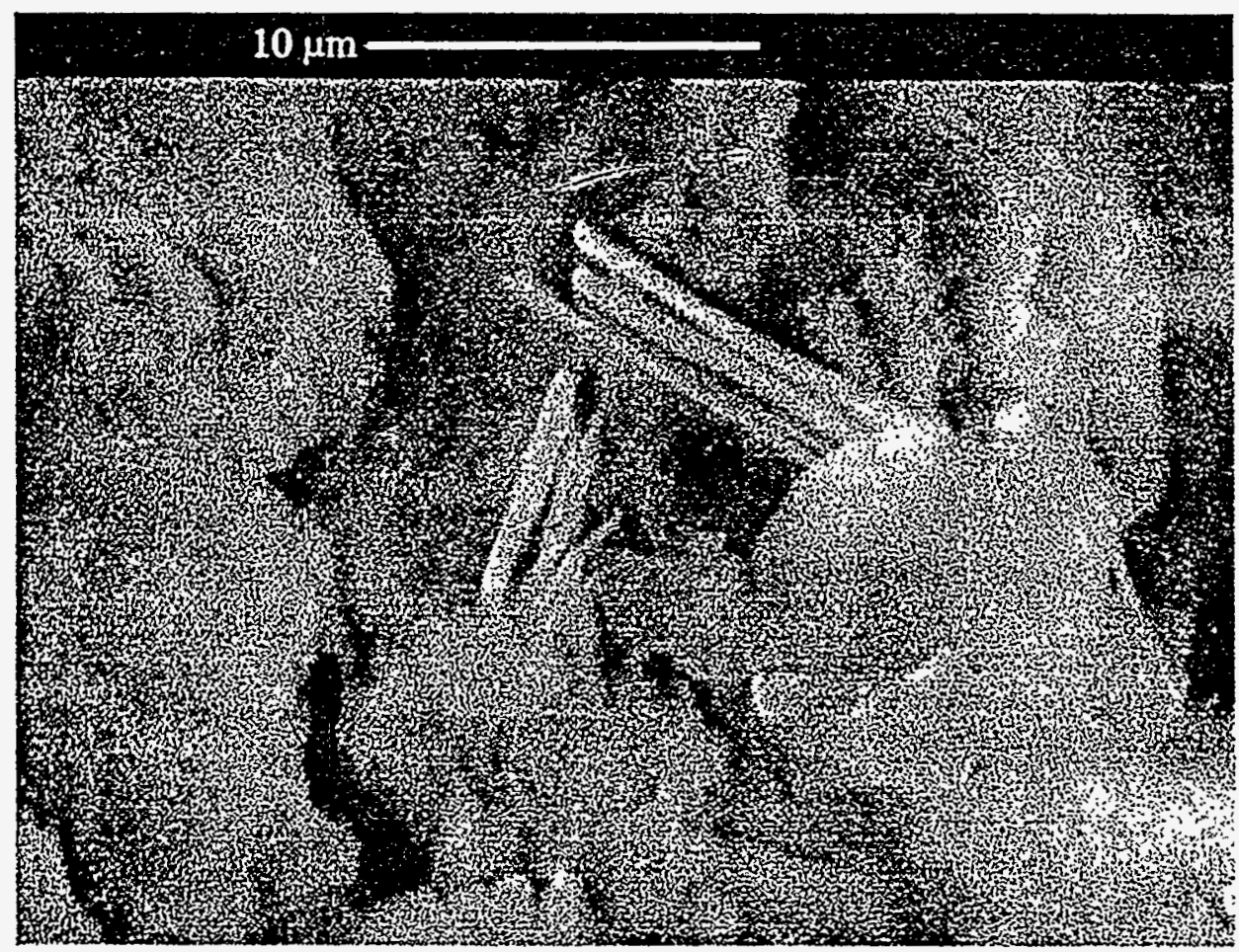

Figure 15 - The stick like structures in this micrograph are calcium aluminate chloride hydrates in a lab-scale $4 c$ sample.

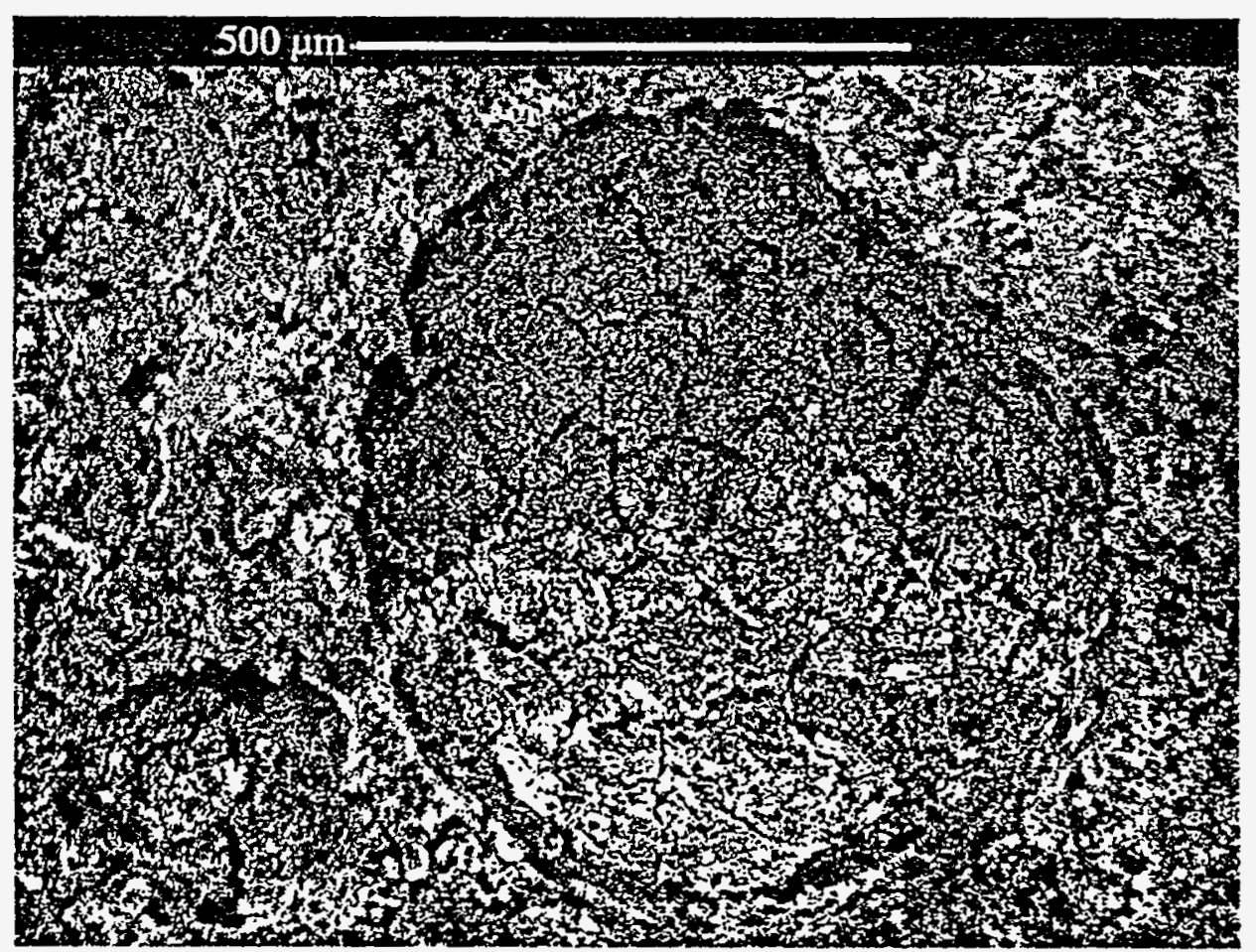

Figure 16 - The microvoids in the lab-scale sample $4 \mathrm{c}$ were full of shrinkage cracks as shown in this micrograph. 


\section{Table 2}

\section{Whole Sample Energy Dispersive X-ray (EDS) Analysis}

$\begin{array}{lr}\text { Spray Dried Salt } \\ \text { Apr 28, } 94 \\ \text { Element } & \text { Atomic \% } \\ \mathrm{Na}> & 56.0 \\ \mathrm{Cl}> & 23.9 \\ \mathrm{~K}> & 10.3 \\ \mathrm{~S}> & 6.1 \\ \mathrm{Ca} \ll< & 2.2 \\ \mathrm{Sl} \ll & 0.6 \\ \mathrm{P} \gg & 0.5 \\ \mathrm{Al} \ll & 0.2 \\ \mathrm{Mg}< & 0.2\end{array}$

$\begin{array}{lr}\text { SC-25 Bulged Area } \\ \text { Oct 8, 94 } \\ \text { Element } & \\ \mathrm{Ca} & 33.7 \\ \mathrm{Na} & 31.9 \\ \mathrm{Cl} & 11.0 \\ \mathrm{Si} & 8.6 \\ \mathrm{~K} & 6.6 \\ \mathrm{~S} & 4.5 \\ \mathrm{Al} & 1.3 \\ \mathrm{Fe} & 0.9 \\ \mathrm{Mg} & 0.8 \\ \mathrm{P} & 0.7\end{array}$

Bulged Jan 4, 93

Element Atomic \%

$\mathrm{Ca} \quad 33.6$

$\mathrm{Na} \quad 32.8$

Cl $\quad 10.4$

$\begin{array}{ll}\mathrm{Si} & 8.7\end{array}$

$\begin{array}{ll}\mathrm{K} & 5.6\end{array}$

$\begin{array}{ll}\mathrm{S} & 4.9\end{array}$

. $\mathrm{Fe}$

A) $\quad 1.5$

$\mathrm{Fe} \quad 0.9$

$\mathrm{Mg} \quad 0.9$

$\begin{array}{ll}P & 0.7\end{array}$

LS-7c Type V With Class F Fly Ash

Element Atomic \%

$\mathrm{Na}>\quad 28.6$

$\mathrm{Ca}<\quad 26.9$

$\mathrm{Si}>\quad 15.2$

$\mathrm{Cl}<\quad 8.1$

$\mathrm{Al} \gg>\quad 6.7$

$K<\quad 5.8$

$S<\quad 4.4$

$\mathrm{Mg}>\quad 2.5$

$\mathrm{Fe}<\quad 1.1$

$P$

0.7

SC-17 Non-bulging Jan 5, 93

Element Atomic\%

$\mathrm{Ca}$

$\mathrm{Na}$

$\mathrm{Cl}$

Si

K

$S$

Al

$\mathrm{Fe}$

$\mathrm{Mg}$

$P$

\section{LS-1 Type I/II}

Without Fly Ash

Element Atomic \%

$\mathrm{Ca} \quad 47.2$

$\mathrm{Na} \quad 20.6$

Si $>\quad 11.8$

$\mathrm{Cl}<\quad 6.7$

$\mathrm{K}$

$S$

Al

$M g>$

$\mathrm{Fe}<$

$P$

$\begin{array}{lr}\text { SC-35 Non-bulging } \\ \text { Oct 8, } 94 \\ \text { Element } & \\ \mathrm{Ca} & \text { Atomic \% } \\ \mathrm{Na} & 34.1 \\ \mathrm{Cl} & 31.8 \\ \mathrm{Si} & 10.5 \\ \mathrm{~K} & 9.2 \\ \mathrm{~S} & 6.0 \\ \mathrm{Al} & 4.5 \\ \dot{\mathrm{F}} & 1.4 \\ \mathrm{Mg} & 0.8 \\ \mathrm{P} & 0.9 \\ & 0.8\end{array}$

Sc-48 Non-bulging Jan 11, 94

Element Atomic \%

$\mathrm{Ca} \quad 35.1$

$\mathrm{Na} \quad 33.0$

Cl $\quad 10.2$

Si $\quad 7.9$

$\mathrm{K} \quad 5.3$

S $\quad 4.2$

Al $\quad 1.4$

$\mathrm{Fe} \quad 1.1$

$\mathrm{Mg} \quad 1.1$

$P$

0.7

SC-37 Away from

Bulge Oct 7, 92

\section{SC-40 Bulged Area}

Oct 7, 92

Element Atomic\%

$\mathrm{Ca} \quad 33.8$

$\mathrm{Na} \quad 31.8$

$\mathrm{Cl} \quad 10.7$

$\begin{array}{ll}\mathrm{Si} & 8.8\end{array}$

K 6.3

$\begin{array}{ll}\mathrm{S} & 4.7\end{array}$

Al $\quad 1.3$

$\mathrm{Mg}>\quad 1.0$

$\mathrm{Fe}<\quad 0.8$

$P \quad 0.8$
Element Atomic \%

$\mathrm{Ca} \quad 34.3$

$\mathrm{Na} \quad 31.3$

$\begin{array}{ll}\mathrm{Cl} & 10.7\end{array}$

$\begin{array}{ll}\mathrm{Si} & 8.5\end{array}$

K $\quad 6.6$

$\mathrm{S} \quad 4.5$

Al $\quad 1.4$

$\mathrm{Mg}>$

$\mathrm{Fe}<$

$P$
SC-13 Bulged Area Jan 4, 93

Element Atomic \%

$\mathrm{Ca} \quad 33.4$

$\mathrm{Na} \quad 33.0$

$\mathrm{Cl} \quad 10.5$

$\mathrm{Si} \quad 8.5$

K 6.0

S $\quad 5.0$

Al $\quad 1.4$

Fe $\quad 0.9$

$\begin{array}{ll}\mathrm{Mg} & 0.7\end{array}$

$\begin{array}{ll}\mathrm{P} & 0.7\end{array}$

SC-31 Non-bulging Oct 8,92

Element Atomic \%

$\mathrm{Ca} \quad 35.5$

$\mathrm{Na} \quad 30.5$

Cl $\quad 10.2$

Si $\quad 9.3$

K 6.0

$\mathrm{S} \quad 4.5$

Al $\quad 1.5$

$\mathrm{Mg}>\quad 0.9$

$\mathrm{F} \theta<\quad 0.9$

LS-4c Type I With

Class C Fly Ash

Element Atomic \%

$\mathrm{Na}>\quad 32.5$

$\mathrm{Ca}<\quad 25.2$

$\mathrm{Si}>\quad 12.4$

$\mathrm{Cl}<\quad 8.8$

Al $>\quad 6.2$

$S \quad 5.0$

$\mathrm{Mg} \gg \quad \quad 3.7$

$\mathrm{K} \ll<\quad 3.6$

$\mathrm{Fe}<\quad 1.2$

$\begin{array}{ll}\mathrm{P} & 0.8 \\ \mathrm{Ti}+ & 0.4\end{array}$

One " $>$ " symbol is included with an element for each increase in element rank from the average rank One " $<$ " symbol is included with an element for each decrease in element rank from the average rank. The " + " symbol is included if ithe element is new and is not in average element analysis. 


\section{DISCUSSION}

The optical analysis performed by Halliburton Energy Services and the SEM and XRD analyses performed by DDT agreed very well with one another. Microvoids, micropores, crystal growth in cracks, and crystal growth away from cracks were observer both in the optical microscope and the SEM. A considerable portion of the Portland cement had hydrated based on observations of thin sections in the optical microscope and XRD analysis. Phases observed with XRD analysis were also found in the SEM with the EDS detector.

The amount of hydration that occurred in the saltcrete is difficult to quantify with optical and XRD analyses. There are several reasons that support a considerable amount of Portland cement hydration. Optical microscope observation showed a number of partially hydrated grains of cement. Further evidence of hydration came from the identification of $\mathrm{Ca}(\mathrm{OH})_{2}, \mathrm{CaCO}_{3}$, and $\mathrm{Ca}_{4} \mathrm{Al}_{2} \mathrm{O}_{6} \mathrm{Cl}_{2} \cdot 10 \mathrm{H}_{2} \mathrm{O}$ and the absence of large amounts of unhydrated cement phases in the XRD analysis. Complete hydration was not observed in any of the thin sections analyzed with the optical microscope. The amount of hydration appeared to increase with the age of the saltcrete half-crates.

An expansive phase has a volume increase or a density decrease when it forms. Density alone is not enough to identify expansive phases that can bulge a half-crate. There must be additional evidence that the phase change occurred when the saltcrete had sufficient strength to bulge the half-crate. If the saltcrete does not have sufficient strength to bulge the crate, the saltcrete will expand upward in the unconfined direction. The expansive phase can form either during the curing process as water is absorbed by new phases, with a temperature change, or with a change in humidity of the environment.

The first expansive phase that was investigated was darapskite $\left[\mathrm{Na}_{3}\left(\mathrm{NO}_{3}\right)\left(\mathrm{SO}_{3}\right) \cdot \mathrm{H}_{2} \mathrm{O}\right.$. Darapskite, as shown in Table 1 , is generally present in higher concentrations in the cores taken from bulging area in the half-crates. Darapskite has a density of $2.20 \mathrm{~g} / \mathrm{cm}^{3}$ [2] while the three components of darapskite, sodium nitrate $\left(\mathrm{NaNO}_{3}\right)$, sodium sulfate $\left(\mathrm{NaSO}_{4}\right)$, and water $\left(\mathrm{H}_{2} \mathrm{O}\right)$ in the proper ratios to form darapskite have a density of 2.28 $\mathrm{g} / \mathrm{cm}^{3}$. Darapskite then will expand approximately $3.6 \%$ as it forms. Additional expansion can be caused by voids that are created as the darapskite forms. Darapskite can be made easily by mixing together the three components with an excess of water and allowing the mixture to dry. Darapskite is also the only double salt that can be formed from nitrate and sulfate. Figures 5 and 7 show that darapskite has been located in a region where there is a cracking in the matrix.

Cracking can only occur after the material has some set strength and it is caused by either expansion or contraction. Expansion cracking will have radial cracks emanating from an expansive phase, while contraction cracking will form either concentric rings around a contracting phase or crack as a dried up river bottom. Contraction cracking is shown in the microvoid in Figure 16, while expansive cracking can be seen in Figures 5 and 7 around the darapskite. 
From Table 1, no darapskite was found in the lab-scale samples. There are other phases in the Tab-scale samples that could cause expansion in these samples. In an earlier report done by the Waste Programs group where the lab-scale samples were originally investigated [3], a small expansion was observed during the wet/dry cycling while a large expansion occurred during the first freeze of freeze/thaw cycling. Two similar phases that could explain this type of expansion are calcium aluminate chloride hydrates $\left(\mathrm{Ca}_{4} \mathrm{Al}_{2} \mathrm{O}_{6} \mathrm{Cl}_{2}\right.$ - $10 \mathrm{H}_{2} \mathrm{O}$ or $\mathrm{Ca}_{4} \mathrm{Al}_{2} \mathrm{O}_{4} \mathrm{Cl}_{2} \cdot 10 \mathrm{H}_{2} \mathrm{O}$ ). The $\mathrm{Ca}_{4} \mathrm{Al}_{2} \mathrm{O}_{6} \mathrm{Cl}_{2} \cdot 10 \mathrm{H}_{2} \mathrm{O}$ phase is stable only below $28{ }^{\circ} \mathrm{C}$. During the first freeze/thaw cycling, the lab-scale samples were taken from the curing temperature of $55^{\circ} \mathrm{C}$ measured for volume and then subjected to freeze cycle of $12^{\circ} \mathrm{C}$. If $\mathrm{Ca}_{4} \mathrm{Al}_{2} \mathrm{O}_{6} \mathrm{Cl}_{2} \cdot 10 \mathrm{H}_{2} \mathrm{O}$ is an expansive phase this would explain the volume increase during the first freeze cycle and the reason not much increase in volume was obtained during the wet/dry cycling at temperatures above $28^{\circ} \mathrm{C}$. The calcium aluminate chloride hydrates were present in both the lab-scale and core sample. They would have a tendency to break up the saltcrete as it cycles though the transformation temperature of $28^{\circ} \mathrm{C}$.

In Figure 13 a large amount of silicone was also detected. Silicone from an unknown phase appeared to be mixed in with the calcium aluminate chloride hydrates. The form of this phase and whether it could be expansive is not known. Table 3 summarizes the amount of expansion with the amount of calcium aluminate chloride hydrates, silicon, and aluminum. No trait was found that matched the behavior of expansion in the lab-scale samples. During collection of the XRD data, the room temperature was not measured. Since $\mathrm{Ca}_{4} \mathrm{Al}_{2} \mathrm{O}_{6} \mathrm{Cl}_{2} \cdot 10 \mathrm{H}_{2} \mathrm{O}$ changes phase near room temperature the amount of this phase is highly dependent on the temperature of the sample during analysis. The amount of the calcium aluminate chloride hydrates observed with XRD also did not follow amount of the limiting element aluminum in this phase. Because of this complicated behavior, a complete explanation for expansion in the lab-scale specimens is not known. Other phases could exist in the saltcrete that could cause harmful expansion.

Table 3

\section{Expansion Comparison of the Lab-Scale Samples}

\begin{tabular}{|c|c|c|c|c|c|}
\hline $\begin{array}{l}\text { Samp. } \\
\#\end{array}$ & Binder Composition & \begin{tabular}{|l|} 
Expansion \\
{$[3]$}
\end{tabular} & $\begin{array}{l}\text { Calcium Aluminate } \\
\text { Chloride Hydrates }\end{array}$ & $\begin{array}{l}\text { Silicon } \\
\text { Conc. }\end{array}$ & $\begin{array}{l}\text { Aluminum } \\
\text { Conc. }\end{array}$ \\
\hline $\begin{array}{l}\text { LS-7c } \\
\text { LS-1c }\end{array}$ & $\begin{array}{l}\text { Type V with Class F fly ash } \\
\text { Type I/II with no fly ash }\end{array}$ & Small & $\begin{array}{l}\text { Small conc. } \\
\text { Large conc. } \\
\text { Medium }\end{array}$ & $\begin{array}{l}\text { Large } \\
\text { Small } \\
\text { Medium }\end{array}$ & $\begin{array}{l}\text { Large } \\
\text { Small } \\
\text { Medium }\end{array}$ \\
\hline
\end{tabular}

Expansion of the saltcrete is finite and will decrease with time. The formation of darapskite requires the presence of sodium sulfate, sodium nitrate and water in equal molecular concentrations. If anyone of these three molecules is not present then darapskite cannot form. Darapskite cannot form in an excess of water since it is soluble in water. After enough of the cement has cured, absorbing excess water, darapskite can form. Once darapskite has started to form it will continue to form until it depletes the supply of one of the required constitute molecules. During the darapskite formation, any 
addition of moisture through a high humidity environment will impede the growth of darapskite. The calcium aluminate chloride hydrates will form when the temperature is below $28^{\circ} \mathrm{C}$. Cycling of the temperature near $28^{\circ} \mathrm{C}$ will cause the creation of some additional cracks and voids. After a few temperature cycles the expansion will decrease to zero.

\section{CONCLUSIONS}

1) The optical analysis performed by Halliburton Energy Services and the SEM and XRD analyses performed by DDT agreed very well with one another.

2) A considerable portion of the cement is hydrating in these cores.

3) Darapskite $\left[\mathrm{Na}_{3}\left(\mathrm{NO}_{3}\right)\left(\mathrm{SO}_{3}\right) \cdot \mathrm{H}_{2} \mathrm{O}\right]$ causes much of the expansion in the saltcrete.

4) Calcium aluminate chloride hydrates $\left(\mathrm{Ca}_{4} \mathrm{Al}_{2} \mathrm{O}_{6} \mathrm{Cl}_{2} \cdot 10 \mathrm{H}_{2} \mathrm{O}\right.$ or $\left.\mathrm{Ca}_{4} \mathrm{Al}_{2} \mathrm{O}_{4} \mathrm{Cl}_{2} \cdot 10 \mathrm{H}_{2} \mathrm{O}\right)$ are phases that could expand and fatigue the saltcrete structure.

5) Other phases could exist in the saltcrete that could cause harmful expansion and damage the half-crates.

6) Expansion of the saltcrete is finite and will decrease with time.

\section{RECOMMENDATIONS}

A new capability has been established at Rocky Flats Environmental Technology Site to examine saltcrete and other cemented waste forms for hydration and expansive phase identification. The next logical step to take is to utilize this new capability to optimize the saltcrete process. The understanding that was gained during this study can be used to maximize the amount of waste salt placed in a half-crate and minimize the number of rejected half-crates.

\section{REFERENCES}

1. W.J. Caveny report, Cementing Method and Materials, Hallibuton Energy Service, CCX-2102-94, May 18, 1994.

2. M.J. Redden, Master Thesis, The Crystal Structure of Darapskite, Massachusetts Institute of Technology, June, 1968.

3. J.M. Connell, A.M. Faucette, S.C. Jorgensen, J.H. Oldham, and K.M. Swan-Bogard report, Saltcrete Evaluation. 
Note: The report by Halliburton Energy Services includes over 40 pages of color micrographs. Neither the black-and-white or the color copies of the micrographs were of sufficient quality to be included. Only the summary of the Halliburton report is included. 


\title{
HALLIBURTON ENERGY SERVICES
}

\author{
DUNCAN TECHNOLOGY CENTER - DUNCAN, OKLAHOMA \\ A HALLIBURTON COMPANY \\ CEMENTING METHODS AND MATERIALS
}

\section{PROJECT REPORT}

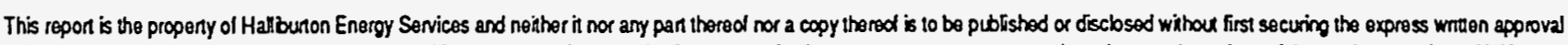
of laboratory management; i may however, be used in the course of regular business operation by any person or concern and employees thereol receiving such report from Haltbunon Energy Services.

To: Mr. J.M. Connell

CCX-2102-94

Mr. S.C. Jorgensen

Final Report

Technology Development

EG\&G Rocky Flats Plant

Golden, CO

July 26,1994

Title: Solidified Waste Samples at Rocky Flats Plant, Colorado

Prepared by: Bill Caveny, Jerry Childs, Gant McPherson

\section{PURPOSE}

The purpose of this project was to perform microscopic examination on the solidified waste to determine cement hydration reaction with the waste materials.

\section{CONCLUSION}

A meeting was held at Halliburton Technology Center in Duncan, Oklahoma, July 6, 1994. Those present at the meeting were Dan Armentrout EG\&G, Gant MCPherson, Jerry Childs, and Bill Caveny, all with Halliburton Energy Services. The purpose of the meeting was to evaluate X-Ray diffraction (XRDA) and scanning electron microscopy (SEM) data collected from the cement solidified waste samples that have been cored for analysis in this project. The data evaluated had been collected by Dan Armentrout of EG\&G.

General conclusion based on the X-Ray diffraction analysis and Scanning Electron Microscopy analysis generated by Dan Armentrout EG\&G, and the Microscopy Analysis by polarized transmitted light, and reflected light microscopy. generated by Bill Caveny of Halliburton are as follows:

1. A considerable portion of the Portland cement has hydrated (based on formation of $\mathrm{Ca}(\mathrm{OH})_{2}, \mathrm{Co}_{4} \mathrm{Al}_{2} \mathrm{O}_{6} \mathrm{Cl}_{2} \cdot 10 \mathrm{H}_{2} \mathrm{O}, \mathrm{CaCO}_{3}$, presence of amorphous cement gel phase pattern, absence of large amounts of unhydrated cement phases such as tricalcium silicate, etc.. and microscopical observation and photograph of partially hydrated grains of cement). 
2. Darapskite $\left(\mathrm{Na}_{3} \mathrm{NO}_{3} \mathrm{SO}_{4} \bullet \mathrm{H}_{2} \mathrm{O}\right)$ may be responsible for some of the expansion of the cement solidified waste in the halfcrates (based on the XRDA identification and the tentative SEM and Light microscopy identifications of this material in core samples that had significant expansion).

3. $\mathrm{Ca}_{4} \mathrm{Al}_{2} \mathrm{O}_{6} \mathrm{Cl}_{2} \bullet 10\left(\mathrm{H}_{2} \mathrm{O}\right.$ ) appears (by XRDA) to be more abundant in the samples exhibiting greater expansion. Possibly this compound may be contributing to the expansion (further investigations would be needed).

4. Due to the extremely complex and variable nature of the waste material and the numerous possible reactions with the hydrating cement, it is difficult to arrive at a set of positive conclusions and quantitative data.

5. Based on the observations in this investigation, it appears that the present solidification formulation may be improved for some of the nitrates wastes at the Rocky Flats Plant. In future projects, some changes which should be considered are:

(a) Determination of the water ratio where recrystalization of the nitrate and other salts is minimized. Controlled porosity and permeability systems can be formulated through the informed use of dispersants and adjustments in the particle size distributions of the solids involved.

(b) Evaluation of latexes in combination with Portland cement, high aluminate cement and/or ultra fine cement as solidification media.

(c) Evaluation of non-cement systems based on the cross-linking and vulcanization of latexes to encapsulate the nitrate salts in a rubber or plastic type environment. 
cc: Ralph Voss

Larry Watters

Joe Sandy - ERC

Fred Sabins - Houston

\section{Respectfully submitted,}

Laboratory Analyst

HALLIBURTON ENERGY SERVICES

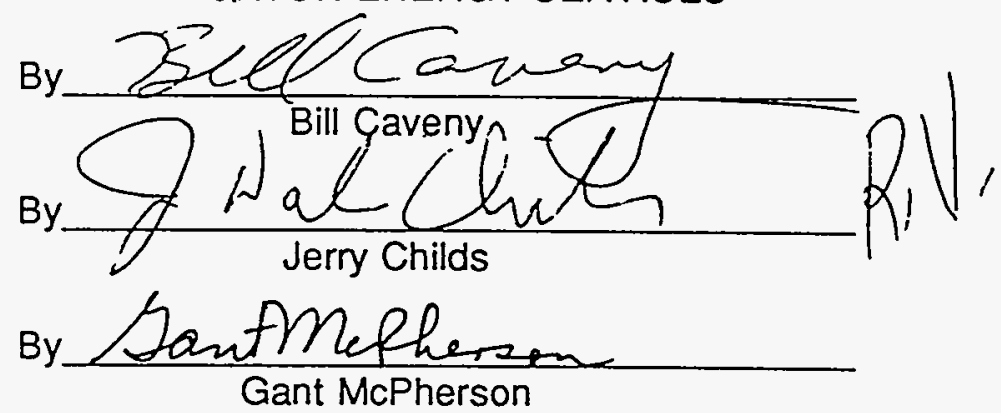

js

LIMITATION OF LIABILITY:

This report was prepared by and is the property of Halliburton Energy Services, a Division of Halliburton Company; the dala reported is intended for the private information of the above named party; accordingly, any user of this report agrees that Halliburton shall not be llable for any loss or damage, regardless of cause, including any act or omission of Halliburton, resulting from the use of the data reported herein; and Halliburton makes no warranties, express or implied, whether of fitness for a particular purpose, merchantability or otherwise, as to the accuracy of the data reportod. 


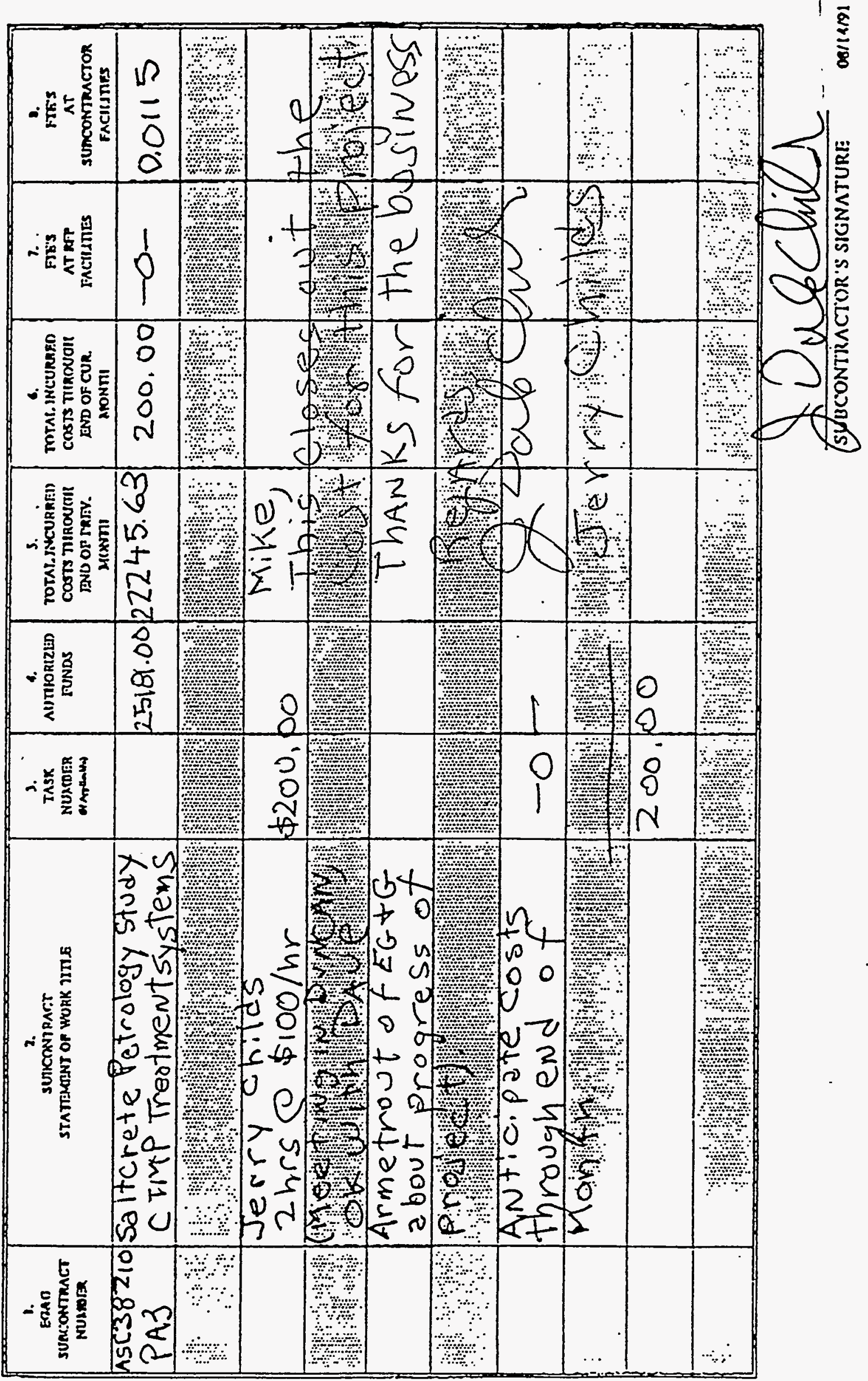

